Auxílio à leitura de textos em português facilitado: questões de acessibilidade 



\title{
Auxílio à leitura de textos em português facilitado: questões de acessibilidade
}

\author{
Willian Massami Watanabe
}

Orientador: Profa. Dra. Renata Pontin de Mattos Fortes

Dissertação apresentada ao Instituto de Ciências Matemáticas e de Computação - ICMC/USP, como parte dos requisitos para obtenção do título de Mestre em Ciências de Computação e Matemática Computacional. 



\section{Agradecimentos}

O aluno gostaria de agradecer a professora Dra. Renata Pontin de Mattos Fortes, por todo seu apoio durante todo o projeto; aos membros do projeto PorSimples, por suas valiosas contribuições e enriquecimento da proposta de mestrado; e pelo apoio financeiro realizado pela FAPESP e Microsoft Research. 
Often it appears that there is no better way to solve a problem than to try all possible solutions. This approach, called exhaustive search, is almost always slow, but sometimes it is better than nothing.

Ian Parberry 


dos provenientes de todas as partes do planeta, independentemente de onde elas estejam. Mas essas possibilidades não são estendidas a todos, sendo necessário mais que o acesso a um computador e a Internet para que sejam realizadas. Indivíduos que apresentem necessidades especiais (deficiência visual, cognitiva, dificuldade de locomoção, entre outras) são privados do acesso a sites e aplicações web que façam mal emprego de tecnologias web ou possuam o conteúdo sem os devidos cuidados para com a acessibilidade. Um dos grupos que é privado do acesso a esse ambiente é o de pessoas com dificuldade de leitura (analfabetos funcionais). A ampla utilização de recursos textuais nas aplicações pode tornar difícil ou mesmo impedir as interações desses indivíduos com os sistemas computacionais. Nesse contexto, este trabalho tem por finalidade o desenvolvimento de tecnologias assistivas que atuem como facilitadoras de leitura e compreensão de sites e aplicações web a esses indivíduos (analfabetos funcionais). Essas tecnologias assistivas utilizam recursos de processamento de língua natural visando maximizar a compreensão do conteúdo pelos usuários. Dentre as técnicas utilizadas são destacadas: simplificação sintática, sumarização automática, elaboração léxica e reconhecimento das entidades nomeadas. Essas técnicas são utilizadas com a finalidade de promover a adaptação automática de conteúdos disponíveis na Web para usuários com baixo nível de alfabetização. São descritas características referentes à acessibilidade de aplicações web e princípios de design para usuários com baixo nível de alfabetização, para garantir a identificação e entendimento das funcionalidades que são implementadas nas duas tecnologias assistivas resultado deste trabalho (Facilita e Facilita Educacional). Este trabalho contribuiu com a identificação de requisitos de acessibilidade para usuários com baixo nível de alfabetização, modelo de acessibilidade para automatizar a conformidade com a WCAG e desenvolvimento de soluções de acessibilidade na camada de agentes de usuários.

palavras-chave: Acessibilidade na Web, Processamento de língua natural, Simplificação Sintática, Sumarização Automática, Elaboração Léxica e Reconhecimento das Entidades Nomeadas. 


possibilities and opportunities for users. The development of high performance networks and ubiquitous devices allow users to retrieve content from any location and in different scenarios or situations they might face in their lives. Unfortunately the possibilities offered by the Web are not necessarily currently available to all. Individuals who do not have completely compliant software or hardware that are able to deal with the latest technologies, or have some kind of physical or cognitive disability, find it difficult to interact with web pages, depending on the page structure and the ways in which the content is made available. When specifically considering the cognitive disabilities, users classified as functionally illiterate face severe difficulties accessing web content. The heavy use of texts on interfaces design creates an accessibility barrier to those who cannot read fluently in their mother tongue due to both text length and linguistic complexity. In this context, this work aims at developing an assistive technologies that assists functionally illiterate users during their reading and understanding of websites textual content. These assistive technologies make use of natural language processing (NLP) techniques that maximize reading comprehension for users. The natural language techniques that this work uses are: syntactic simplification, automatic summarization, lexical elaboration and named entities recognition. The techniques are used with the goal of automatically adapting textual content available on the Web for users with low literacy levels. This work describes the accessibility characteristics incorporated into both resultant applications (Facilita and Educational Facilita) that focus on low literacy users limitations towards computer usage and experience. This work contributed with the identification of accessibility requirements for low-literacy users, elaboration of an accessibility model for automatizing WCAG conformance and development of accessible solutions in the user agents layer of web applications.

keywords: Web Accessibility, Natural Language Processing, Syntactic Simplificaion, Automatic Summarization, Lexical Elaboration and Named Entities Recognition. 

$\begin{array}{lll}\text { Resumo } & \mathbf{v}\end{array}$

$\begin{array}{lll}\text { Abstract } & \text { vii }\end{array}$

1 Introdução $\quad 1$

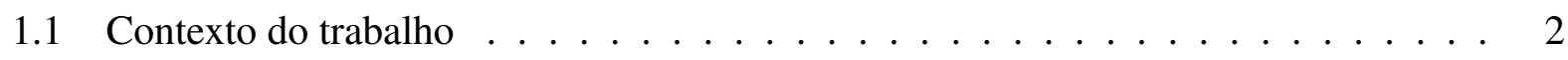

1.2 Projeto PorSimples . . . . . . . . . . . . . . . . . 5

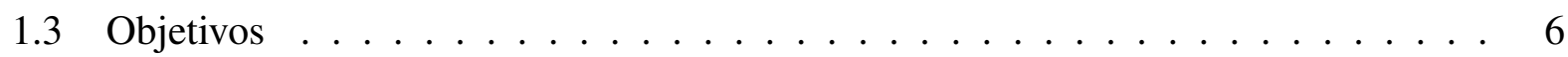

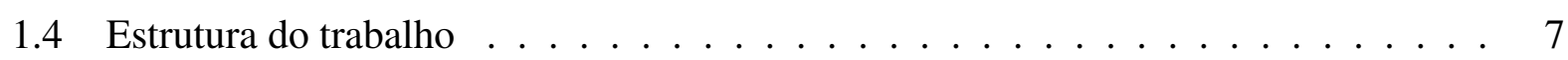

2 Acessibilidade na web 9

2.1 Considerações iniciais . . . . . . . . . . . . . . . . . . . . 9

2.2 Tecnologias assistivas . . . . . . . . . . . . . . . . . 10

2.3 Abordagem da WAI . . . . . . . . . . . . . . . . . . . . . 14

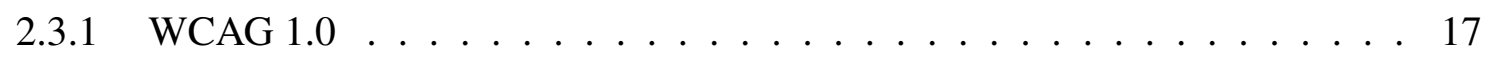

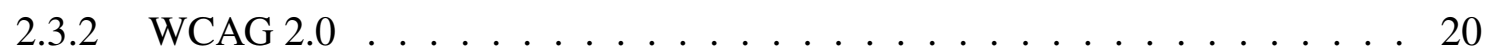

2.3.3 Diretrizes relativas à dificuldade de leitura na web . . . . . . . . . . 23

2.4 Considerações finais . . . . . . . . . . . . . . . . . 27

3 Revisão Sistemática da Literatura $\quad 29$

3.1 Considerações iniciais . . . . . . . . . . . . . . . . . . . . . . 29

3.2 Revisão sistemática . . . . . . . . . . . . . . . . . . . . . . 31

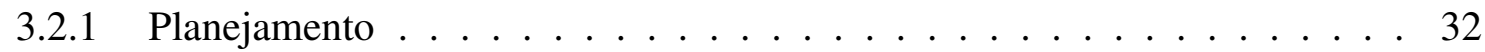

3.2 .2 Condução . . . . . . . . . . . . . . . . . 33

3.2 .3 Resultados . . . . . . . . . . . . . . . . . . 34

3.3 Metodologias de desenvolvimento de interfaces . . . . . . . . . . . . 35

3.3.1 Abordagens experimentais de design . . . . . . . . . . . . . . 36

3.3.2 Metodologias de avaliação da interface . . . . . . . . . . . . . . 37

3.4 Recursos de design . . . . . . . . . . . . . . . . . . . . 38

3.5 Considerações finais . . . . . . . . . . . . . . . . . 42 
4 Facilita $\quad 43$

4.1 Considerações iniciais . . . . . . . . . . . . . . . . . . . . 44

4.2 Conteúdo Facilitado . . . . . . . . . . . . . . . . . . . . . . 46

4.2.1 Sumarização automática . . . . . . . . . . . . . . . . . . . 47

4.2.2 Simplificação Sintática . . . . . . . . . . . . . . . . . . . . 48

4.3 Abordagem de design realizada . . . . . . . . . . . . . . . . . . . . 50

4.3 .1 Primeira iteração . . . . . . . . . . . . . . . . . . . 51

4.3 .2 Segunda iteração . . . . . . . . . . . . . . . . . 53

4.4 Considerações finais . . . . . . . . . . . . . . . . . . . 57

5 Facilita Educacional $\quad 59$

5.1 Considerações iniciais . . . . . . . . . . . . . . . . . . . . 59

5.2 Módulos de Processamento de Língua Natural . . . . . . . . . . . . . . . . . . . . 61

5.2 .1 Elaboração léxica . . . . . . . . . . . . . . . . . . . 61

5.2.2 Reconhecimento das entidades nomeadas e pós-classificação . . . . . . . . 62

5.3 Características de Design . . . . . . . . . . . . . . . . . . . . . 64

5.4 Implementação Web . . . . . . . . . . . . . . . . . . . . . 67

5.5 Protótipo do Facilita Educacional . . . . . . . . . . . . . . . . . . 68

5.6 Considerações finais . . . . . . . . . . . . . . . . . 71

6 Conclusões e Trabalhos Futuros $\quad 73$

6.1 Contribuições . . . . . . . . . . . . . . . . . . . 75

6.2 Limitações das Aplicações Desenvolvidas . . . . . . . . . . . . . . . 76

6.3 Trabalhos Futuros . . . . . . . . . . . . . . . . . . 76

$\begin{array}{ll}\text { Referências } & 79\end{array}$ 
1.1 Porcentagem de pessoas classificadas de acordo com nível de letramento (Montenegro e Educativa, 2009) . . . . . . . . . . . . . 3

2.1 Uso do leitor de tela como exemplo de tecnologia assistiva . . . . . . . . . . 12

2.2 Leitores de tela sem descrição textual nas figuras . . . . . . . . . . . . . . 13

2.3 Leitores de tela com descrição textual nas figuras . . . . . . . . . . . . . . . 13

2.4 Relação entre as guidelines da WAI . . . . . . . . . . . . . . . . . . . . . . . . . . . . . .

2.5 Responsáveis pela acessibilidade no modelo da WAI. . . . . . . . . . . . . . . 17

3.1 Evolução dos artigos selecionados, classificados pelo portal em que foi encontrado 35

4.1 Arquitetura de adaptação automática para conformidade com a WCAG (Watanabe et al., 2010b) . . . . . . . . . . . . . . . . . . . 45

4.2 Esquema de auxílio à leitura do Facilita (Watanabe et al., 2009a). . . . . . . . . . . 46

4.3 Mockup 1: modelo conceitual de um editor de textos. . . . . . . . . . . . 51

4.4 Mockup 2: modelo conceitual de um sistema de buscas. . . . . . . . . . . . . . . 52

4.5 Mockup 3: inserção do Facilita nos websites. . . . . . . . . . . . . . . . 53

4.6 Mockup 4: plugin do navegador. . . . . . . . . . . . . . 53

4.7 Barra de favoritos do navegador com o link do Facilita . . . . . . . . . . . . 54

4.8 Apresentação do conteúdo Facilitado no protótipo inicial. . . . . . . . . . . . . 55

4.9 Apresentação do conteúdo Facilitado no segundo protótipo. . . . . . . . . . . . 56

5.1 Esquema geral de funcionamento do Facilita Educacional (Watanabe et al., 2010a) 60

5.2 Processamento da elaboração léxica (Watanabe et al., 2010a) . . . . . . . . . . . 62

5.3 Processamento do reconhecimento das entidades nomeadas (Watanabe et al., 2010a) 66

5.4 Integração entre os módulos do Facilita Educacional (Watanabe et al., 2010a) . . . 67

5.5 Arquitetura de integração dos módulos e funcionalidades do Facilita (Watanabe et al., 2010a) . . . . . . . . . . . . . . . . . 69

5.6 Screenshot do link do Facilita Educacional. . . . . . . . . . . . . . . . . . 69

5.7 Screenshot apresentando as entidades destacadas no Facilita Educacional. . . . . . 70 
5.8 Screenshot da apresentação dos sinônimos para as palavras complexas destacadas no texto. . . . . . . . . . . . . . . . . . . . . 70

5.9 Screenshot da apresentação das informações adicionais a respeito da entidade nomeada destacada no texto. . . . . . . . . . . . . . . . . . 71 


\section{Lista de Tabelas}

4.1 Simplificações alternativas de uma mesma sentença . . . . . . . . . . . . . . . 49 
Web, atualmente, se caracteriza pela universalização de acesso à informação que suas 1 tecnologias viabilizam. Em geral, notícias, propagandas e serviços podem ser facil1 mente obtidos por meio da utilização de um navegador ( browser $^{1}$ ), computador e Internet, localizados em qualquer parte do mundo.

Como se isso não bastasse, pode ser observada a popularização da nova geração de aplicações que caracterizam a chamada Web $2 \cdot 0^{2}$. Essas aplicações possibilitam ao usuário uma forma mais ativa de participação desse meio de comunicação. Anteriormente, os usuários apenas realizavam buscas e consultas nos conteúdos disponibilizados, enquanto que agora, lhes é possível participar, inclusive, da autoria e disponibilização dos conteúdos. Dadas essas características, na atualidade, se formam verdadeiras comunidades virtuais sobre essas aplicações, como são verificadas em sistemas como Orkut ${ }^{3}$, Myspace ${ }^{4}$ e Youtube ${ }^{5}$.

No entanto, essas possibilidades não são estendidas para todos. Em grande parte dos casos, fazse necessário o cumprimento de um determinado número de requisitos para que as pessoas possam se tornar usuários de fato e usufruir desse potencial imenso. Dentre estes requisitos, se destacam: acesso a componentes de hardware (computador, handhelds, celulares) e softwares (sistema operacional, navegador) necessários para a interação, bem como características sensoriais e culturais plenamente desenvolvidas nos indivíduos, como por exemplo: capacidades de visão, audição (para

\footnotetext{
${ }^{1}$ programa que habilita a obtenção e apresentação de páginas web

${ }^{2}$ nova geração da Web que é caracterizada pelo fato de os usuários participarem no processo de autoria de conteúdo. Em contraste ao modelo da Web anterior, em que os usuários apenas buscavam ou procuravam informações.

${ }^{3}$ http://www.orkut.com

${ }^{4} \mathrm{http}: / /$ www.myspace.com/

${ }^{5} \mathrm{http}: / /$ www.youtube.com/
} 
determinadas aplicações), motoras (controle de mouse e utilização do teclado), cognitivas (relativos à aprendizagem e reconhecimento das informações), leitura (devido a grande quantidade de textos, normalmente, disponíveis nas interfaces), entre outras.

Essa necessidade de características sensoriais e culturais plenamente desenvolvidas implica diretamente na incapacidade de acesso a informações e serviços disponíveis na web por indivíduos que possam apresentar algum tipo de deficiência (indivíduos sem o sentido da visão, audição ou sem a capacidade plena de leitura, por exemplo). Nesse contexto, inserem-se os estudos de acessibilidade na web, que têm por finalidade possibilitar a qualquer usuário, independentemente de suas capacidades, utilizando qualquer agente (software ou hardware), poder perceber, entender, navegar e interagir com o conteúdo de um site (Thatcher e Waddell, 2003).

\subsection{Contexto do trabalho}

No Brasil, considerando-se restrições devido a características culturais, ainda persistem problemas associados a eficácia escolar, dentre eles, a evasão, a repetência, assim como a qualidade média da educação ministrada nas escolas brasileiras (IBGE, 2008).

O IBGE (Instituto Brasileiro de Geografia e Estatística) relata que, em 2008, 10\% dos indivíduos do país com 15 anos de idade ou mais são analfabetos (IBGE, 2008). Quando este conceito é estendido ao índice de analfabetos funcionais, definido pela UNESCO como o percentual da população com 15 anos de idade ou mais com menos de 4 anos de estudo, o valor de $21 \%$ da população brasileira é atingido (IBGE, 2009).

Para aperfeiçoar esse tipo de classificação da população, considerando não apenas aspectos quantitativos, mas também qualitativos do ensino na população, foi desenvolvido o Indicador de Analfabetismo Funcional (INAF) pelo Instituto Paulo Montenegro e Ação Educativa. O INAF é um instrumento de mensuração dos níveis de alfabetismo da população adulta brasileira e é implementado anualmente no país (Montenegro e Educativa, 2009). Este instrumento utiliza-se de entrevistas e testes cognitivos aplicados a 2.000 pessoas representativas dos cidadãos brasileiros entre 15 e 64 anos de idade, residentes de zonas urbanas e rurais em todas as regiões do país.

Como resultado desse procedimento, são apresentadas quantidades da população classificadas de acordo com suas habilidades de "letramento" e "numeramento" (Montenegro e Educativa, 2009), as quais são apresentadas a seguir:

- Analfabetos: indivíduos incapazes de realizar tarefas simples como a leitura de palavras e frases, ainda que uma parcela destes consiga ler números familiares (números de telefone, preço).

- Alfabetismo de nível rudimentar: indivíduos com capacidade de localizar informações explícitas em textos curtos e familiares (como um anúncio ou pequena carta), ler e escrever números usuais e realizar operações simples, como manusear dinheiro para o pagamento de pequenas quantias ou fazer medidas de comprimento utilizando fita métrica. 
- Alfabetismo de nível básico: pessoas classificadas neste nível podem ser consideradas funcionalmente alfabetizadas, pois já lêem e compreendem textos de média extensão, localizam informações mesmo que seja necessário realizar pequenas inferências, lêem números na casa dos milhões, resolvem problemas envolvendo uma seqüência simples de operações e têm noção de proporcionalidade. Mostram, no entanto, limitações quando as operações requeridas envolvem maior número de elementos, etapas ou relações.

- Alfabetismo de nível pleno: pessoas cujas habilidades não mais impõem restrições para compreender e interpretar elementos usuais da sociedade letrada: lêem textos mais longos, relacionando suas partes, comparam e interpretam informações, distinguem fato de opinião, realizam inferências e sínteses. Quanto à matemática, resolvem problemas que exigem maior planejamento e controle, envolvendo percentuais, proporções e cálculo de área, além de interpretar tabelas de dupla entrada, mapas e gráficos.

No Brasil em 2008, 7\% dos indivíduos foram avaliados como analfabetos; $21 \%$, como alfabetizados de nível rudimentar; 47\%, básico; e 25\%, pleno, sendo que indivíduos classificados até alfabetizados de nível rudimentar são considerados analfabetos funcionais. Essas porcentagens são representadas graficamente na Figura 1.1.

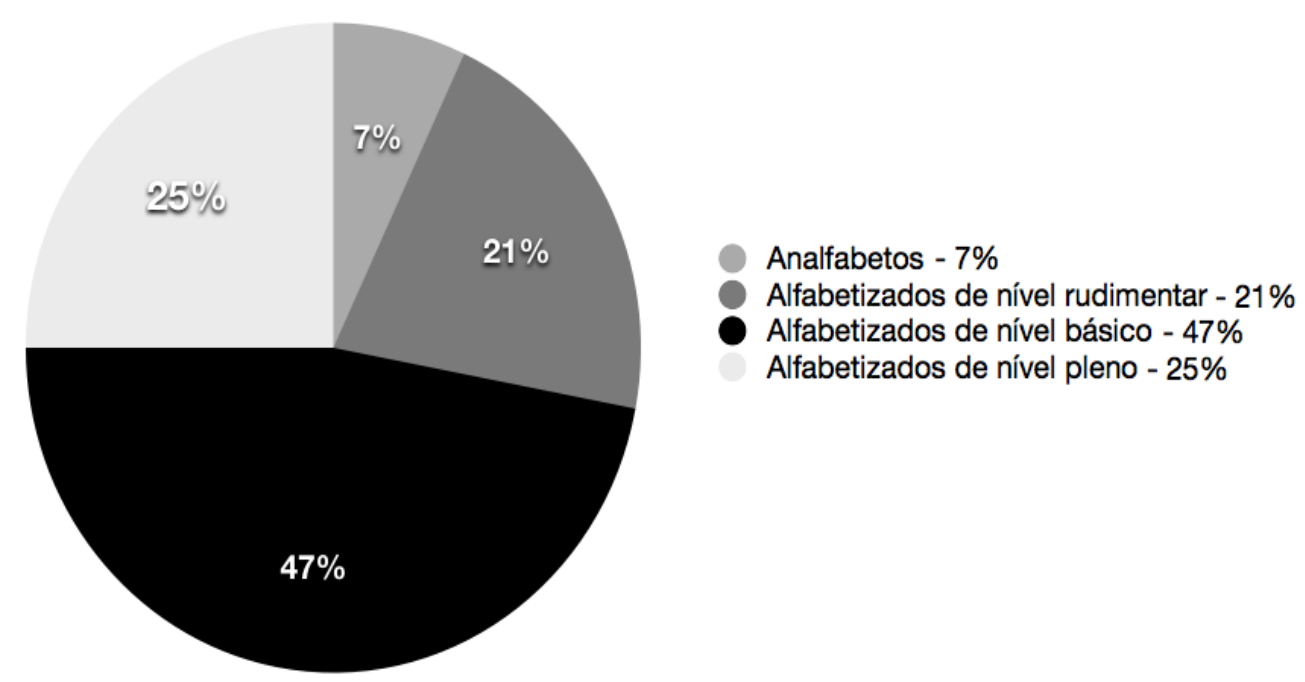

Figura 1.1: Porcentagem de pessoas classificadas de acordo com nível de letramento (Montenegro e Educativa, 2009)

É importante observar que tanto os alfabetizados de nível rudimentar, como os de nível básico, os quais totalizam 68\% da população segundo o INAF 2008 (Montenegro e Educativa, 2009), possuem dificuldades com atividades que envolvam a leitura e compreensão de textos dependendo do seu tamanho e complexidade, logo, possuem acesso restrito aos meios de comunicação que demandem tais requisitos.

Nesse contexto, sites e aplicações web que apresentem conteúdos compostos por grande quantidade de informações textuais sem o devido cuidado, com relação a sua complexidade, representam barreiras de acessibilidade a esses indivíduos (analfabetos funcionais e alfabetizados de nível 
básico). Para usuários analfabetos, mesmo a utilização de textos com estrutura simplificada e de reduzidas dimensões não garante o seu acesso a informação, sendo necessários outros meios de transmissão do conteúdo. Assim, o desenvolvimento de aplicações para esses indivíduos (analfabetos, analfabetos funcionais e alfabetizados de nível básico) requer cuidados especiais na elaboração de seu conteúdo, ou a utilização de componentes de design, tecnologias e mídias alternativas que são freqüentemente utilizadas (textuais), com a finalidade de promover acesso e compreensão do conteúdo e garantir um maior grau de satisfação de acordo com as funcionalidades que as aplicações podem dispor. Como exemplos de recursos desenvolvidos com essa finalidade, podem ser citados: narração do conteúdo a ser disponibilizado (Hahn et al., 2004), representações gráficas de conhecimento (Boucheix, 2004), simplicidade dos conteúdos textuais (Becker, 2004) (Summers et al., 2006).

A necessidade da utilização desses recursos para promover a acessibilidade na web é mencionada em trabalhos bem conhecidos e amplamente referenciados, como a Web Content Accessibility Guidelines (WCAG) da W3C ${ }^{6}$.

Uma das guidelines da WCAG 1.0 é direcionada à simplicidade e clareza dos documentos (guideline 14) (W3C, 1999). Esta guideline está vinculada ao princípio de compreensibilidade da aplicação e sugere a utilização de técnicas que focam o estilo de escrita (tornar os conteúdos mais fáceis de serem lidos) e equivalentes multimídia para o conteúdo (gráficos, linguagem dos sinais e versões narradas do conteúdo).

A WCAG 2.0, que atingiu o status de recomendação da W3C em dezembro de 2008, contempla, em seu princípio de compreensibilidade (understandable), um requisito de acessibilidade relativo ao nível de escrita das aplicações (W3C, 2008c). Neste requisito (critério de sucesso 3.1.5) é especificado que textos que requerem habilidade de leitura superior a dos indivíduos com ensino secundário inferior (lower secondary education, fazendo menção ao sistema de ensino inglês quinta a oitava séries no Brasil), devem apresentar uma versão alternativa do mesmo conteúdo ou um conteúdo complementar que seja destinado a indivíduos sem essa habilidade (disponibilização de sumário textual com conteúdo simplificado; ilustrações, fotos e símbolos para facilitar o entendimento; versões narradas do texto; entre outros).

É importante destacar, no entanto, que essas recomendações de acessibilidade (checkpoint 14.1 da WCAG 1.0 e Critério de sucesso 3.1.5 da WCAG 2.0) descrevem características relacionadas ao conteúdo da aplicação web. E, para satisfazê-las, torna-se necessária a implementação manual desses requisitos no conteúdo da aplicação (Watanabe et al., 2009a,b). Ou seja, para garantir a acesso à informação por indivíduos analfabetos funcionais e alfabetizados de nível básico, os autores do conteúdo devem considerar a utilização desses recursos (utilização de conteúdo simplificado, ilustrações, fotos, símbolos, versões narradas, entre outros) na aplicação. Para grande maioria dos casos, porém, os responsáveis pela elaboração do conteúdo não são também os responsáveis pelo desenvolvimento do site ou aplicação web (autores de conteúdo contratam outros

\footnotetext{
${ }^{6}$ World Wide Web Consortium
} 
indivíduos que sejam desenvolvedores web para implementar seus sites). Freire et al. conduziram um levantamento sobre o conhecimento das diretrizes de acessibilidade na web com desenvolvedores web (Freire et al., 2008b) e a acessibilidade observada em websites de munícipios do Brasil (Freire et al., 2008a). A conclusão de ambos os trabalhos é de que a acessibilidade web ainda está longe de ser considerada no Brasil e muito trabalho ainda deve ser realizado. Considerando o contexto da "Web 2.0", em que usuários, sem nenhum conhecimento a respeito das diretrizes de acessibilidade, podem participar ativamente do processo de autoria de conteúdo na Web, torna-se ainda mais difícil desenvolver websites que se mantenham em conformidade com os requisitos propostos na WCAG.

Um outro aspecto a ser destacado diz respeito ao fato de que usuários com baixo nível de alfabetização, são, muitas vezes também, classificados como analfabetos computacionais e, portanto, requerem interações simples de utilização, dadas sua dificuldade e pouca familiaridade com o uso de sistemas computacionais. A simples disponibilização de recursos como ilustrações, fotos, símbolos ou versões narradas do texto não garante a acessibilidade da aplicação a usuários que sejam analfabetos funcionais ou alfabetizados de nível básico. Cada alternativa de representação de conteúdo possui diferentes níveis de compreensibilidade (Medhi et al., 2007a) e diferentes requisitos de design para garantir que seja compreendida. Assim, são necessárias múltiplas interações com os usuários para determinação de um design da aplicação que seja aceito e compreendido pelos usuários.

\subsection{Projeto PorSimples}

O projeto PorSimples (Simplificação Textual do Português para Inclusão e Acessibilidade Digital $^{7}$ ), considerando os requisitos de acessibilidade das aplicações web, teve como objetivo o desenvolvimento de tecnologias que facilitem o acesso a informação por indivíduos alfabetizados de níveis rudimentar e básico, por meio de recursos simplificação sintática, sumarização automática, elaboração léxica e reconhecimento automático das entidades nomeadas. Portanto, esses recursos foram aplicados de forma automática sobre textos, adaptando-os em textos escritos em linguagem simples, mais facilmente compreendida por indivíduos alfabetizados de níveis rudimentar e básico. Esses recursos de processamento de língua natural foram utilizados como uma forma de adaptar automaticamente aplicações web convencionais em aplicações web em conformidade com os requisitos estabelecidos pela WCAG (Diretrizes 3.1.3 e 3.1.5 da WCAG 2.0 (W3C, 2008c)).

Neste projeto foram desenvolvidas as seguintes aplicações:

- Facilita: aplicação que visa facilitar a leitura de conteúdos textuais em português de páginas e aplicações Web. Deve atuar como uma tecnologia assistiva que possibilite, ao usuário, a leitura de conteúdos textuais disponíveis na Web aplicando operações de simplificação

\footnotetext{
${ }^{7}$ http://caravelas.icmc.usp.br/wiki/index.php/Principal
} 
sintática e sumarização automática. A aplicação dessas operações sobre o texto deve gerar um conteúdo também textual, mais facilmente compreendido por usuários alfabetizados de níveis rudimentar e básico. Essa adaptação do conteúdo web deve ser realizada como uma forma de satisfazer o critério de sucesso 3.1.5 da WCAG 2.0 (W3C, 2008c).

- Facilita Educacional: aplicação de auxílio a leitura que deve promover a inserção de mecanismos que auxiliem o usuário na compreensão de determinadas palavras ou expressões contidas nos textos. Para realizar essa tarefa são utilizados os métodos de elaboração léxica e reconhecimento das entidades nomeadas. Essa disponibilização automática de mecanismos de compreensão das palavras e expressões contidas nos websites é realizada como uma forma de satisfazer o critério de sucesso 3.1.3 (disponibilizar mecanismos que apresentem definições para palavras ou expressões incomuns) da WCAG 2.0 (W3C, 2008c).

O projeto PorSimples foi desenvolvido pelo Núcleo de Interinstitucional de Lingüística Computacional $\left(\mathrm{NILC}^{8}\right.$ ), juntamente com o laboratório Intermídia ${ }^{9}$ do Instituto de Ciências Matemáticas e de Computação (ICMC-USP) e conta com o apoio da FAPESP (Fundação de Amparo à Pesquisa de São Paulo) e da MSR (Microsoft Research).

\subsection{Objetivos}

Esta pesquisa esteve inserida nos objetivos do projeto PorSimples e teve por finalidade o desenvolvimento, mais especificamente voltado às características de design da interface, das aplicações Facilita e Facilita Educacional, de maneira a oferecer auxílio à leitura de informações disponíveis na web, promovendo a acessibilidade na web a indivíduos classificados como alfabetizados de níveis rudimentar e básico.

Como característica de design da interface foi considerada a vinculação de recursos de simplificação sintática, sumarização automática, elaboração léxica e reconhecimento das entidades nomeadas com outros recursos de design destinados a usuários analfabetos funcionais (analfabetos e semi-analfabetos, inclusive), para garantir que o Facilita seja acessível e utilizável por seus usuários.

O tema de desenvolvimento de interfaces para usuários com baixo nível de alfabetização é pouco referenciado na literatura para aplicações web com conteúdos dinâmicos, embora já exista uma série de estudos relacionados com o desenvolvimento de aplicações locais. A adaptação das características de design utilizadas nesses estudos para a arquitetura na web também é um dos focos deste trabalho.

Dessa forma, os principais objetivos deste trabalho foram:

\footnotetext{
${ }^{8} \mathrm{http}: / /$ www.nilc.icmc.usp.br/nilc/index.html

${ }^{9} \mathrm{http}: / /$ intermidia.incubadora.fapesp.br/portal
} 
1. Identificação dos recursos de design que podem ser utilizados no desenvolvimento de aplicações acessíveis a indivíduos analfabetos funcionais e alfabetizados de nível básico. Esses recursos foram utilizados junto com as operações de simplificação sintática, sumarização automática, elaboração léxica e reconhecimento das entidades nomeadas.

2. Projetar e implementar as aplicações Facilita e Facilita Educacional em arquitetura distribuída, para ser executada via web, considerando as devidas etapas de design de interface, de acordo com normas de acessibilidade para os usuários alvo da aplicação. As aplicações Facilita e Facilita Educacional se apresentam como prova de conceito do modelo de acessibilidade que automatiza a conformidade com a WCAG e desenvolvimento de soluções de acessibilidade na camada de agente de usuário.

\subsection{Estrutura do trabalho}

Este trabalho está organizado da seguinte forma: o capítulo seguinte (Capítulo 2, Acessibilidade na Web) apresenta uma visão geral do que tem sido desenvolvido em termos de acessibilidade na web, atualmente, destinado a usuários com dificuldade de leitura; o Capítulo 3 (Revisão Sistemática da Literatura) introduz os conceitos que são considerados no desenvolvimento de aplicações que visam o público alvo da aplicação a ser desenvolvida neste projeto (Facilita), de acordo com as metodologias adotadas para o seu desenvolvimento, juntamente com os recursos, princípios de design utilizados para auxiliar as interações com os usuários; o Capítulo 4 descreve a aplicação Facilita, bem como os requisitos tecnológicos necessários ao seu desenvolvimento; o Capítulo 5 descreve a aplicação Facilita Educacional, suas características arquiteturais, tecnológicas e os recursos de processamento de língua natural utilizados; por fim, o Capítulo 6 (Conclusões e Trabalhos Futuros) apresenta as considerações finais deste trabalho, juntamente, com as contribuições alcançadas e os trabalhos futuros. 

este capítulo, são apresentadas as principais abordagens de desenvolvimento de aplicações web com acessibilidade. São descritos os conceitos relacionados e o modelo de conformidade da WAI - Web Accessibility Initiative, um dos trabalhos mais referenciados na área.

A compreensão dos conceitos de acessibilidade foi essencial para este trabalho de mestrado para assegurar as contribuições do mesmo no cenário científico atual.

\subsection{Considerações iniciais}

O tema "acessibilidade na web" corresponde a uma característica de qualidade relativa ao design da página web de forma geral, de maneira que os usuários sejam capazes de acessá-la a partir de diferentes situações (W3C, 1999). Como por exemplo, casos em que os usuários:

- Sejam incapazes de ver, ouvir, se mover ou compreender determinadas formas de disponibilização do conteúdo,

- Possuam dificuldades de leitura e compreensão do texto,

- Sejam incapazes de utilizar o teclado ou o mouse,

- Utilizem navegadores apenas em modo texto, tela com dimensões reduzidas ou conexão com a Internet lenta, 
- Estejam em situações em que olhos, ouvidos ou mãos possam estar ocupadas em outras atividades, e

- Utilizem versões antigas ou diferentes navegadores, navegador por voz ou diferentes sistemas operacionais.

É importante observar que essas situações envolvem tanto requisitos tecnológicos necessários para a interação, quanto características do usuário.

As situações relacionadas aos requisitos tecnológicos consideram as características do hardware e do software utilizados na interação com o usuário. Dessa forma, os sites devem ser implementados de forma que possam ser apresentados e visualizados, independentemente dos dispositivos, sistema operacional e navegadores sendo utilizados. Por outro lado, nas situações relacionadas com as características do usuário é priorizada a adaptação, redundância e substituição do conteúdo de acordo com as deficiências físicas ou cognitivas que os usuários possam apresentar. As deficiências físicas em geral são: deficiência visual, audível e motora. Já as deficiências cognitivas consideradas são: patologias, como alzheimer e dislexia, dificuldades de leitura e compreensão do conteúdo, entre outras.

A preocupação de acordo com as características dos usuários, mais especificamente de acordo com suas deficiências, possui também um impacto relacionado à sua inclusão social, por meio do seu acesso à informação e utilização de serviços que possam ser disponibilizados na web. A importância desse impacto social pode ser observada pela regulamentação de conteúdo acessível por parte de orgãos governamentais de países como Estados Unidos (Section 508 ${ }^{1}$ ), Canadá, Portugal, Japão e, inclusive, o Brasil (obrigatoriedade de acessibilidade nos portais e sítios eletrônicos da administração pública na rede mundial de computadores, determinada no Decreto Lei 5.296, promulgado em 2004).

Este capítulo apresenta os principais conceitos e trabalhos desenvolvidos que são associados ao tema de acessibilidade na web. A próxima seção (Seção 2.2) apresenta os conceitos de tecnologias assistivas, juntamente com suas relações no desenvolvimento de aplicações acessíveis; a Seção 2.3 introduz a abordagem da W3C para com a acessibilidade na web, apresentando a WCAG (1.0 e 2.0), ATAG e UAAG como formas de desenvolvimento de aplicações web acessíveis e introduz o que é considerado, atualmente, no desenvolvimento de acessibilidade na web para usuários com dificuldade de leitura; por fim, na Seção 2.4, são apresentadas considerações finais sobre o tema de acessibilidade na web.

\subsection{Tecnologias assistivas}

No Brasil, em 2000, 24,6 milhões de indivíduos se declararam portadores de algum tipo de deficiência, representando $14,5 \%$ da população total (IBGE, 2000b). Como portadores de defici-

\footnotetext{
${ }^{1}$ http://www.section508.gov/
} 
ência, são classificadas as pessoas que possuam algum tipo de deficiência física (incapacidades de visão, audição ou locomoção) ou cognitiva (dificuldades ou limitações intelectuais).

Esses indivíduos possuem dificuldades no desempenho de determinadas atividades diárias, conforme o tipo de deficiência por eles manifestada. Como exemplos podem ser destacados: entrada nos meios de transporte coletivos por indivíduos com locomoção reduzida ou leitura de cardápios em restaurante por pessoas com deficiência visual.

Quando considerando a utilização dos sistemas de informação, inclusive da web, por esses indivíduos, essas dificuldades também podem ser observadas: leitura da tela por indivíduos com deficiência visual, utilização do mouse por pessoas com deficiências motoras nos membros superiores, entre outras.

A taxa de portadores de deficiência aumenta conforme a faixa etária da população, de forma que 4,3\% indivíduos que apresentam deficiências são crianças de até 14 anos, enquanto que 54\% são indivíduos com mais de 65 anos (IBGE, 2000a). Esse fato aliado ao envelhecimento da população brasileira, observada nos últimos anos (aumento mais acelerado para segmentos da população com idade superior a 60 anos (IBGE, 2008)), denota ainda uma maior importância de estudos que estejam vinculados a acessibilidade por indivíduos que apresentem algum tipo de deficiência.

Nesse contexto se insere o uso de tecnologias assistivas, como uma forma de auxílio no desempenho dessas atividades por esses indivíduos. O termo tecnologia assistiva é definido como o conjunto de equipamentos, serviços, estratégias e práticas concebidas e aplicadas para atenuar os problemas encontrados por pessoas com necessidades especiais (Cook e Hussey, 2001).

Como exemplos de tecnologias assistivas, comumente observadas, podem ser citadas: cadeira de rodas, lentes de correção de deficiências visuais (óculos), aparelhos auditivos, entre outras.

Para o desenvolvimento de atividades que envolvam a utilização de computadores (sistemas de informação), também podem ser observadas algumas tecnologias assistivas. Essas tecnologias agem como uma forma de interface entre os conteúdos e informações disponíveis no computador e o usuário, durante as interações.

Os conteúdos disponibilizados em formato inacessível ou de difícil compreensão pelos usuários são convertidos em uma forma alternativa de mídia que seja mais facilmente visualizada e interpretada, durante interações de saída de informações do computador para o usuário. Esse procedimento é ilustrado na Figura 2.1, para a tecnologia assistiva do leitor de telas. A Figura 2.1 ilustra o uso de uma tecnologia assistiva por um usuário com deficiência visual. O usuário é incapaz de ler ou enxergar os conteúdos visuais apresentados no computador. Dessa forma, a tecnologia assistiva narra o conteúdo disponível, para que o usuário com baixa acuidade visual possa interagir com o computador.

Nas interações de entrada, o funcionamento é o mesmo, o usuário que não consiga utilizar o teclado ou o mouse para efetuar a entrada de dados no computador utiliza um meio diferente de inserção de dados, que seja apropriado para superar sua deficiência. Os dados são então convertidos pela tecnologia assistiva em um formato que seja compreendido pelo computador. 

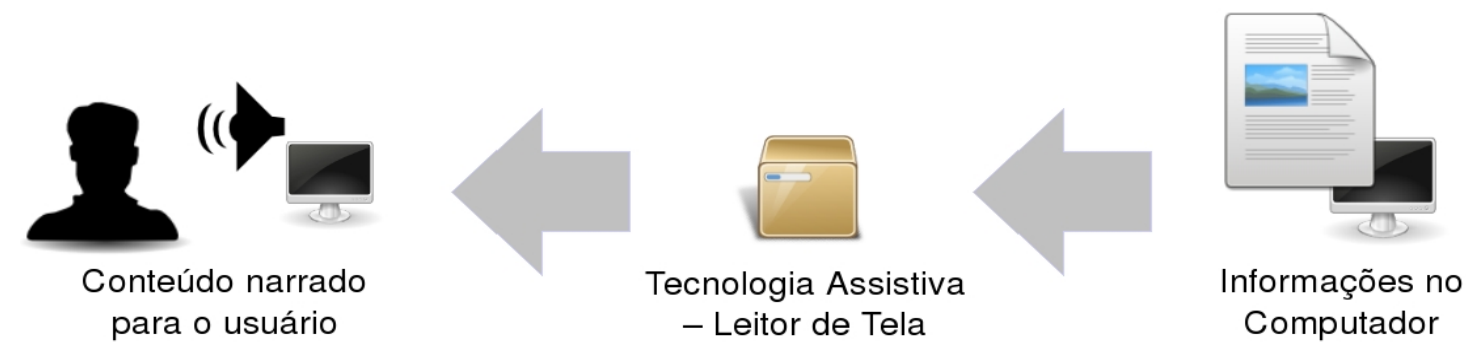

Figura 2.1: Uso do leitor de tela como exemplo de tecnologia assistiva

Entre os principais exemplos de tecnologias assistivas utilizadas em computadores, temos:

- Leitor de tela: software que realiza a leitura dos componentes apresentados na tela do computador, emitindo-os por voz a indivíduos com deficiência visual. Exemplo: Orca ${ }^{2}$.

- Navegador textual: navegador que apresenta apenas o conteúdo textual das páginas e aplicações web. Normalmente, utilizado junto com um software de leitor de tela para auxiliar a navegação na Web por usuários com deficiência visual. Exemplo: Lynx³ .

- Reconhecedor de fala: software que traduz comandos passados por voz pelos usuários em tarefas a serem executadas pelo computador. Pode ser utilizado por indivíduos que possuam algum tipo de deficiência que limite a utilização de dispositivos de entrada como mouse ou teclado. Exemplos: Microsoft's speech technologies ${ }^{4}$ e Dragon NaturallySpeaking 10 Preferred ${ }^{5}$.

É importante destacar que a utilização de apenas uma tecnologia assistiva, na maioria das vezes, não é suficiente para o desempenho das tarefas por pessoas com deficiências. Como exemplo pode ser citado o uso de cadeira de rodas, que somente é possível em ambientes planos, sendo necessária a presença de rampas de acesso ou elevadores em prédios e construções que possuam mais de um andar.

Com relação à atividade de navegação web, o leitor de tela, quando aplicado para efetuar a leitura de sites, necessita que sejam atribuídas descrições em texto para os conteúdos apresentados em formas não textuais, como imagens ou figuras, para que a informação contida neles seja narrada ao usuário. A ausência dessas descrições determina que qualquer informação representada pelas figuras é perdida, não acessada por usuários que não disponham do sentido da visão, visto que o leitor de telas é capaz apenas de sintetizar em voz os conteúdos textuais das aplicações. Este exemplo está ilustrado nas Figuras 2.2 e 2.3.

Requisitos de design como esses, rampas de acesso em prédios e construções, e descrição textual para os elementos não textuais nos sites também são considerados tecnologias assistivas e

\footnotetext{
${ }^{2} \mathrm{http}: / /$ projects.gnome.org/orca/

${ }^{3}$ http://lynx.isc.org/

${ }^{4}$ http://www.microsoft.com/speech/speech2007/default.mspx

${ }^{5}$ http://www.nuance.com/naturallyspeaking/products/preferred.asp
} 


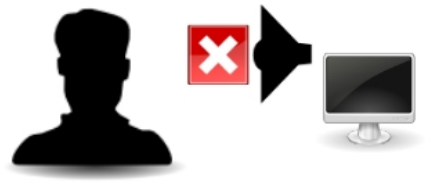

Conteúdo não narrado para o usuário

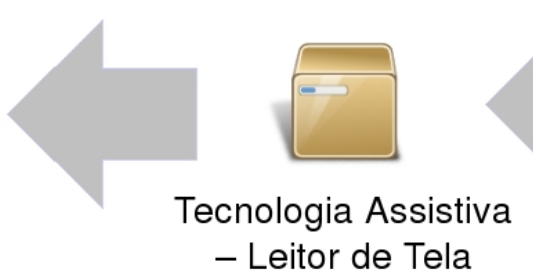

- Leitor de Tela

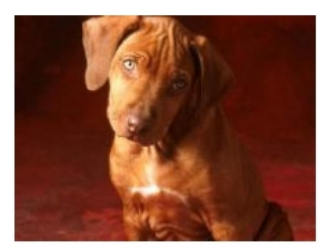

Imagem sem descrição textual

Figura 2.2: Leitores de tela sem descrição textual nas figuras
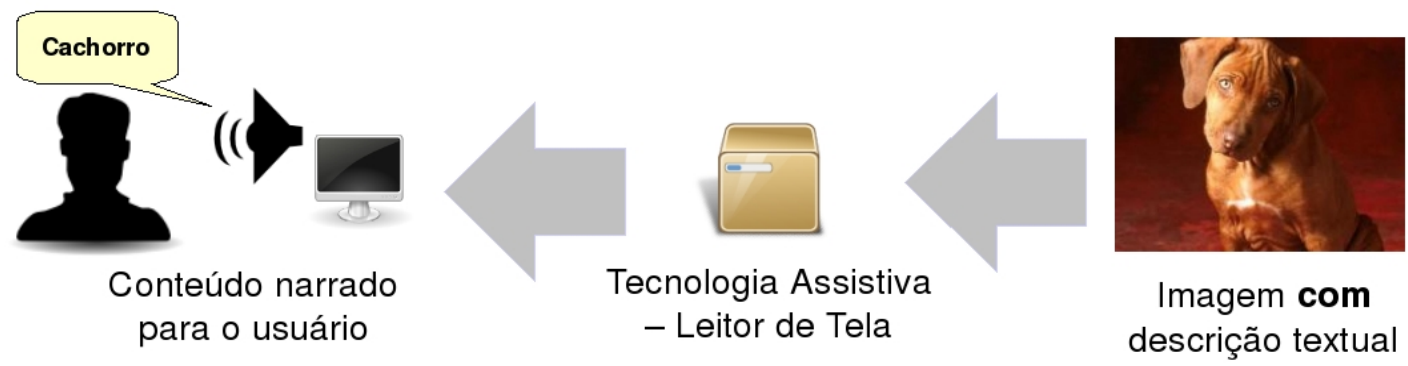

Figura 2.3: Leitores de tela com descrição textual nas figuras

devem ser implementados por designers para garantir a acessibilidade. Esses requisitos levam a um determinado nível de padronização que garante a flexibilidade dos ambientes e produtos de acordo com as deficiências que possam ser apresentadas e as diferentes tecnologias assistivas que venham a ser utilizadas pelos usuários e são de responsabilidade de designers ou, no caso da web, disponibilizadores de conteúdo.

Essa padronização é o foco dos estudos sobre acessibilidade na web, e sua utilização em conjunto com as tecnologias assistivas de acesso ao computador (leitores de tela, reconhecedores de voz, mouses alternativos, entre outras) garantem o acesso a esse meio de comunicação, por qualquer indivíduo.

$\mathrm{Na}$ Web, o padronização é alcançada por meio do desenvolvimento de características de design das tecnologias web (HTML ${ }^{6}, \mathrm{CSS}^{7}$, Javascript, entre outras) que, em conjunto com a utilização de determinadas tecnologias assistivas (leitores de tela, mouses alternativos, navegadores textuais), sejam acessíveis a todos os usuários, independentemente das deficiências físicas e cognitivas que apresentem.

A próxima seção descreve as diretrizes da WAI (Web Accessibility Initiative) no desenvolvimento de sites e aplicações web acessíveis e a WCAG (Web Content Accessibility Guidelines) que agrega uma série de padrões de design de tecnologias web e características do conteúdo a ser disponibilizado, considerando a implementação da padronização para essas aplicações.

\footnotetext{
${ }^{6}$ Hypertext markup language

${ }^{7}$ Cascading Style Sheets
} 


\subsection{Abordagem da WAI}

Quando considerando as questões de acessibilidade na web, uma das referências de maior importância (Kelly et al., 2005) (Freire et al., 2007) é a WCAG - Web Content Accessibility Guidelines, elaborada pela WAI (Web Accessibility Initiative).

A WAI (Web Accessibility Initiative) é uma organização criada pela W3C que tem como missão definir princípios e regras de design e desenvolvimento de sites que sejam acessíveis a pessoas com necessidades especiais (Lucca et al., 2005). Para este fim, foi estabelecido um modelo de conformidade com três conjuntos de diretrizes agregadas nos seguintes documentos (Kelly et al., 2005) (Kelly et al., 2007):

- WCAG 1.0 - Web Content Accessibility Guidelines: explicam como tornar o conteúdo web acessível a indivíduos com deficiências e disponível a todos os usuários, qualquer que sejam os agentes de usuário que estejam sendo utilizados (navegadores de desktop, navegadores por voz, celulares entre outros) e restrições de operações (ambientes barulhentos, com pouca iluminação, entre outros) (W3C, 1999).

- ATAG 1.0 - Authoring Tool Accessibility Guidelines: tem como propósito assistir desenvolvedores na implementação de ferramentas de autoria de conteúdo Web que seja acessível e na criação de ferramentas de autoria acessíveis (W3C, 2000a).

- UAAG 1.0 - User Agent Accessibility Guidelines: destinado ao desenvolvimento de agentes de usuário (user agents) que reduzam as barreiras à acessibilidade na Web para pessoas com deficiências (visual, auditiva, física, cognitiva e neurológica). Como agentes de usuário são incluídos os navegadores HTML e outros tipos de software que apresentam conteúdo Web (W3C, 2002).

Para cada diretriz contida nesses documentos, são descritos checkpoints que definem etapas ou partes de um projeto que podem apresentar barreiras a usuários com algum tipo de limitação (indivíduos cegos, surdos, com problemas cognitivos, entre outros). A cada um desses checkpoints é determinado um valor de prioridade, de acordo com o seu impacto na acessibilidade e conformidade com os respectivos documentos (W3C, 1999) (W3C, 2002) (W3C, 2000a):

- Prioridade 1: o não cumprimento do checkpoint acarreta que um ou mais grupos de usuários vão ser impossibilitados de acessar a informação do site.

- Prioridade 2: o não cumprimento do checkpoint acarreta que um ou mais grupos de usuários vão ter dificuldades para acessar as informações contidas do site.

- Prioridade 3:o não cumprimento do checkpoint acarreta que um ou mais grupos de usuários vão ter um pouco de dificuldade para acessar as informações contidas no site. 
Especificamente para a ATAG, existem checkpoints de prioridade relativa (Relative Priority) (W3C, 2000a). Esses checkpoints se referem a geração, autoria e verificação de conteúdo web, ou seja, estão relacionados, diretamente, a checkpoints da WCAG 1.0. Dessa forma, o nível de importância a eles atribuído depende da prioridade atribuída ao checkpoint correspondente na WCAG 1.0. Por exemplo: o checkpoint 4.1 da ATAG 1.0 indica a importância da verificação e aviso ao autor a respeito de problemas de acessibilidade. A verificação de equivalentes textuais a imagens e audio (checkpoint 1.1 de prioridade 1 da WCAG 1.0) na ferramenta de autoria também é de prioridade 1 . No entanto, a verificação do agrupamento de links no mecanismo de navegação (checkpoint 13.6 de prioridade 3 da WCAG 1.0) é de prioridade 3.

De acordo com a verificação desses checkpoints na aplicação, a WAI atribui um valor de conformidade com o conjunto de diretrizes entre A e AAA:

- Conformance Level "A": todos checkpoints de prioridade 1 são satisfeitos para a WCAG 1.0 e a UAAG 1.0. Para a ATAG 1.0 também é necessária a satisfação de todos os checkpoints de prioridade relativa.

- Conformance Level "AA": todos checkpoints de prioridade 1 e 2 são satisfeitos para a WCAG 1.0 e a UAAG 1.0. Para a ATAG 1.0 também é necessária a satisfação de todos os checkpoints de prioridade relativa.

- Conformance Level "AAA": todos checkpoints de prioridade 1, 2 e 3 são satisfeitos para a WCAG 1.0 e a UAAG 1.0. Para a ATAG 1.0 também é necessária a satisfação de todos os checkpoints de prioridade relativa.

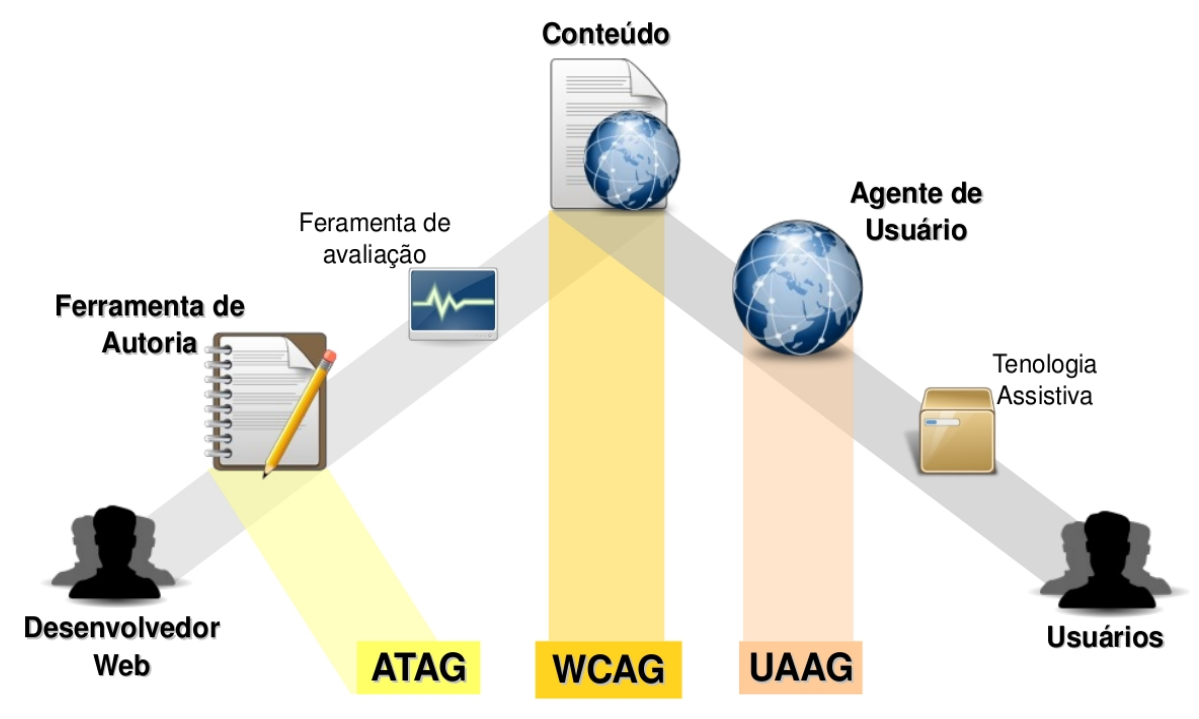

Diretrizes de Acessibilidade da WAI

Figura 2.4: Relação entre as guidelines da WAI. Figura adaptada do site da WAI: http://www.w3.org/WAI/intro/specs.png 
No contexto da relação entre as diretrizes WCAG, ATAG e UAAG, conforme esquematizado na Figura 2.4, o termo tecnologia assistiva possui definição específica. A tecnologia assistiva é tida como hardware ou software que atua como um agente de usuário, ou em conjunto com um agente de usuário principal, para promover funcionalidades que satisfaçam requisitos de usuários com deficiências que vão além das oferecidas pelo agente do usuário principal (W3C, 2002) (W3C, 2008c). Com isso, a conformidade com cada um dos conjuntos de diretrizes de acessibilidade, nas interações compreendidas entre a autoria de conteúdo e disponibilização do mesmo aos usuários, junto com a utilização de uma determinada tecnologia assistiva, conforme o tipo de necessidade especial apresentada pelo usuário, garantem o acesso a informação, de acordo com o modelo definido.

É importante destacar que cada uma dessas diretrizes de acessibilidade são destinadas a diferentes componentes e públicos-alvo na web. A WCAG diz respeito à estrutura e ao conteúdo inserido nas tecnologias de desenvolvimento web (HTML, CSS, Javascript, entre outras), sendo destinada a autores de páginas web, web designers e desenvolvedores de ferramentas de autoria (editores HTML) (W3C, 1999). ATAG refere-se às características necessárias nas ferramentas de autoria, sendo destinada aos desenvolvedores dessas aplicações (W3C, 2000a). Por fim, a UAAG é dirigida a implementação de navegadores, players multimídia, plugins (programas que executam como parte do agente de usuário, e não faz parte do conteúdo Web), entre outros (inclusive tecnologias assistivas) (W3C, 2002).

Dessa forma, esse modelo de conformidade com os conjuntos de diretrizes de acessibilidade pode ser classificado de acordo com os três componentes, conteúdo, ferramentas de autoria e agentes de usuários, que devem ser considerados na garantia de acessibilidade na web. Cada componente tem o seu desenvolvimento realizado por diferentes indivíduos, conforme esquematizado na Figura 2.5, e, para que se alcance a padronização na aplicação final, faz-se necessária a conformidade de cada um dos componentes com suas respectivas diretrizes de acessibilidade.

Pode ser observado que esse modelo é dependente do desenvolvimento de agentes de usuários (navegadores) e ferramentas de autoria de conteúdo, que sigam as diretrizes determinadas nos documentos UAAG e ATAG, respectivamente. Uma vez que os desenvolvedores web não possuem o controle sobre o desenvolvimento nessas áreas ou sobre as escolhas de utilização de navegadores e tecnologias assistivas utilizadas pelos usuários (Kelly et al., 2005) (Kelly et al., 2007), um maior enfoque e importância, com relação a acessibilidade na web, é atribuído à WCAG, considerando esses desenvolvedores.

As seções seguintes (Seção 2.3.1 e Seção 2.3.2) apresentam as diretrizes de acessibilidade que compõem a WCAG 1.0 e WCAG 2.0 que, recentemente (Dezembro de 2008), atingiu o estado de Recomendação da W3C. 


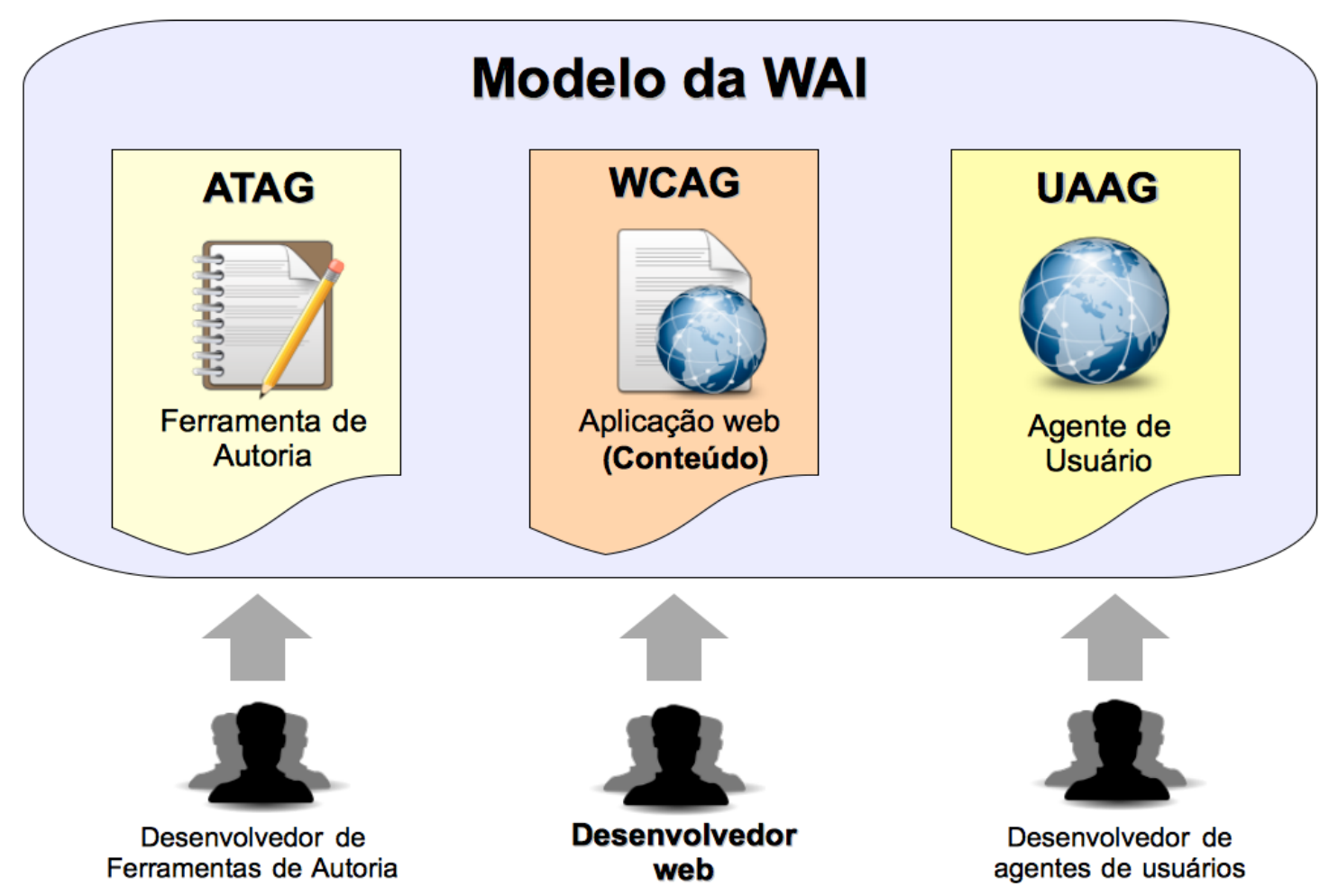

Figura 2.5: Responsáveis pela acessibilidade no modelo da WAI.

\subsubsection{WCAG 1.0}

A WCAG 1.0 consiste de um documento que apresenta um conjunto de guidelines que discutem problemas de acessibilidade na utilização de tecnologias web e soluções de design acessíveis (W3C, 1999).

As diretrizes são classificadas de acordo com dois temas:

1. Assegurar a transformação harmoniosa: a transformação harmoniosa das páginas garante que o conteúdo permanece acessível, mesmo em situações em que os usuários sejam deficientes físicos, sensoriais ou cognitivos, ou estejam operando com restrições de trabalho e barreiras tecnológicas.

Este tema é abordado nas diretrizes 1 a 11.

2. Tornar o conteúdo compreensível e navegável: utilizar linguagem clara e simples nos conteúdos e promover mecanismos compreensíveis de navegação entre as páginas. A disponibilização de ferramentas de navegação e orientação de informação nas páginas maximiza a acessibilidade e usabilidade nas aplicações.

Este tema é abordado nas diretrizes 12 a 14.

Cada diretriz apresenta:

- Um número de identificação 
- Definição da guideline

- Motivação de uso da mesma e alguns grupos de usuários que se beneficiam por ela

- Uma lista de pontos de verificação (checkpoints), que explicam como a diretriz se aplica no cenário de desenvolvimento. Para cada checkpoint são apresentadas implementações e exemplos da solução discutida (W3C, 2000b).

As 14 diretrizes da WCAG 1.0 são (W3C, 1999):

1. Promover alternativas equivalentes a conteúdos audíveis e visuais: disponibilizar equivalentes textuais para conteúdos não textuais (imagens, audio e vídeos). Os conteúdos textuais, ao contrário de figuras e gravações de áudio por exemplo, podem ser convertidos e apresentados em diferentes modos, conforme a necessidade especial apresentada pelo usuário, por meio do uso de tecnologias assistivas.

2. Não recorrer apenas a cor: garantir que textos e gráficos sejam compreensíveis com e sem a visualização de cores. Quando a cor é utilizada como meio único para representação de determinadas informações, essas informações tornam-se inacessíveis a usuários que não conseguem diferenciar certas cores, ou estejam utilizando equipamentos com display sem cor ou sem visão (non-visual).

3. Utilizar corretamente a marcação e folhas de estilo: utilizar marcações de acordo com a estrutura dos elementos apresentados e controlar a apresentação com folhas de estilo, ao invés de elementos de apresentação e atributos. A estrutura de marcação do documento é um fator essencial na navegação da página por softwares especializados, por isso deve ser utilizada adequadamente, e separada das informações de apresentação.

4. Indicar claramente o idioma utilizado: utilizar marcações que facilitem a pronúncia ou interpretação de abreviaturas ou palavras estrangeiras. Quando as mudanças de linguagem natural no documento são marcadas corretamente, as tecnologias assistivas podem, automaticamente, se adaptar a nova língua, tornando o documento mais acessível a usuários que falem mais de uma língua.

5. Criar tabelas passíveis de transformação harmoniosa: tabelas devem ser implementadas para marcar dados tabulares. Sua utilização para fins de layout prejudica a navegação e apresentação das informações contidas nela por meio de tecnologias assistivas e determinados agentes de usuário.

6. Assegurar que páginas que utilizem novas tecnologias tenham transformação harmoniosa: garantir que a utilização de novas tecnologias não afetem a acessibilidade em situações em que essas tecnologias não sejam suportadas ou estejam desligadas. 
7. Assegurar o controle ao usuário sobre alterações temporais do conteúdo: assegurar que mídias com alteração de conteúdo ou apresentação durante determinados períodos de tempo possam ser interrompidas. Grupos de usuários podem apresentar dificuldades de interação e visualização de conteúdos em aplicações com movimentação de elementos.

8. Assegurar a acessibilidade direta em interfaces integradas pelo usuário: assegurar que a interface seja funcional e acessível, independentemente dos recursos, componentes (applets e script) que estejam sendo utilizados. Esses componentes, quando utilizados para disponibilização de interações ou informações essenciais a aplicação, podem representar barreiras de acessibilidade em ambientes que não os suportem.

9. Projetar a página considerando a independência de dispositivos: possibilitar a interação com a página com quaisquer dispositivos de entrada (mouse, teclado, reconhecedor de voz, entre outros).

10. Utilizar soluções provisórias: utilizar soluções tecnológicas provisórias de acessibilidade, até que os agentes de usuários sejam capazes de lidar com determinados recursos. Versões antigas de agentes de usuários e tecnologias assistivas apresentam o conteúdo de forma diferenciada, ou incompleta de acordo com os tipos de elementos ou recursos utilizados no site. Até que esses recursos sejam incorporados nas tecnologias web, a sua utilização deve ser limitada.

11. Utilizar tecnologias e recomendações W3C: as tecnologias W3C são recomendadas pelos seguintes motivos:

- Tecnologias W3C incluem soluções de acessibilidade integradas

- As especificações W3C passam por diversas revisões para garantir a acessibilidade

- As especificações W3C são desenvolvidas num processo aberto de consenso da indústria

12. Fornecer informações de contexto e orientação: agrupar elementos semelhantes e disponibilizar informações contextuais a respeito de relacionamentos entre elementos, para ajudar usuários a compreender páginas complexas.

13. Fornecer mecanismos claros de navegação: disponibilizar mecanismos de navegação claros e consistentes entre as páginas, como por exemplo: informações de orientação, barra de navegação, mapa do site, entre outros.

14. Assegurar a clareza e simplicidade dos documentos: simplicidade de linguagem de escrita, layout consistente, figuras compreensíveis e didáticas nos sites beneficiam a todos os usuários, particularmente pessoas com deficiências cognitivas ou que apresentem dificuldade de leitura.

A próxima seção apresenta as diretrizes da WCAG 2.0. 


\subsubsection{WCAG 2.0}

A simplicidade do modelo de acessibilidade proposto pela WAI ajudou a aumentar a popularidade do problema de acessibilidade na web. Suas diretrizes são reconhecidas como a principal abordagem na elaboração de recursos web acessíveis (Kelly et al., 2005).

A primeira versão das diretrizes destinada ao conteúdo web, a WCAG 1.0, foi publicada no ano de 1999, quando grande parte das páginas eram implementadas utilizando HTML. Dessa forma, a WCAG 1.0 foi desenvolvida com enfoque nessa tecnologia HTML, em como torná-la acessível (Kelly et al., 2007) (Reid e Snow-Weaver, 2008).

No entanto, os sites, atualmente, utilizam uma maior diversidade de tecnologias na sua construção. A nova geração da web (Web 2.0), juntamente com a implementação de aplicações e serviços web (RIA - Rich Internet Applications), por exemplo, possuem um nível de interação mais dinâmico (Gibson, 2007) e requerem tecnologias como: ECMAScript, XMLHTTPRequest, SVG (Scalable Vector Graphics), SMIL (Synchronized Multimidia Integration Language), Flash, Java Applets, entre outras (Munson e da Graça Pimentel, 2008). Tecnologias como essas, mesmo com os esforços, por parte de seus proprietários e desenvolvedores, no seu desenvolvimento com acessibilidade, não são previstas e aceitas pelas diretrizes da WAI (Kelly et al., 2005). As diretrizes WCAG 1.0 não permitem sequer que os desenvolvedores web utilizem soluções que promovam a acessibilidade, devido a sua natureza restritiva quanto ao uso de tecnologias que não sejam da W3C.

Um outro fator limitante na utilização da WCAG 1.0 diz respeito à subjetividade de determinados checkpoints (Centeno et al., 2005). Essa característica torna difícil uma avaliação total de conformidade com suas diretrizes (Reid e Snow-Weaver, 2008). Fator, inclusive, determinante na decisão dos Estados Unidos de não adotar a WCAG 1.0 como padrão de acessibilidade na web no país (Estados Unidos guiam seu desenvolvimento web de acordo com as diretrizes da Section $\left.508^{8}\right)$.

Considerando isso, a WAI desenvolveu a WCAG 2.0. A WCAG 2.0 foi desenvolvida com base na WCAG 1.0 e suas diretrizes devem ser aplicáveis ao maior número de tecnologias possível agora e no futuro (tecnologicamente neutra) (Kelly et al., 2007) e ser testáveis, de maneira objetiva, com uma combinação de testes automáticos e avaliações humanas (Reid e Snow-Weaver, 2008) (W3C, 2008c).

As diretrizes WCAG 2.0 não descrevem condições tecnológicas para satisfação dos requisitos de acessibilidade, mas disponibilizam informações a respeito dos métodos conhecidos para o desenvolvimento em conformidade com as diretrizes (Reid e Snow-Weaver, 2008). Este documento é complementado por uma seção não-normativa que descreve detalhes específicos de como as tecnologias devem ser utilizadas (Kelly et al., 2007) (W3C, 2008b). Manter as informações a respeito das técnicas, separadamente do documento da WCAG 2.0, permite alterações e atualizações sem

\footnotetext{
${ }^{8} \mathrm{http}: / /$ www.section508.gov/
} 
a necessidade de alterar o padrão (sem a necessidade de passar pelo processo de recomendação da W3C) (Reid e Snow-Weaver, 2008).

A WCAG 2.0, assim como sua precursora, define maneiras de como tornar o conteúdo Web mais acessível a pessoas com necessidades especiais (W3C, 2008c). Embora as diretrizes referenciem uma grande quantidade de cenários, elas podem não ser suficientes para garantir o acesso a informação por pessoas com todos os tipos, níveis e combinações de deficiências. Essas diretrizes também ajudam no desenvolvimento de conteúdo mais usável por indivíduos de idade avançada e com melhor usabilidade por usuários em geral (Petrie e Kheir, 2007).

A WCAG 2.0, diferentemente da WCAG 1.0, divide suas diretrizes em quatro princípios, que servem como características necessárias ao conteúdo Web, para que o mesmo seja apresentado ao usuário (W3C, 2008a):

1. Perceptível: os usuários devem ser capazes de perceber a informação sendo apresentada (o conteúdo não pode ser invisível a todos os seus sentidos).

2. Operável: os usuários devem ser capazes de operar a interface (a interface não pode exigir interações com as quais um usuário não possa realizar).

3. Compreensível: os usuários devem ser capazes de entender a informação e as operações da interface (o conteúdo e as operações não podem ir além do conhecimento do usuário).

4. Robusto: os usuários devem ser capazes de acessar o conteúdo conforme a tecnologia avança (mesmo com o avanço tecnológico e dos agentes de usuário, o conteúdo deve permanecer acessível).

Cada diretriz apresenta um determinado número de critérios de sucesso, que descrevem especificamente o que deve ser alcançado para satisfazer o padrão (W3C, 2008a). Todos os critérios de sucesso devem considerar:

- Problemas de acessibilidade que afetam pessoas com necessidades especiais, diferentemente dos problemas de usabilidade que podem ser apresentados a todos os usuários.

- Aspectos testáveis na interface, ou seja, deve ser possível determinar, objetivamente, se a interface satisfaz ou não o critério de sucesso.

As prioridades, presentes na WCAG 1.0, também foram alteradas. Cada critério de sucesso é classificado em níveis de relevância entre A, AA e AAA, em que o nível A representa os critérios de maior importância. Essa classificação foi determinada por meio da avaliação de acordo com os seguintes fatores (Reid e Snow-Weaver, 2008) (W3C, 2008a):

- Possibilidade da tecnologia assistiva tornar o conteúdo acessível

- Aplicabilidade a todos os sites e tipos de conteúdo 
- Facilidade de compreensão por autores de conteúdo

- Limitações na apresentação, funcionalidade, liberdade de expressão e estética

- Existência de outros meios para contornar o problema

Também é apresentada uma grande variedade de técnicas que auxiliam no desenvolvimento em conformidade com os critérios de sucesso e são classificadas como: suficientes para satisfação do critério e complementares.

As diretrizes do conjunto WCAG 2.0 são apresentadas a seguir, agrupadas nos seus respectivos princípios (W3C, 2008c):

\section{Perceptível}

(a) Alternativas textuais: disponibilizar alternativas textuais para conteúdos não textuais.

(b) Mídias temporais: disponibilizar alternativas para mídias temporais.

(c) Adaptabilidade: criar conteúdo que possa ser disponibilizado de diferentes maneiras sem perder a informação ou estrutura.

(d) Distinguíveis: facilitar aos usuários ver e ouvir o conteúdo, apresentando foco ao conteúdo principal sendo disponibilizado.

\section{Operável}

(a) Acessível pelo teclado: tornar todas as funcionalidades acessíveis pelo teclado.

(b) Tempo suficiente: disponibilizar tempo suficiente para leitura e utilização do conteúdo.

(c) Apreensibilidade: não estruturar o site com conteúdos que possam causar apreensão nos usuários, como por exemplo: flash de frequiência superior a três vezes por segundo.

(d) Navegabilidade: disponibilizar meios que auxiliem a navegação do usuário, busca por conteúdos e localização.

\section{Compreensível}

(a) Legível e compreensível: disponibilizar o conteúdo de forma legível e compreensível aos usuários.

(b) Previsibilidade: os sites devem aparecer e operar por meios previsíveis.

(c) Assistência de entrada: auxiliar os usuários a evitar e corrigir erros.

\section{Robusto}

(a) Compatibilidade: maximizar a compatibilidade com agentes de usuário e tecnologias disponibilizados atualmente ou no futuro.

A próxima seção (Seção 2.3.3) apresenta o que é considerado na acessibilidade web a usuários com dificuldades de leitura. 


\subsubsection{Diretrizes relativas à dificuldade de leitura na web}

No Brasil, cerca de $65 \%$ da população é classificada como alfabetizados de nível rudimentar ou básico (Montenegro e Educativa, 2007), conforme mencionado no Capítulo 1. Esses indivíduos apresentam dificuldades no desempenho de atividades que envolvam a leitura e compreensão de textos dependendo do seu tamanho e complexidade.

É fato que, atualmente, as interfaces fazem amplo uso de recursos textuais para disponibilização de conteúdo (Medhi et al., 2007b). Mesmo para as aplicações e páginas web, cuja principal característica é a universalização dos meios de acesso a informação ${ }^{9}$, a ampla utilização desses recursos não pode ser excluída. No entanto, a elaboração desses conteúdos textuais sem os devidos cuidados pode implicar no surgimento de barreiras de acessibilidade para indivíduos com dificuldade de leitura.

O tipo de necessidade especial, apresentada pelos indivíduos que possuem dificuldade de leitura, é prevista e considerada nos documentos das diretrizes para garantia de acessibilidade do conteúdo Web, WCAG 1.0 e WCAG 2.0.

A WCAG 1.0 logo em sua primeira diretriz (guideline 1) menciona a necessidade de fornecer equivalentes textuais para conteúdos não textuais, visto a capacidade de sua apresentação em diferentes modalidades (áudio, braille, entre outras) como forma de contornar deficiências sensoriais que possam ser apresentadas pelos usuários (W3C, 1999). É também destacado que a disponibilização de equivalentes não textuais (fotos, vídeos, áudio) para as informações textuais beneficia determinados grupos de usuários, embora nenhum dos checkpoints dessa diretriz seja direcionado a esse requisito. Entre os tipos de usuários que pertencem a esses grupos são mencionados os analfabetos (non-readers) e indivíduos com dificuldade de leitura.

Esse tipo de necessidade especial é, novamente, referenciada na diretriz 14, do documento. Nessa diretriz é realçada a importância de manter os documentos claros e simples em sua elaboração, ao promover comunicação efetiva com os usuários (W3C, 1999). Para este fim, são apresentados dois checkpoints:

- 14.1: Utilizar a linguagem mais clara e simples, apropriada ao conteúdo do site.

\section{- Prioridade 1}

- 14.2: Facilitar a compreensão do site utilizando apresentações gráficas e sonoras como um complemento ao texto.

\section{- Prioridade 3}

É importante destacar que, como o checkpoint 14.1 é de prioridade 1, ele é um requisito de acessibilidade aos sites e aplicações web, desde o primeiro nível, mais essencial, de conformidade com a WCAG 1.0.

\footnotetext{
${ }^{9}$ Conforme a afirmativa de Tim Berners Lee, inventor da Web e diretor da World Wide Web Consortium - (W3C)
} 
No documento de técnicas necessárias para satisfação dos checkpoints da WCAG 1.0, os checkpoints 14.1 e 14.2 pertencem ao grupo de técnicas de compreensão (W3C, 2000b). Nesse grupo são apresentadas técnicas relacionadas ao estilo de escrita e equivalentes multimídia.

Com relação às técnicas de estilo de escrita, são descritas sugestões que devem tornar o conteúdo mais fácil de ser compreendido por todos, especialmente indivíduos com dificuldade de leitura e deficiências cognitivas (W3C, 2000b). As sugestões são as seguintes:

1. Ser claro e preciso na escrita de títulos e descrição de links.

2. Apresentar o tópico da sentença ou parágrafo no início da expressão.

3. Expressar apenas uma idéia por parágrafo.

4. Evitar a utilização de gírias, jargões e palavras com significado diferente do normal, a menos que sejam definidos no documento.

5. Dar preferência a palavras comuns.

6. Dar preferência à voz ativa à passiva.

7. Evitar sentenças de estrutura complexa.

Ao final das sugestões, como forma de determinar o nível de facilidade de leitura do texto, é recomendada a métrica de leitura Gunning-fog (Spool et al., 1997).

O grupo de estudos sobre técnicas multimídia equivalentes discute a importância de utilização de gráficos para ilustrar dados complexos, tradução do texto em forma de um clipe com o conteúdo em linguagem dos sinais, entre outras. Deve ser destacado, no entanto, que apresentações multimídias nem sempre são convenientes à compreensão. Essas mídias de apresentação de conteúdo devem estar de acordo com os costumes e fatores culturais dos usuários para que sejam compreendidas. Determinados estudos apresentam um grande enfoque no desenvolvimento dessas mídias em adequação ao contexto cultural dos usuários (Blake, 2002) (Jibaja-Weiss et al., 2006) (Medhi et al., 2007a).

A WCAG 2.0 discute a dificuldade de leitura, por seus usuários, nos critérios de sucesso de 3.1.3 a 3.1.6, pertencentes à diretriz 3.1 (legibilidade e compreensibilidade do conteúdo) (W3C, 2008c).

Os critérios 3.1.3, 3.1.4 e 3.1.6 são destinados a pessoas que possuem dificuldade na decodificação de palavras, e na utilização do contexto como forma de auxílio à compreensão (W3C, 2008a). Esses critérios são descritos a seguir:

- 3.1.3 Palavras incomuns: necessidade de disponibilização de um mecanismo para definição de palavras utilizadas de forma incomum ou restrita. Nível AAA. 
- 3.1.4 Abreviações: necessidade de um mecanismo para identificação da forma expandida de abreviações. Nível AAA.

- 3.1.6 Pronúncia: necessidade de um mecanismo para identificar a pronúncia de palavras que tenham significado ambíguo, dependendo de sua pronúncia. Nível AAA.

Como formas de se desenvolver esses requisitos são propostas as seguintes soluções:

- Disponibilização de uma lista de definições.

- Utilização do elemento link com direcionamento a um glossário da página.

- Disponibilização de uma função que realize a busca do termo em um dicionário online.

- Utilização de elementos de marcação específicos, como $d f n$ (definição de termos), abbr (expansão de abreviaturas) e ruby (apresentação de fonética).

O critério de sucesso relacionado ao nível de leitura de um site (3.1.5), assim como o checkpoint 14.1 da WCAG 1.0, reforça a necessidade de elaborar o conteúdo de forma simplificada. Esse critério (de Nível AAA) estabelece que textos que requerem habilidade de leitura dos usuários mais avançada que o ensino secundário inferior (de quinta a oitava série, no Brasil) devem apresentar um conteúdo complementar, ou uma versão que seja destinada a esse nível de habilidade (ensino secundário inferior) (W3C, 2008c).

Esse critério foi estabelecido para auxiliar a compreensão de textos complexos e estabelecer uma forma objetiva que indique a necessidade de conteúdo adicional (W3C, 2008a). Textos difíceis e complexos podem ser apropriados para determinados públicos-alvo, no entanto, mesmo entre usuários que possuam conhecimento especializado no assunto, existem indivíduos que possuem dificuldade de leitura.

As técnicas descritas que atendem esse requisito são apresentadas a seguir (W3C, 2008a):

1. Disponibilizar um sumário do texto para os que possuem habilidade inferior ao ensino secundário superior (10 a 12 anos de estudos).

2. Disponibilizar ilustrações, fotos e símbolos que ajudem a explicar idéias, eventos e processos.

3. Disponibilizar uma versão narrada do texto.

4. Tornar o texto mais fácil de ser compreendido.

5. Disponibilizar uma versão das informações, idéias e processos em linguagem de sinais.

Para a implementação da primeira técnica apresentada (Disponibilização de sumário), especificamente, são descritos cinco passos como auxílio à preparação de um sumário para o texto (W3C, 2008a): 
1. Identificar as idéias e informações mais importantes do texto.

2. Elaborar um ou dois parágrafos utilizando sentenças de tamanho reduzido e palavras comuns.

3. Avaliar o nível de habilidade de leitura necessário para compreensão do sumário.

4. Editar, novamente, o sumário, considerando dividir sentenças longas em duas e substituir palavras não familiares por termos mais comuns.

5. Repetir os passos 3 e 4 .

Com relação à técnica "Tornar o texto mais fácil de ser compreendido", são descritas sugestões para a elaboração do texto, de forma semelhante às atribuídas ao checkpoint 14.1 da WCAG 1.0:

- Desenvolver um único tópico ou sub-tópico por parágrafo.

- Utilizar sentenças da forma mais simples possível (sujeito-verbo-objeto).

- Utilizar sentenças curtas (25 palavras para o inglês).

- Considerar dividir as sentenças mais longas em duas.

- Utilizar sentenças que contenham menos de três conjunções.

- Indicar o relacionamento lógico entre frases, sentenças, parágrafos ou seções do texto.

- Evitar termos especializados, cujo significado pode não ser claro para as pessoas.

- Trocar palavras longas ou não familiares por termos mais curtos e mais comuns.

- Remover palavras redundantes.

- Utilizar substantivos simples ou frases curtas com os substantivos.

- Remover frases e palavras complexas que podem ser trocadas por palavras mais comuns.

- Utilizar listas de ítens em preferência a séries de palavras ou frases separadas por vírgulas.

- Tornar claras as referências de pronomes e referências a outros trechos do documento.

- Utilizar, preferencialmente, a voz ativa na construção das sentenças.

- Utilizar os tempos verbais de maneira consistente.

- Utilizar nomes e rótulos de maneira consistente.

Pode-se observar que os cuidados com o tratamento lingüístico do texto são priorizados e objetivamente descritos nas diretrizes de acessibilidade. Assim, é importante investigar mecanismos que auxiliem, por meio do processamento de língua natural, a garantia de acesso aos textos disponibilizados na Web. 


\subsection{Considerações finais}

Neste capítulo foram discutidos os principais conceitos que envolvem o desenvolvimento do tema "acessibilidade na web". Também foi discutido o modelo da WAI de acessibilidade, por ser um dos trabalhos mais importantes na área (Kelly et al., 2005; Freire et al., 2007). Existem outros trabalhos que também estabelecem diretrizes de acessibilidade (Section $508^{10}$ e e-MAG ${ }^{11}$ ), no entanto esse trabalhos abordam apenas a camada de conteúdo das aplicações web.

O modelo da WAI abrange o desenvolvimento de tecnologias assistivas em diferentes componentes da web (conteúdo, navegadores e ferramentas de autoria) e, ainda, requer o desenvolvimento de outras tecnologias de acesso ao computador (leitores de tela, reconhecedores de voz, mouses alternativos) que satisfaçam as necessidades especiais apresentadas por determinados usuários. A compreensão disso é de muita relevância a qualquer estudo que tenha como objetivo a acessibilidade na web.

O estudo de acessibilidade na web é essencial para determinação do ponto de inserção deste trabalho de mestrado. Também é importante destacar a importância desses estudos na escolha de abordagens de desenvolvimento de tecnologias web, objetivo deste trabalho, que atendam aos requisitos de acessibilidade.

O próximo capítulo (Capítulo 3) apresenta os princípios de design considerados no desenvolvimento de interfaces para usuários com baixo nível de alfabetização.

\footnotetext{
${ }^{10} \mathrm{http}: / /$ www.section508.gov/

${ }^{11} \mathrm{http}: / /$ www.governoeletronico.gov.br/acoes-e-projetos/e-MAG
} 



\section{Revisão Sistemática da Literatura}

$\mathrm{N}$ este capítulo é apresentada uma revisão sistemática da literatura, realizada em 2008 para extrair recursos de design para usuários com baixo nível de alfabetização. A revisão se insere na proposta geral do trabalho de mestrado como uma forma de identificar os requisitos de design e características do público alvo das aplicações Facilita e Facilita Educacional.

Este trabalho de revisão sistemática da literatura foi reportado na forma de um artigo publicado no SEMISH 2009 - 36th Seminar on Software and Hardware. O trabalho é intitulado "Revisão Sistemática sobre recursos de design de aplicações web acessíveis para analfabetos funcionais". O aluno apresentou este trabalho no Congresso da Sociedade Brasileira de Computação 2009 que foi realizado em Bento Gonçalves - Porto Alegre - Brasil (Watanabe e Fortes, 2009).

\subsection{Considerações iniciais}

O tema de desenvolvimento de aplicações para usuários com baixo nível de alfabetização é, comumente, associado a introdução de sistemas de informação a comunidades presentes em países em desenvolvimento. O foco dos estudos atribuído a esses países vem do fato de que tais regiões apresentam poucas qualidades ao nível de infraestrutura tecnológica e ensino da sua população.

A inclusão dos indivíduos dessas regiões no uso de sistemas de informação é, muitas vezes, implementada visando fornecer acesso a conteúdos sobre condições de trabalho e informações a respeito da região em que se encontram de forma automática e simplificada (Plauché e Prabaker, 2006) (Plauche et al., 2006) (Medhi et al., 2007b). Nessas regiões, a trasmissão desse tipo de conhecimento era realizada por meio de conversas entre os cidadãos do ambiente. O aumento de 
conhecimento agregado nas interações com os sistemas desenvolvidos aumentaria a qualidade das decisões tomadas no trabalho dessas pessoas.

É importante destacar que a falta de habilidades relacionadas à leitura e à educação do indivíduo não implica na sua incapacidade profissional. Ghosh et al. apresenta grupos conhecidos por atividades de microfinança ${ }^{1}$ na Índia (Ghosh et al., 2003). Dentre as pessoas que formam esses grupos têm-se altos níveis de educação matemática, provenientes, provavelmente, pelo treinamento que as atividades de microfinança exigem. Essas características culturais possibilitaram o desenvolvimento de uma série de representações baseadas em números e estruturas organizacionais, observadas nos diários de trabalho (cadernos em que os dados de trabalho eram armazenados por escrito) desses indivíduos. Essas representações foram, inclusive, utilizadas na implementação de uma interface compreendida por eles (Ghosh et al., 2003) (Parikh et al., 2003).

Por uma outra perspectiva, alguns trabalhos revelam que o acesso aos próprios computadores, dada as características sócio-econômicas dessas regiões, é muito restrito, de forma que o desenvolvimento de sistemas destinados a essa plataforma seria inviável. Assim, o desenvolvimento de aplicações nessas regiões deveria ser destinado a plataforma de telefones e celulares, que, por sua vez, possuem um custo muito inferior ao de um computador (Cervantes e Sambasivan, 2008) (Kumar et al., 2007b) (Kumar et al., 2007a) (Agarwal et al., 2008). Dentre esses trabalhos, ainda, é apontada a necessidade de participação desses indivíduos na Web, sendo necessário o desenvolvimento de uma nova arquitetura que suporte não apenas o acesso a informação, mas também a possibilidade dos mesmos de prover conteúdos e serviços por meio dela (Kumar et al., 2007b) (Kumar et al., 2007a) (Agarwal et al., 2008).

O desenvolvimento de aplicações para fins de aprendizagem e educação também é um alvo de muitos estudos. Alguns trabalhos apresentam como a utilização de diferentes mídias e representações disponíveis nos computadores pode afetar a atividade de aprendizagem e treinamento, mesmo para esses indivíduos (Boucheix, 2004), enquanto outros focam nas possibilidades de ampliação geográfica ao nível de formação e qualificação de profissionais (Martins et al., 2003).

Embora os países em desenvolvimento sejam o ambiente de desenvolvimento da maior parte dos estudos, nos países desenvolvidos a preocupação com esse tema também existe.

Nesses países há uma grande quantidade de estudos relacionados à área de saúde. Pesquisas relacionadas à verificação dos padrões de qualidade de vida de indivíduos são freqüentemente realizadas por meio de questionários escritos destinados a pacientes. O fato dos questionários serem escritos torna difícil o seu preenchimento por usuários com dificuldade de leitura. Com isso, a utilização de dispositivos computacionais é implementada para disponibilização de mídias alternativas que possibilitem a compreensão do questionário por usuários com baixo nível de alfabetização (Hahn et al., 2004) (Akan et al., 2006). Ainda na área da saúde, são também realizados estudos na área de avaliação de conteúdos sobre saúde em sites (Becker, 2004) e auxílio a pacientes na tomada de decisões (Patient Decision Aid) (Jibaja-Weiss et al., 2006).

\footnotetext{
${ }^{1}$ Um sistema de microfinanças pode prover os cidadãos de diversos serviços financeiros, dentre os quais empréstimos, poupança e seguros (de Lima Caldas, 2003)
} 
Como outras linhas de pesquisa em que o tema é relevante, em países desenvolvidos, foram observados estudos referentes a: informatização de áreas rurais (Akan et al., 2006) e alfabetização de comunidades indígenas (Fulcher et al., 2003).

Para desenvolver interfaces para esses usuários (analfabetos, semi-analfabetos e analfabetos funcionais), faz-se necessária a implementação de diferentes modos de comunicação que substituam ou complementem os conteúdos textuais das interfaces. Essas alternativas de disponibilização de conteúdo são implementadas como recursos de design na interface do sistema, e devem estar, ainda, vinculadas ao conhecimento de costumes e fatores culturais dos usuários, para garantir que as mesmas sejam compreendidas.

Este capítulo apresenta os recursos de design que favorecem a utilização de computadores por indivíduos com baixo nível de alfabetização. A elaboração desses recursos é comumente associada a metodologias de desenvolvimento de interfaces. Essas metodologias e as características dos usuários que tornaram propícia a implementação desses recursos também serão abordadas.

A pesquisa e a extração de informações relacionadas foram realizadas de acordo com o procedimento da revisão sistemática (SLR - Systematic Literature Review) (Kitchenham, 2004).

Este capítulo apresenta a seguinte estrutura: a próxima seção (Seção 3.2) descreve o processo de revisão sistemática (protocolo e condução), especificando os objetivos da pesquisa e as fontes que foram utilizadas; a Seção 3.3 descreve metodologias de desenvolvimento de interfaces que são utilizadas, considerando usuários com baixo nível de alfabetização; a Seção 3.4 apresenta recursos de design que são considerados como forma de auxílio a compreensão por esses usuários; por fim, na Seção 3.5 são apresentadas algumas considerações finais de acordo com o tema "desenvolvimento de interfaces para usuários com baixo nível de alfabetização”.

\subsection{Revisão sistemática}

A revisão sistemática é um procedimento utilizado para identificar, avaliar e interpretar todos estudos disponíveis relevantes a um determinado problema de pesquisa, tópico ou fenômeno de interesse (Kitchenham, 2004). Esse procedimento é utilizado no intuito de realizar revisões de literatura valendo-se do aspecto sistemático do mesmo, que garante uma pesquisa criteriosa e justa dentre os trabalhos disponíveis.

Muitos estudos têm reportado trabalhos sobre o tema de desenvolvimento de interfaces para usuários com baixo nível de alfabetização. A extração dos recursos de design utilizados nesses estudos por meio de uma revisão da literatura é uma das formas mais adequadas de se iniciar pesquisas nessa área. Por essa razão foi realizado o procedimento de revisão sistemática com foco no desenvolvimento de interfaces ou aplicações destinadas a usuários com baixo nível de alfabetização (analfabetos e semi-analfabetos), para realizar a extração dos recursos utilizados.

O procedimento de revisão sistemática desenvolvido, neste trabalho, foi realizado com base no documento desenvolvido por Kitchenham (Kitchenham, 2004). Este documento descreve uma 
série de guidelines para a realização da revisão dentro da área de Engenharia de Software. Essas guidelines foram adaptadas de estudos em áreas médicas para a Engenharia de Software.

O objetivo dessa revisão é sumarizar as evidências existentes numa linha de pesquisa, juntamente com os benefícios e limitações da utilização de determinadas tecnologias.

Assim, uma revisão sistemática deve considerar as seguintes etapas:

\section{Planejamento}

(a) Identificação da necessidade da revisão

(b) Desenvolvimento do protocolo da revisão

\section{Condução}

(a) Identificação do campo de pesquisa

(b) Seleção dos estudos primários

(c) Avaliação da qualidade dos estudos

(d) Extração dos dados

(e) Síntese dos dados

\section{Resultados}

As etapas de planejamento e condução são descritas nas Sub-seções 3.2.1 e 3.2.2, respectivamente. Os resultados são discutidos na Sub-seção 3.2.3 (considerações iniciais e quantitativas dos estudos selecionados) e Seções 3.3 e 3.4 desta dissertação.

\subsubsection{Planejamento}

A etapa de planejamento consiste do levantamento das necessidades e motivações para a realização da revisão sistemática. Aspectos operacionais relacionados aos requisitos necessários para a condução da revisão também devem ser abordados, como por exemplo: ambientes a serem efetuadas as buscas, determinação dos critérios de seleção dos estudos, string de busca utilizada, entre outros. Como resultado das informações obtidas durante o levantamento, deve ser elaborado um documento, o protocolo da revisão. A elaboração de um protocolo da revisão faz-se necessária para reduzir as possibilidades de viés dos pesquisadores (Kitchenham, 2004).

A seguir são apresentados campos contidos no documento de protocolo da revisão gerados no planejamento:

- Objetivo: O objetivo deste estudo foi obter uma lista dos recursos de design e tecnologias utilizadas no desenvolvimento de interfaces para indivíduos analfabetos e alfabetizados de nível rudimentar e básico. Esta pesquisa apresenta o que é considerado no desenvolvimento dessas interfaces, para identificar um possível conjunto de padrões para sistemas destinados a esse tipo de usuário. 
- Questão da pesquisa: Qüais os recursos de design e tecnologias utilizadas no desenvolvimento de interfaces para usuários analfabetos e alfabetizados de nível rudimentar e básico?

- Método de busca: Buscas realizadas por meio dos sistemas de busca em periódicos disponibilizados na Web.

- Palavras-chave: Illiterate, semi-literate, functional illiterate, low literacy users

- Lista de fontes: Artigos disponíveis em bibliotecas digitais. Foram utilizadas as seguintes bibliotecas: ACM Portal ${ }^{2}$, IEEE Xplore ${ }^{3}$, Springer ${ }^{4}$, Journals-Elsevier ${ }^{5}$ e Wiley Interscience $^{6}$

- Critérios de inclusão e exclusão: Foram incluídos todos os artigos que referenciem funcionalidades que favoreçam a utilização de aplicações por usuários com um baixo nível de alfabetização.

Não foram considerados os estudos que não tratam do temas relacionados a interfaces, que envolvem usuários com deficiências cognitivas (dislexia, alzheimer) ou que tratem do tema de educação e aprendizagem de crianças.

- Avaliação de qualidade: Disponibilidade dos artigos para download, abstract dos estudos disponíveis nos sistemas de busca; necessária a descrição dos métodos ou recursos de design utilizado nas interfaces e compatibilidade com o tópico principal da revisão.

\subsubsection{Condução}

A etapa de condução consiste das seguintes atividades: execução da busca, seleção dos artigos considerando os critérios de inclusão e exclusão de estudos, avaliação da qualidade dos estudos, definição do formulário de extração dos dados (critérios de inclusão e exclusão de informações contidas nos estudos) e execução da extração. É nessa etapa que ocorrem as buscas na literatura por trabalhos relacionados ao tema definido e a leitura dos mesmos.

Após a definição de uma string de busca padrão, utilizando o campo de palavras-chave do protocolo, foram realizadas as buscas nas bibliotecas digitais disponíveis na Web, entre os dias 10 de setembro de 2008 e 29 de setembro de 2008. Para cada um dos sistemas de busca disponíveis foram necessárias alterações na string para adaptação à sintaxe imposta pelo ambiente. A quantidade de estudos encontrados em cada um dos sistemas é apresentada a seguir:

- ACM Portal: 245 artigos encontrados

\footnotetext{
${ }^{2}$ http://portal.acm.org

${ }^{3} \mathrm{http}: / /$ ieeexplore.ieee.org/Xplore/guesthome.jsp

${ }^{4} \mathrm{http}: / / \mathrm{www}$.springer.com

${ }^{5}$ http://www.elsevier.com/wps/find/journal_browse.cws_home

${ }^{6} \mathrm{http}: / /$ www3.interscience.wiley.com/cgi-bin/home
} 
- IEEE Xplore: 75 artigos encontrados

- Springer: Nenhum artigo encontrado

- Elsevier: 10 artigos encontrados

- Wiley Interscience: 17 artigos encontrados

Em um primeiro ciclo de seleção dos artigos, considerando, principalmente, os critérios de avaliação de qualidade dos estudos e efetuando a leitura dos abstracts dos estudos, foram selecionados 91 dos 347 artigos, resultados da busca.

No segundo ciclo de seleção, utilizando os critérios de inclusão e exclusão de estudos, foram selecionados 27 dos 91 artigos, anteriormente selecionados. Estes 27 artigos foram lidos e utilizados no processo de extração de dados. Inicialmente, dentre os critérios de inclusão de informações a serem extraídas, foram considerados apenas conteúdos associados a metodologia, recursos e tecnologias utilizadas no design da interface e possíveis avaliações de usabilidade efetuadas. No entanto, foi observado que a maioria dos recursos de design e tecnologias utilizadas no design, foram implementados seguindo os costumes e características culturais dos indivíduos focos dos estudos. Com isso, foi incluído, no formulário de extração de dados elaborado, um campo em que seriam descritas características específicas dos usuários para os quais os estudos foram desenvolvidos.

Os resultados obtidos a partir da extração das informações dos artigos são descritos na próxima sub-seção.

\subsubsection{Resultados}

Os artigos selecionados foram classificados de acordo com seus anos de publicação e as bibliotecas digitais em que foram disponibilizados para download. Esta classificação pode ser melhor visualizada na Figura 3.1. Alguns artigos selecionados foram publicados e disponibilizados em portais não utilizados nas buscas iniciais, como por exemplo: SpringerLink ${ }^{7}$ e MIT Press ${ }^{8}$. Esses artigos foram encontrados por sistemas de busca como a ACM Digital Library e IEEEXplore que mapeiam artigos presentes em suas próprias bibliotecas e em bibliotecas de outros agentes publicadores.

Dentre os 27 estudos selecionados, mais de $70 \%$ foram publicados nos últimos 5 anos, e quase $90 \%$ deles foram publicados nos últimos 6 anos. Isso mostra que a preocupação no desenvolvimento de interfaces para esses usuários é recente.

A maioria desses estudos segue a linha de pesquisa de Human Computer Interfaces (HCI), revelando interações com os usuários no intuito de analisar as características do ambiente que levam ao design da aplicação (21 estudos). O restante dos artigos possui um enfoque mais tecnológico em

\footnotetext{
${ }^{7}$ http://www.springerlink.com/home/main.mpx

${ }^{8} \mathrm{http}: / /$ mitpress.mit.edu/main/home/default.asp
} 


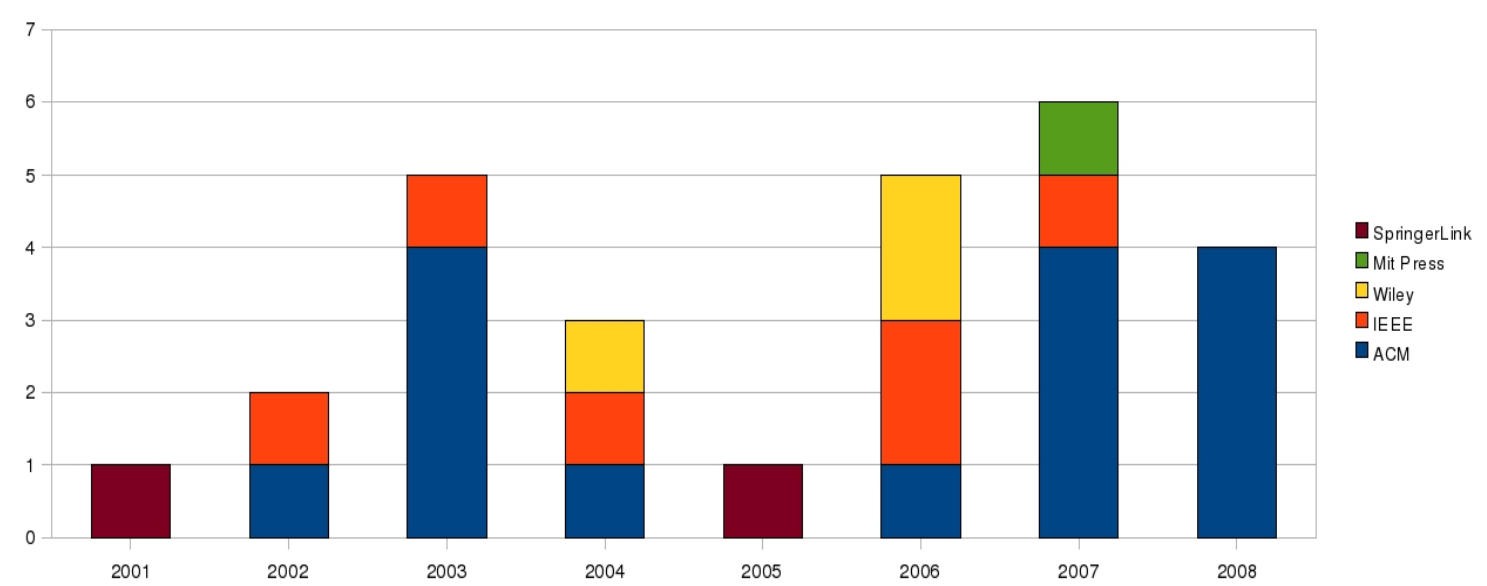

Figura 3.1: Evolução dos artigos selecionados, classificados pelo portal em que foi encontrado

sua elaboração, apresentando detalhes do desenvolvimento de tecnologias e arquiteturas destinadas a indivíduos com baixo nível de alfabetização (6 estudos).

Os resultados referentes aos dados extraídos na leitura dos artigos são descritos nas Seções 3.3 e 3.4 .

\subsection{Metodologias de desenvolvimento de interfaces}

Características como baixo nível educacional e analfabetismo da língua, freqüentemente estão associadas ao analfabetismo computacional. Dessa forma, considerando a ampla diferença cultural entre usuário e desenvolvedor, torna-se difícil a elaboração de um modelo conceitual aceito pelos usuários partindo de abordagens não experimentais no design da interface. Esse fato pode ser observado pelo alto número de estudos que realizam interações com usuários (21 artigos, mais que $75 \%$ dos estudos selecionados), seja durante a fase de implementação ou testes da interface do sistema. É importante observar que muitos desses estudos, inclusive, utilizam-se de interações com os usuários durante as duas fases (implementação e testes).

A não descrição de fases de interação com os usuários durante o trabalho é resultado de um enfoque mais técnico, a respeito das tecnologias utilizadas que devem gerar uma melhor aceitação das aplicações por indivíduos com baixo nível de alfabetização. Embora sejam apresentados recursos de design para esses usuários, pouco é discutido a respeito da elaboração e validação desses recursos. Seis (6) trabalhos apresentam essas características: (Agarwal et al., 2008), (Cervantes e Sambasivan, 2008), (Fulcher et al., 2003), (Jones et al., 2007), (Kumar et al., 2007a) e (Kumar et al., 2007b).

Nas sub-seções seguintes são descritas as formas de interação com os usuários empregadas nos trabalhos: interações na fase de implementação da aplicação (Sub-seção 3.3.1) e interações na fase de testes (Sub-seção 3.3.2). 


\subsubsection{Abordagens experimentais de design}

Dentre os estudos que descrevem interações com os usuários durante a fase de implementação da aplicação (14 estudos dos 21 mencionados), grande parte deles não descreve uma abordagem ou metodologia formal utilizada no design das interfaces ( 8 artigos). Nesses estudos são descritos procedimentos efetuados no intuito de se familiarizar com os conhecimentos dos usuários, como por exemplo:

- Observação do ambiente de trabalho

Utilizado em 2 trabalhos: (Ghosh et al., 2003) (Parikh et al., 2003).

- Sessões de gravação de atividades relacionadas a aplicação a ser desenvolvida Utilizado em 3 trabalhos: (Boucheix, 2004) (Plauche et al., 2006) (Summers et al., 2006)

- Entrevistas

Utilizado em 1 trabalho: (Joshi et al., 2008)

- Interação com o usuário para validação de componentes desenvolvidos Utilizado em 3 trabalhos: (Blake, 2002) (Martins et al., 2003) (Parikh et al., 2003)

As metodologias formais de design de interfaces implementadas nos estudos são apresentadas a seguir:

- Design Participativo: Emprego da parcipação dos próprios usuários nas interações de design da aplicação. Em determinados casos, são utililzados modelos de representação (desenhos, gestos) em reuniões com os usuários, para melhor expressar idéias e conceitos a serem considerados no design (Allen, 2005) (Medhi et al., 2007a).

Utilizado em 2 trabalhos: (Allen, 2005) (Medhi et al., 2007a).

- Design Etnográfico: Etnografia emprega o conceito de imersão social, durante um determinado período, em uma determinada comunidade no intuito compreender de forma coerente as características da mesma (Hemmings e Crabtree, 2002). Este conceito é utilizado como metodologia de design no intuito de compreender as necessidades dos usuários de acordo com a aplicação a ser desenvolvida (Medhi et al., 2007b).

Utilizado em 1 trabalho: (Medhi et al., 2007b).

- Wizard-of-Oz: Procedimento para execução de testes, em que o usuário é instruído a se comunicar com o computador utilizando linguagem natural, quando na verdade a interação com o computador é intermediada por um operador humano (Dahlback et al., 1993). Utilizada para elaborar características específicas de uma interação por voz efetuada pelo sistema no trabalho (Taoufik et al., 2007), durante sua fase de implementação.

Utilizado em 1 trabalho: (Taoufik et al., 2007). 
- Modelo Evolucionário: Emprego de um ciclo que envolve a implementação de protótipos da interface, que não estão completamente desenvolvidos, apresenta-los aos usuários a fim de receber feedback e comentários que são utilizados no refinamento do protótipo . O ciclo é repetido até que uma interface adequada seja elaborada (Taoufik et al., 2007). Utilizado em 2 trabalhos: (Taoufik et al., 2007) (Walsh e Meade, 2003).

- Design Contextual: A metodologia guia os designers a entender e implementar o redesing do trabalho realizado pelos usuários, com base em decisões, tomadas a partir de dados extraídos dos próprios usuários, sobre quais necessidades devem ser focadas, o que o sistema deve fazer e como deveria ser estruturado (Beyer e Holtzblatt, 1999).

Utilizado em 1 trabalho: (Prasad et al., 2008).

\subsubsection{Metodologias de avaliação da interface}

A execução de testes nas interfaces finais desenvolvidas foi realizada em 14 trabalhos. A grande maioria destes trabalhos não define uma abordagem específica ou formal de avaliação da interface. É importante ressaltar que em muitos desses trabalhos, mais de uma forma de avaliação de interfaces foi implementada. As metodologias utilizadas são descritas a seguir:

- Observação da utilização dos usuários para realizar o levantamento de problemas Utilizado em 1 trabalho: (Akan et al., 2006)

- Apresentação da interface aos usuários instruindo-os a verbalizar seus pensamentos de acordo com suas impressões do sistema (semelhante ao método Think Aloud, no entanto isso não é explicitado nos estudos)

Utilizado em 2 trabalhos: (Parikh et al., 2003) (Plauché e Prabaker, 2006).

- Teste da fixação do conteúdo apresentado na interface (sistemas que tem por finalidade instrução e aprendizagem dos usuários)

Utilizado em 1 trabalho: (Boucheix, 2004).

- Avaliação quantitativa relevando tempo necessário para conclusão de uma tarefa

Utilizado em 4 trabalhos: (Hahn et al., 2004) (Joshi et al., 2008) (Medhi et al., 2007b) (Plauché e Prabaker, 2006).

- Avaliação da quantidade de erros nas interações

Utilizado em 3 trabalhos: (Joshi et al., 2008) (Plauché e Prabaker, 2006) (Taoufik et al., 2007).

- Análise dos níveis de utilização dos recursos da interface

Utilizado em 1 trabalho: (Jibaja-Weiss et al., 2006). 
- Teste de reconhecimento das componentes de interface ou representações Utilizado em 3 trabalhos: (Ghosh et al., 2003) (Medhi et al., 2007a) (Shakeel e Best, 2002).

- Avaliação qualitativa de acordo com preferências dos usuários Utilizado em 2 trabalhos: (Hahn et al., 2004) (Shakeel e Best, 2002).

- Análise da eficácia do sistema de reconhecimento de voz (ASR - Automatic Speech Recognition)

Utilizado em 1 trabalho: (Petta e Woloshyn, 2001).

- Assistências necessárias para a conclusão de uma determinada tarefa Utilizado em 1 trabalho: (Taoufik et al., 2007).

Dentre os trabalhos que apresentaram a implementação de metodologias formais na execução dos testes às interfaces, apenas dois se destacam:

- Becker realizou uma Estudo de usabilidade de sites que disponibilizam informações a respeito de saúde analisando, entre outras características, o nível de complexidade do conteúdo textual dos mesmos (Becker, 2004);

- Taoufik et al. executou o procedimento de inspeção de usabilidade de avaliação heurística (Taoufik et al., 2007). A Avaliação Heurística é implementada por meio da observação da interface, considerando alguns recursos de usabilidade, com a finalidade de se expressar opiniões a respeito dos pontos positivos e negativos da mesma (Nielsen e Molich, 1990).

\subsection{Recursos de design}

Os recursos de design são características específicas presentes na interface de uma aplicação que garantem um determinado grau de generalização de acordo com a sua finalidade. Nos estudos selecionados, durante o procedimento de revisão sistemática, esses recursos têm por finalidade garantir ou melhorar o reconhecimento e compreensão do conteúdo e das funcionalidades das aplicações desenvolvidas para usuários com baixo nível de alfabetização (analfabetos, semi-analfabetos e analfabetos funcionais).

Os recursos extraídos foram classificados em 7 grupos descritos a seguir:

1. TTS (Text-to-speech) e ASR (Automatic Speech Recognition): narração do conteúdo da aplicação e reconhecimento de voz para realização de entrada de dados no sistema.

Para esses estudos a voz é compreendida como um meio universal de comunicação entre as comunidades. Recursos como a síntese de texto em voz são utilizados para facilitar a disponibilização dos conteúdos textuais (Shakeel e Best, 2002) (Walsh e Meade, 2003). No entanto os sistemas de síntese são de uso restrito a determinadas línguas. Alguns indiomas possuem peculiaridades fonéticas entre regiões ou até mesmo falta de desenvolvimento 
da tecnologia de síntese de texto em voz. Como solução para esses casos são utilizadas gravações dos conteúdos a serem transmitidos (Taoufik et al., 2007), para assegurar maior identificação, pelos usuários, com o sistema.

O recurso de reconhecimento automático de fala também apresenta os mesmos problemas de desenvolvimento dos de síntese (diferenças fonéticas entre determinadas regiões). Nesse contexto, um estudo especificamente aborda a implementação de uma estrutura simplificada nos diálogos para melhorar o índice de acerto do sistema, utilizando apenas palavras simples como entrada (Plauché e Prabaker, 2006).

Utilizado em 19 trabalhos: (Agarwal et al., 2008) (Boucheix, 2004) (Cervantes e Sambasivan, 2008) (Fulcher et al., 2003) (Hahn et al., 2004) (Jibaja-Weiss et al., 2006) (Kumar et al., 2007a) (Kumar et al., 2007b) (Martins et al., 2003) (Medhi et al., 2007b) (Medhi et al., 2007a) (Parikh et al., 2003) (Petta e Woloshyn, 2001) (Plauché e Prabaker, 2006) (Plauche et al., 2006) (Prasad et al., 2008) (Shakeel e Best, 2002) (Taoufik et al., 2007) (Walsh e Meade, 2003)

2. Simplificação do conteúdo textual: simplificação dos textos disponíveis na aplicação.

O não alinhamento dos níveis de complexidade textuais das aplicações com as capacidades de compreensão de leitura dos usuários pode gerar consequências severas de acesso à informação (Becker, 2004). No entanto, a utilização de recursos associados à simplificação textual, a qual objetiva a simplificação da estrutura linguística do texto para melhorar sua compreensão (Aluisio et al., 2008), tem como foco indivíduos com um mínimo de habilidade de leitura, não sendo recomendado para usuários analfabetos e semi-analfabetos.

Utilizado em 2 trabalhos: (Becker, 2004) (Summers et al., 2006)

3. Representações gráficas: Utilização de figuras ou símbolos, para identificar esquemas de navegação ou até mesmo conteúdo da aplicação.

Representações gráficas agregam componentes que envolvem animações, vídeos, fotos, ícones, entre outros. Medhi et al. descreve em seu trabalho que essas representações possuem níveis de entendimento diferenciado de acordo com o domínio que se deseja representar e contexto cultural dos usuários (Medhi et al., 2007a). A necessidade de adequação ao contexto cultural no desenvolvimento dessas representações pode ser evidenciada em vários outros trabalhos (Blake, 2002) (Jibaja-Weiss et al., 2006) (Medhi et al., 2007b). Dentre esses trabalhos também são utilizados cores como forma de indexação de informações (Joshi et al., 2008) e indicação de conteúdo (Parikh et al., 2003), tutoriais de vídeo (Akan et al., 2006) (Taoufik et al., 2007), tabelas para estruturação dos dados (Ghosh et al., 2003) (Parikh et al., 2003) (recurso altamente associado a cultura dos usuários do sistema), entre outros.

Utilizado em 15 trabalhos: (Akan et al., 2006) (Blake, 2002) (Boucheix, 2004) (Ghosh et al., 2003) (Hahn et al., 2004) (Jibaja-Weiss et al., 2006) (Joshi et al., 2008) (Martins et al., 
2003) (Medhi et al., 2007b) (Parikh et al., 2003) (Plauche et al., 2006) (Prasad et al., 2008) (Shakeel e Best, 2002) (Boucheix, 2004) (Medhi et al., 2007a) (Taoufik et al., 2007) (Joshi et al., 2008) (Martins et al., 2003)

4. Dados numéricos: números utilizados para identificação de conceitos e esquemas de navegação.

Alguns estudos evidenciam que, embora os usuários sejam analfabetos, ele são capazes de identificar números (Taoufik et al., 2007) e para determinadas culturas (Micro-finanças na Índia) é observada a familiaridade com operações matemáticas relativamente complexas (Ghosh et al., 2003) (Parikh et al., 2003). Para esses últimos estudos foi observado que utilização de representações de unidade como o cifrão (\$), símbolo de porcentagem (\%) são informações representativas no reconhecimento de funcionalidades atribuídas a determinados campos de entrada na interface.

Utilizado em 3 trabalhos: (Ghosh et al., 2003) (Prasad et al., 2008) (Taoufik et al., 2007)

5. Help: disponibilização de Help em todas as interações do sistema.

A possibilidade de auxílio oferecida pelos sistemas é ainda mais crítica, quando considerando usuários analfabetos computacionais. Para eles a atividade exploratória do sistema é pouco utilizada, pelo não conhecimento das funções básicas oferecidas pelo dispositivo. Medhi et al., para incentivar ainda mais o uso da ajuda do sistema, implementam uma metáfora de uma pessoa ajudando diretamente durante as interações, por meio de uma foto de uma mulher disponibilizada em todas as interfaces. Ao evento mouse-over da foto, frases de ajuda são narradas descrevendo o propósito da tela e as funcionalidades dos ícones (Medhi et al., 2007b). Já Taoufik et al. descrevem que com a disponibilização de auxílio de caráter proativo (disparado de acordo com o tempo de inatividade do sistema), narrando as funcionalidades do sistema conforme são realizadas as interações de navegação na interface, obtém-se resultados mais satisfatórios no uso do sistema (Taoufik et al., 2007).

Utilizado em 4 trabalhos: (Jibaja-Weiss et al., 2006) (Medhi et al., 2007b) (Prasad et al., 2008) (Taoufik et al., 2007) .

6. Alternativas ao uso de computadores: alternativas de hardware que utilizam modelos conceituais e metáforas de interação de melhor reconhecimento pelo usuário.

Os recursos de interação disponibilizados pelos computadores podem ser inacessíveis aos usuários por questões financeiras (Kumar et al., 2007a) ou operacionais (dificuldade de utilização) (Kumar et al., 2007b). Para tanto, são utilizadas alternativas de dispositivos como: touchscreens (Hahn et al., 2004) (Taoufik et al., 2007), celulares e telefones (Joshi et al., 2008) (Kumar et al., 2007b) (Kumar et al., 2007a) (Agarwal et al., 2008) ou sistemas de uso específico para a aplicação (Jones et al., 2007) (Shakeel e Best, 2002).

Utilizado em 11 trabalhos: (Akan et al., 2006) (Jones et al., 2007) (Plauché e Prabaker, 2006) (Plauche et al., 2006) (Hahn et al., 2004) (Taoufik et al., 2007) (Shakeel e Best, 2002) 
(Kumar et al., 2007a) (Kumar et al., 2007b) (Agarwal et al., 2008) (Cervantes e Sambasivan, 2008)

7. Guided linearity: linearização da estrutura navegacional durante as interações com os usuário.

A diminuição do número de tarefas a serem efetuadas por tela é denotado como um facilitador de compreensão da interface (Parikh et al., 2003).

Utilizado em 2 trabalhos: (Parikh et al., 2003) (Summers et al., 2006)

É importante ressaltar que a grande maioria dos estudos utiliza mais de um princípio no seu desenvolvimento. A implementação de mais de um princípio produz resultados diferenciados, permitindo, inclusive, uma melhora no nível de entendimento das componentes, conforme pode ser observado nos testes executados por Medhi et al. (Medhi et al., 2007a).

Alguns desses recursos estão fortemente vinculados a características culturais da população foco do estudo, de forma que para garantir o entendimento desses recursos na interface é necessário um amplo contato com os usuários durante as fases de desenvolvimento, conforme já apresentado na Seção 3.3. Esse requisito de desenvolvimento implica num alto grau de especialização da interface, o que implica em restrições de acessibilidade a outras comunidades. Dessa forma, a utilização desses recursos deve ser efetuada seguindo padrões de design contextual, etnográfico ou participativo e ainda vir acompanhados de outros recursos para não limitar o acesso a um determinado grupo de usuários. Os recursos que mais claramente denotam essa característica são: Representações gráficas e Dados numéricos. É importante observar, que algumas representações desses recursos são menos afetadas por essa característica como por exemplo: utilização de cores para denotar informações (Joshi et al., 2008) (Parikh et al., 2003) e símbolos de unidades de medida (Ghosh et al., 2003) (Parikh et al., 2003). Provavelmente, devido à universalidade do significado a elas empregado.

Por outro lado, poucos estudos revelam cuidados na elaboração das interações de voz com os usuários, de forma que pouco tempo é empregado na etapa de desenvolvimento na elaboração das mesmas. Taoufik et al. utilizam-se do método de Wizard-of-oz para elaboração das frases a serem escutadas pelos usuários; no entanto, seu enfoque é na compreensão do texto lido, não em aspectos de usabilidade da interação multimodal (voz e interface visual)(Taoufik et al., 2007). Esse aspecto de usabilidade em interações multimodais é tratado no trabalho de Walsh e Meade, em que é considerado um controle sobre os modos em que estão sendo efetuadas as interações com a interface, para evitar uma possível sobrecarga sensorial do usuário (Walsh e Meade, 2003). Com relação à preocupação nas interações, apenas em interfaces de voz, uma possível simplificação dos diálogos com o sistema é abordada, no trabalho de Plauche e Prabaker (Plauché e Prabaker, 2006), conforme previamente descrito nesta seção. É importante destacar ainda que, para este princípio, sua utilização é altamente dependente no desenvolvimento de tecnologias de sintetização de texto e reconhecimento de voz compatíveis com a língua compreendida pela população para a qual a aplicação é destinada. 
Os recursos de Simplicidade do conteúdo textual, Guided linearity e utilização de Help já são reconhecidos entre campos de estudo relacionados à acessibilidade na web (Sevilla et al., 2007) (W3C, 1999) (W3C, 2008c) e usabilidade das aplicações em geral (décima heurística de Nielsen (Nielsen, 1994)).

\subsection{Considerações finais}

O objetivo da revisão sistemática foi a identificação de recursos de design e tecnológicos destinados a usuários com baixo nível de alfabetização, que foram utilizados na literatura até o ano de 2009.

A maior parte dos estudos encontrados por meio do procedimento de revisão sistemática mostra a utilização de técnicas de design centrado em usuários para realizar a implementação desses recursos. Isso se deve ao fato de que a elaboração de meios alternativos às mídias textuais, que de fato sejam reconhecidos e compreendidos por esses usuários, requer vínculo com as características sociais e culturais desses indivíduos.

Também pôde ser observado que determinados recursos de design utilizados requerem maior empenho em sua fase de elaboração que outros, conforme foi visto pelos recursos de Representações gráficas e Dados numéricos. Enquanto outros, embora aparentemente menos custosos a nível de desenvolvimento, ainda devem ser melhor abordados e possuem limitantes tecnológicos a serem implementados (TTS e ASR).

O conhecimento sobre esses recursos, juntamente com as formas de implementação associadas aos mesmos, é de grande importância na determinação de características de design que sejam incorporados à tecnologia assistiva, foco deste trabalho. Essas características devem ser utilizadas como forma de auxílio à compreensão das funcionalidades e do conteúdo da aplicação.

O próximo capítulo (Capítulo 4) apresenta a proposta de utilização de recursos de processamento de língua natural para promover a adaptação de conteúdo e disponibilização de mecanismos de acessibilidade automaticamente nas páginas web. Também é descrito o desenvolvimento e design da aplicação Facilita que utiliza os recursos de Simplificação Sintática e Sumarização Automática para gerar um conteúdo mais facilmente compreendido por usuários classificados como alfabetizados de níveis rudimentar e básico. 


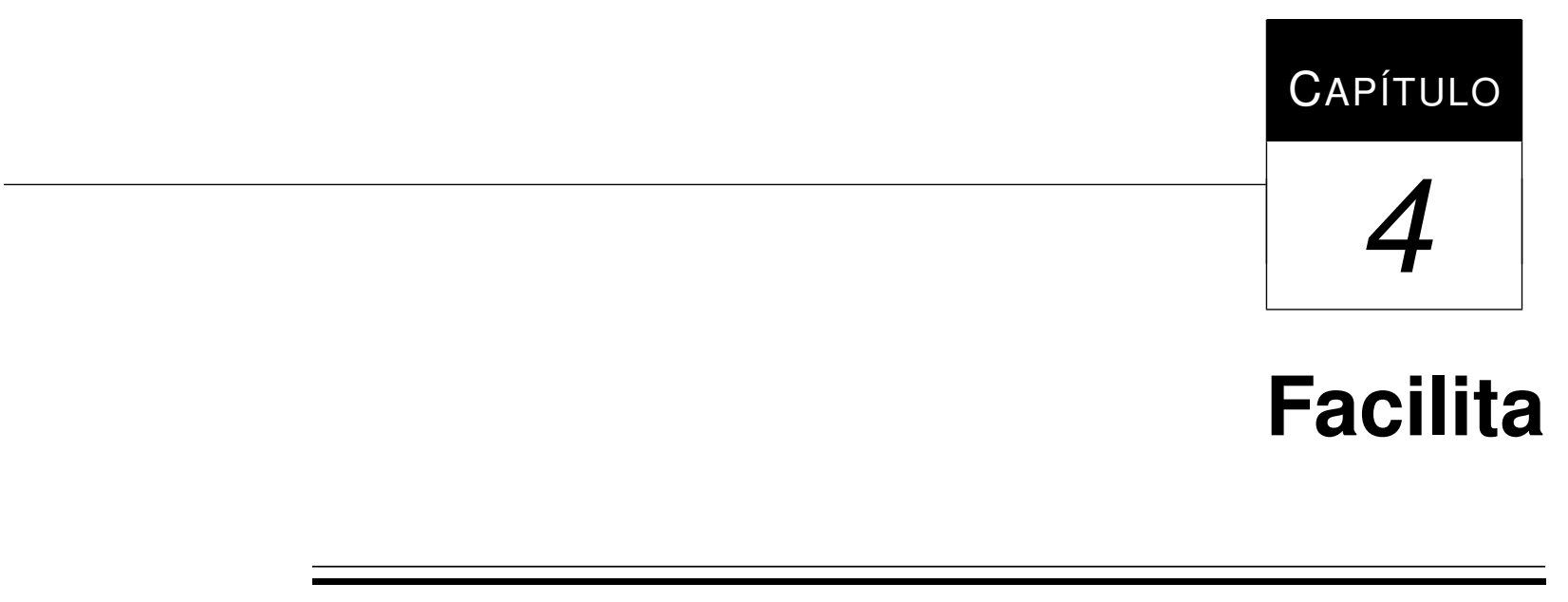

$\mathrm{N}$ este capítulo, é apresentada a aplicação Facilita que utiliza os recursos de simplificação sintática e sumarização automática para estabelecer a conformidade automática de websites com critérios de acessibilidade da WCAG. Também é descrita a metodologia de design realizada para a implementação do Facilita.

Como resultados do trabalho reportado neste Capítulo são destacados:

Artigo publicado no WebMedia 2009 - Simpósio Brasileiro de Sistemas Multimídia e Web : Facilita: auxílio à leitura de textos disponíveis na Web (Watanabe et al., 2009b).

Artigo publicado no SIGDOC 2009 - International Conference on Design of Communication

: Facilita: reading assistance for low-literacy readers (Watanabe et al., 2009a). O aluno apresentou este trabalho no SIGDOC 2009 - 27th International Conference on Design of Communication que foi realizado em Bloomington - Indiana - Estados Unidos.

Artigo submetido para o CLEI 2010 - XXXVI Conferência Latino-americana de Informática : “Ajax Design Patters for Usability in Web applications: a Case Study” (Watanabe et al., 2010c).

Artigo submetido para o WebMedia 2010 - Simpósio Brasileiro de Sistemas Multimídia e Web : Improving WCAG Conformance: Browser Strategies (Watanabe et al., 2010b). 


\subsection{Considerações iniciais}

A WCAG estabelece um conjunto de diretrizes que discutem critérios de acessibilidade e propõem o uso de soluções de design acessíveis (W3C, 2008c). Esse modelo de acessibilidade requer a implementação manual das soluções tecnológicas e de design propostas por desenvolvedores web e autores de conteúdo (Watanabe et al., 2009a,b). No entanto, considerando a natureza distribuída e colaborativa da web, não há garantias que as diretrizes e recomendações de desenvolvimento de acessibilidade vão ser seguidas. Freire et al., por exemplo, conduziram um levantamento sobre o conhecimento a respeito das diretrizes de acessibilidade de pessoas envolvidas em projetos de desenvolvimento web no Brasil (Freire et al., 2008b) e de conformidade de websites de municípios brasileiros com a WCAG (Freire et al., 2008a). Em ambos os trabalhos, foi concluído que ainda existe uma lacuna importante de conhecimento sobre as recomendações de acessibilidade e sua implementação em aplicações web no Brasil.

É importante destacar que as recomendações de acessibilidade apresentadas na WCAG não consideram apenas os aspectos tecnológicos ou estruturais de uma aplicação web. A diretriz 3.1 (apresentar conteúdos textuais intelegíveis e compreensíveis) da WCAG 2.0, por exemplo, descreve recomendações a respeito de como o conteúdo de uma aplicação web deve ser disponibilizado para os usuários. No entanto, os desenvolvedores web não são sempre responsáveis pela preparação e autoria de conteúdo de um website. Quando considerando o contexto da "Web 2.0", em que os usuários sem, necessariamente, possuir conhecimento a respeito das diretrizes de acessibilidade participam do processo de autoria de conteúdos nas aplicações web. Torna-se ainda mais difícil garantir os níveis de acessibilidade estabelecidos pelo modelo de acessibilidade da WAI na Web.

Assim o objetivo da proposta nesta dissertação é o desenvolvimento de uma estratégia de adaptação automática de conteúdo web para melhorar a conformidade de websites disponíveis com a WCAG. Para implementar essas estratégias de adaptação automática de conteúdo, são utilizadas técnicas de processamento de língua natural que incrementam a acessibilidade de conteúdos textuais na web.

Os critérios de sucesso 3.1.3 e 3.1.5 da WCAG 2.0, especificamente, descrevem características do conteúdo textual que possuem melhores índices de intelegibilidade e compreensibilidade para os usuários. As aplicações descritas neste trabalho utilizam as técnicas de processamento textual de sumarização automática, simplificação sintática, elaboração léxica e reconhecimento das entidades nomeadas, para disponibilizar conteúdo acessível aos usuários, por meio da adaptação automática de aplicação web que não estejam, necessariamente, em conformidade com a WCAG.

A estratégia de adaptação automática foi implementada na camada de acessibilidade web de agentes de usuário (navegador web - browser). A funcionalidade foi disponibilizada como uma extensão de navegador e, dessa forma, torna-se possível utiliza-lá em todas as aplicações web disponíveis na Web, sem a necessidade de mudanças ou melhorias nos websites. Na Figura 4.1, é ilustrado como a abordagem de adaptação automática de conteúdo desenvolvida no navegador (User 
Agent with automatic adaptation features) permite que todo e qualquer website (Web Content) seja beneficiado pela técnica de processamento de língua natural (Natural Language Processing). Essa técnica de processamento da língua natural tem como entrada uma aplicação da Web e gera como saída um novo website em conformidade com os critérios de acessibilidade da WCAG (WCAG Conformant Web page) para o usuário (User). A implementação da estratégia em nível de aplicações web (Web Content) disponibilizaria a adaptação automática de conteúdo para apenas uma aplicação. E qualquer outra aplicação web, que apresentasse a necessidade de implementar essa funcionalidade, precisaria ser re-implementada ou alterada para utilizar o recurso de adaptação automática de conteúdo textual.

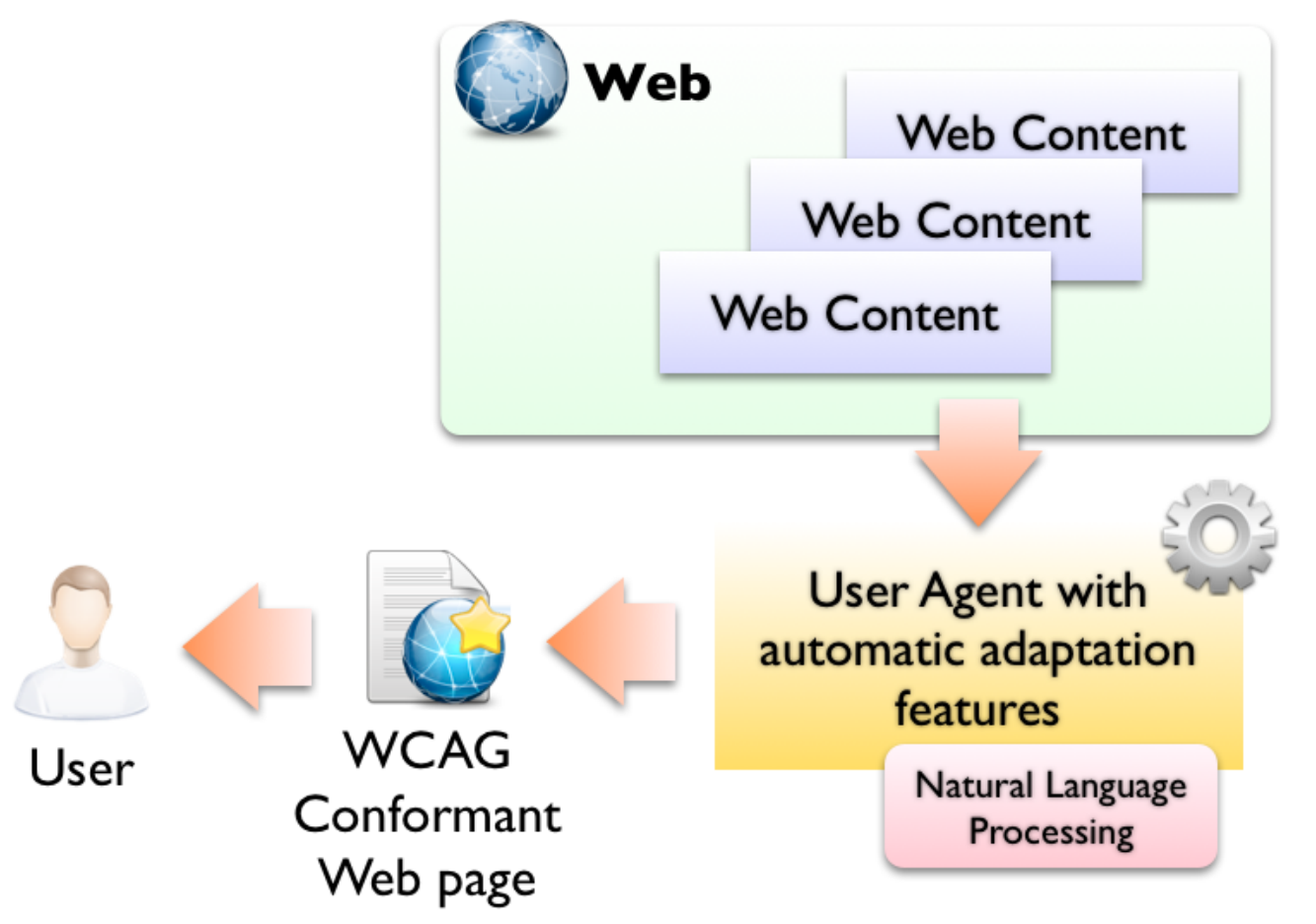

Figura 4.1: Arquitetura de adaptação automática para conformidade com a WCAG (Watanabe et al., 2010b)

Foram implementadas duas extensões de agentes de usuário que são direcionadas à adaptação automática do conteúdo considerando diferentes requisitos de acessibilidade: Facilita (descrito neste capítulo), que promove a adaptação de conteúdo de acordo com o critério de sucesso 3.1.5 da WCAG 2.0; e Facilita Educacional (Capítulo 5), que promove a adaptação considerando a conformidade com o critério de sucesso 3.1.3 da WCAG 2.0. As abordagens descritas para o desenvolvimento da funcionalidade de adaptação automática de conteúdo utiliza um framework Javascript para implementar as extensões de navegador. Também são descritos outros recursos necessários para disponibilizar essas aplicações na web.

O Facilita é uma aplicação web que funciona como uma tecnologia assistiva de auxílio à leitura de conteúdos textuais disponíveis em páginas web. Esse auxílio à leitura é realizado por meio da adaptação automática de textos disponíveis na web em textos de reduzidas dimensões e de estrutura lingüística simplificada, de forma que sejam mais adequados às habilidades de leitura 
apresentadas por usuários alfabetizados de nível rudimentar e básico. Ao resultado dessa adaptação automática de textos realizada pelo Facilita é atribuído o nome de Conteúdo Facilitado.

Esse Conteúdo Facilitado é um conteúdo também textual, no entanto sua estrutura é simplificada, conforme definido no projeto PorSimples com base no Plain Language ${ }^{1}$, sistemas de simplificação para o Inglês, como, por exemplo, (Siddharthan, 2006) e na análise de corpus de textos reescritos para atender um público mais amplo na Web Brasileira (Aluisio et al., 2008); e o tamanho do texto será reduzido, visto a dificuldade de usuários com baixo nível de alfabetização com textos extensos (Margarido et al., 2008b).

O auxílio à leitura é promovido por meio de uma aplicação que permite executar os procedimentos de Sumarização Automática e Simplificação Textual sintática em textos de site e aplicações web. Dessa forma, torna-se disponível ao usuário uma versão alternativa, mais facilmente compreensível, dos textos apresentados na web. Essse auxílio foi esquematizado na Figura 4.2.

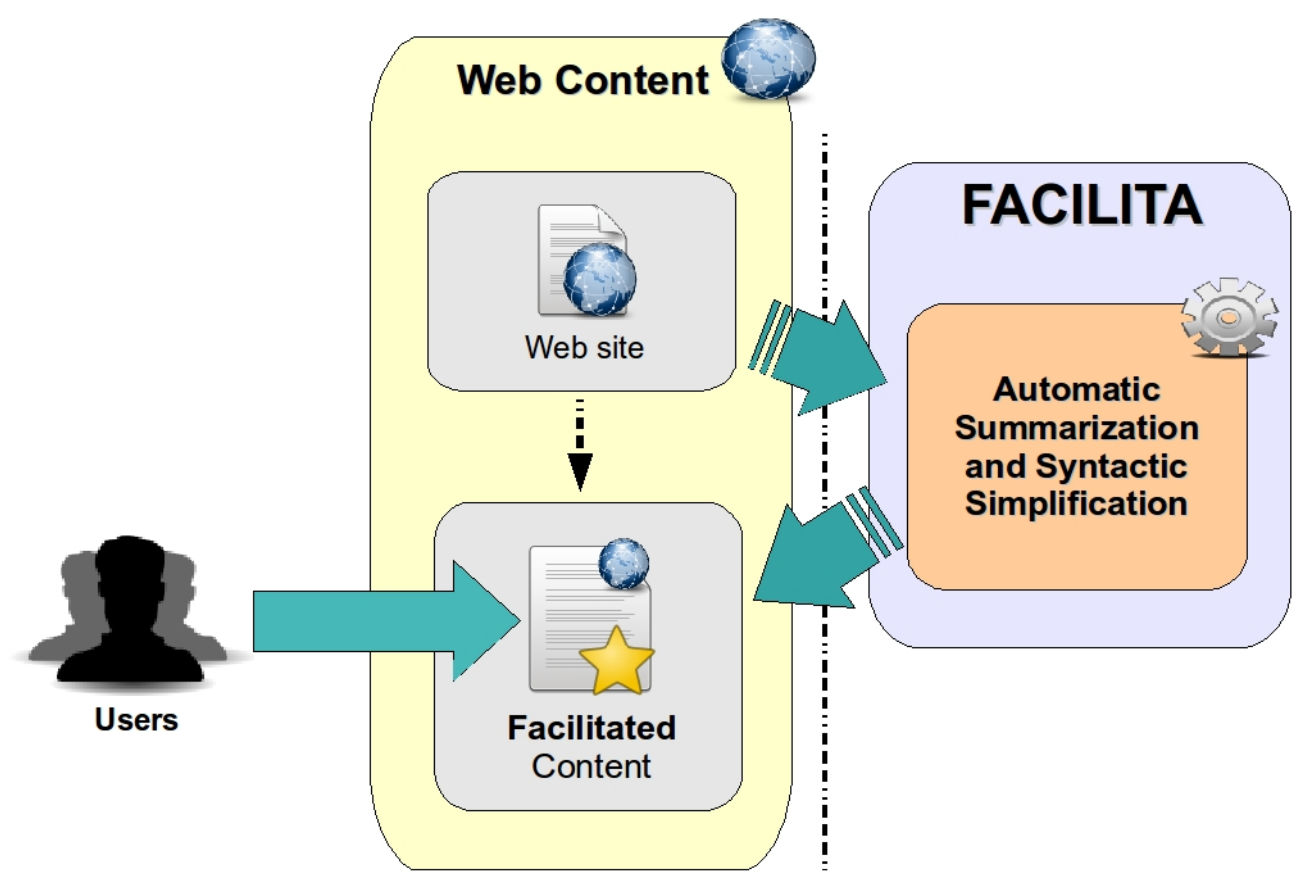

Figura 4.2: Esquema de auxílio à leitura do Facilita (Watanabe et al., 2009a).

\subsection{Conteúdo Facilitado}

Em (Young, 1999) são citadas duas técnicas distintas para Adaptação Textual: A Simplificação Textual e a Elaboração Textual. A primeira técnica, Simplificação Textual, pode ser definida como qualquer tarefa que reduza a complexidade léxica ou sintática de um texto enquanto tenta preservar seu significado e informação (Mapleson, 2006; Max, 2006). Já a segunda técnica, Elaboração Textual, visa esclarecer, elaborar e explicar informação implícita em textos, por exemplo, acrescentando definições ou sinônimos para palavras conhecidas por poucos falantes da língua.

\footnotetext{
${ }^{1}$ http://www.plainlanguage.gov/
} 
A Simplificação Textual aumenta a inteligibilidade do texto, ou seja, a facilidade de leitura do texto. Na técnica de Simplificação Textual para remoção de complexidade sintática, é comum a divisão de sentenças grandes, o que diminui o tamanho das em sentenças menores, porém aumenta o tamanho do texto devido a repetição do sujeito em mais de uma sentença. Na técnica de Simplificação Textual baseada em Sumarização, o tamanho do texto é diminuído, porém existe a possibilidade de perda de informação relevante, o que pode prejudicar a compreensão do texto. No caso da Elaboração Textual, a compreensibilidade do texto é aumentada, ou seja, há um aumento na facilidade de compreensão dos conceitos apresentados no texto. Esta técnica sempre aumenta o tamanho do texto, devido à inserção de informações e redundância de informações para reforçar o entendimento de alguns conceitos.

Em experimentos realizados durante o desenvolvimento do projeto PorSimples, a leitura de textos longos apresentou-se cansativa e difícil para muitos dos leitores pertencentes ao público alvo, em especial, para usuários com letramento rudimentar. Em virtude disso, um foco inicial foi dado em Simplificação Textual, já que a técnica torna a leitura do texto mais fácil e menos cansativa se comparada com a Elaboração Textual. Atualmente, as abordagens de Simplificação Textual utilizadas no Facilita envolvem a redução da complexidade das orações e a sumarização do texto. Estudos para Simplificação Textual no nível lexical também estão em andamento. A Elaboração Textual já se encontra em estudo, e consistirá em explicitação das informações mencionadas no texto (Reconhecimento de entidades nomeadas, Identificação de funções semânticas e Apresentação das relações retóricas).

O projeto PorSimples foca principalmente em alfabetizados de níveis rudimentar e básico. Entretanto, também pode ser utilizado por outros perfis de usuários, como crianças e adultos em fase de alfabetização, portadores de deficiências cognitivas que afetam a capacidade de leitura (dislexia, afasia, entre outras) e aprendizes de segunda língua. A Simplificação Textual sintática também pode ser útil em sistemas de extração de informações ou recuperação de informações, pois torna as orações mais concisas e em casos de divisão de orações, é comum a repetição de sujeito, o que permite explicitar o sujeito de orações subordinadas e coordenadas. A eliminação da voz passiva também favorece a criação de expressões de busca.

As próximas seções detalham as operações textuais para os dois tipos de Simplificação Textual usados no projeto PorSimples (Sumarização Automática e Simplificação Textual sintática) que são efetuadas na geração do Conteúdo Facilitado.

\subsubsection{Sumarização automática}

O sumarizador criado no projeto PorSimples é fundamentado na extração de palavras-chave, em particular, no método apresentado em (Souza e Nunes, 2001). O sumarizador é extrativo, ou seja, o sumário gerado é composto por orações retiradas na íntegra do texto original, sem modificações. A extração de palavras-chave é a estratégia de sumarização mais antiga, e uma das mais utilizadas. Nessa estratégia, um conjunto de palavras-chave previamente existente ou 
gerado automaticamente é utilizado para escolher orações candidatas ao sumário. As orações devem possuir ao menos uma palavra chave.

Dois métodos de extração foram testados: o método EPC-P (Extração de Palavras-Chave por Padrão) e o método EPC-R (Extração de Palavas-Chave por freqüências de Radicais). No primeiro, as palavras-chave são baseadas em padrões como $<$ Noum $>$ ou $<$ Noun+Preposition+Noun $>$ (neste padrão, adjetivos são permitidos em qualquer posição). O segundo utiliza a técnica de stemming, encontra os stems mais freqüentes, e os usa para escolher orações candidatas a pertencerem ao sumário. Há também duas variações EPC-P2 e EPC-R2 paras os método EPC-P e EPC-R, respectivamente. Nessas variações, um ranking de orações baseado no número de palavras-chave que apresentam e o sumário é criado baseado nesse ranking.

Após uma avaliação entre os 4 métodos de extração, optou-se pelo uso do EPC-R no projeto PorSimples, por apresentar melhor resultados (Margarido et al., 2008a). Outros sumarizadores também foram incluídos na avaliação, que analisou a precisão dos sumarizadores (a escolha por boas sentenças para o sumário) e a medida ROUGE (uma medida que compara o sumário gerada com um sumário manual criado por um profissional da área). Apesar de existir sumarizadores com desempenho superior ao EPC-R para a Língua Portuguesa, foi observado que estes não estão facilmente disponíveis, ou apresentam desempenho baixo em relação ao tempo para a sumarização. Após considerar esse fato, o EPC-R se mostrou o sumarizador mais adequado para a tarefa.

Avaliações com usuários foram realizadas no mesmo estudo. Ao todo, 19 pessoas, com diferentes níveis de letramento avaliaram os sumários gerados. Entre os leitores com mais de dois anos estudo e menos de cinco anos, observou-se que $66 \%$ consideraram o sumário de mais fácil compreensão que o texto original. Para os leitores com mais de cinco anos e menos de oito anos de estudo foi observado que o sumário tornou a leitura do texto menos cansativa, e que o nível de compreensão oferecido pelo texto e pelo sumário é equivalente.

\subsubsection{Simplificação Sintática}

A Tabela 4.1 mostra exemplos de diversos tipos de simplificações para uma dada oração original. Todas as simplificações podem ser geradas pelo Facilita. Atualmente, a oração escolhida é aquela que possui o maior número de operações de simplificações, indicada para alfabetizados de nível rudimentar.

A abordagem de "remoção de complexidade sintática" foi inspirada no trabalho de (Siddharthan, 2003) e consiste em um conjunto de regras de reescrita sintática aplicadas sobre a saída do parser Palavras (Bick, 2000) para um dado texto. A saída do parser é uma representação XML do texto, incluindo informações sobre sua árvore sintática. As regras de simplificação tratam 7 fenômenos sintáticos: apostos, voz passiva, orações coordenadas, subordinadas, reduzidas (em estudo) e relativas, posição de adjuntos adverbiais, ordem canônica (Sujeito-Verbo-Objeto - SVO) das orações (em estudo). Um tratamento diferenciado é feito para cada subtipo de orações coordenadas, subordinadas e relativas. Por exemplo, orações coordenadas aditivas passam por um processo de 
Tabela 4.1: Simplificações alternativas de uma mesma sentença

\begin{tabular}{|l|}
\hline Sentença original \\
\hline Isso faz com que sopre mais vento quente \\
do Norte e aumente ainda mais a temperatura \\
- avalia Flávio Varone, do Oitavo Distrito \\
de Meteorologia. \\
\hline Divisão de aposto \\
\hline Isso faz com que sopre mais vento quente do \\
Norte e aumente ainda mais a temperatura \\
- avalia Flávio Varone. Flávio Varone é do \\
Oitavo Distrito de Meteorologia. \\
\hline Divisão de oração coordenada aditiva \\
\hline Isso faz com que sopre mais vento quente do \\
Norte. Isso aumenta ainda mais a temperatura \\
- avalia Flávio Varone, do Oitavo Distrito \\
de Meteorologia. \\
\hline Divisão do aposto e da oração coordenada \\
\hline Isso faz com que sopre mais vento quente do Norte. \\
Isso aumenta ainda mais a temperatura - avalia Flávio Varone. \\
Flávio Varone, é do Oitavo Distrito. \\
\hline
\end{tabular}

divisão, enquanto que orações coordenadas adversativas passam por divisão e por troca de marcadores discursivos.

Ao todo, 7 operações são usadas para o tratamento dos fenômenos sintáticos. Mais de uma operação pode ser aplicada para um dado fenômeno e uma dada oração pode possuir mais de um fenômeno. As operações são:

- Divisão de orações: consiste em encontrar um ponto de divisão da oração original (como conjunções, limite de cláusulas relativas e limite de apostos). Duas novas orações são geradas com o respectivo sujeito ajustado.

- Troca de marcadores discursivos: consiste na substituição de marcadores discursivos por marcadores mais comumente usados. Por exemplo, o marcador "entretanto" é substituído por "mas".

- Mudança para a voz ativa: nessa operação, a ordem dos elementos em um oração na voz passiva é alterada e o verbo é ajustado. Caso existam sentenças (coordenadas, subordinas, e outras) ligadas ao objeto da operação na voz passiva, elas são movidas para o sujeito da oração na voz ativa.

- Inversão de ordem das clausulas: consiste na troca de orações dentro de uma oração maior, de forma que a oração que contém as informações principais sejam movidas para o início. Essa operação trata orações subordinadas atualmente. 
- Ordem Sujeito-Verbo-Objeto (SVO): consiste no ajuste dos componentes da oração de modo que a ordem resultante seja SVO. Por exemplo, a oração "Terminou empatado o jogo entre Brasil e Bolívia” é convertida para "O jogo entre Brasil e Bolívia terminou empatado".

- Topicalização e de-topicalização: consiste na troca de posições dos adjuntos adverbiais, movendo-os para início (topicalização) ou para o final da oração (de-topicalização).

Existe ainda a operação "Não Simplifica", um caso especial reservado para sentenças que não passaram por nenhuma simplificação.

Dois modos de simplificação são previstos dentro do projeto PorSimples: a Simplificação Textual natural (em desenvolvimento) e a forte (já desenvolvida). A primeira foi projetada para alfabetizados de nível básico, e consiste em grau menor de simplificação. Para esse perfil de usuários, a taxa de sumarização será menor (50\%), e parte dos fenômenos não será tratada em parte das orações. Técnicas de Aprendizado de Máquina estão em estudos para determinar quais operações serão efetuadas para uma dada oração. A segunda tem foco em alfabetizados de nível rudimentar, que necessitam de um grau maior de simplificação. Para esse perfil de usuários, a taxa de sumarização será de $70 \%$ e todos os fenômenos serão tratados para todas as orações, sempre que possível.

\subsection{Abordagem de design realizada}

Comumente, requisitos para sistemas iterativos são difíceis de serem completamente estabelecidos no começo do ciclo de desenvolvimento do software. A única forma de se definir determinadas características do design de uma aplicação é implementá-la e testá-la com usuários (Dix et al., 2003). Quando considerando o desenvolvimento de interfaces para usuários alfabetizados de nível rudimentar e básico, esse fato é de extrema relevância, uma vez que o baixo nível de alfabetização, freqüentemente, está associado ao analfabetismo computacional. E, dessa forma, considerando a ampla diferença cultural entre usuário e desenvolvedor, torna-se difícil a elaboração de um modelo conceitual aceito pelos usuários partindo de abordagens não experimentais de design (Watanabe e Fortes, 2009).

Assim, neste trabalho foi utilizada a metodologia de design iterativo: um processo de design em que são realizadas tentativas visando superar problemas inerentes à não especificação completa dos requisitos por meio da avaliação de vários designs que melhoram incrementalmente o produto final em cada iteração (Dix et al., 2003).

A seguir, são apresentadas as interações da metodologia de design iterativo que já foram desenvolvidas no projeto. 


\subsubsection{Primeira iteração}

Na primeira iteração do desenvolvimento, foi utilizada a abordagem de elaboração de protótipos descartáveis (throw away prototypes (Dix et al., 2003)), para determinação da forma como seria conduzida a interação inicial de ativação do recurso disponibilizado pelo Facilita. Nessa etapa foram realizadas reuniões com a equipe do projeto PorSimples para apresentar Mockups que representavam as alternativas de ativação do Facilita, e definir qual o modelo de interação seria utilizado. Os Mockups elaborados são descritos a seguir:

- Editor de textos: nesse modelo de interação, seria necessário que o usuário efetuasse a inserção de conteúdo textual em um campo de texto na aplicação Facilita, que em seguida apresentaria a versão do conteúdo textual inserido na aplicação sumarizado e simplificado (Figura 4.3). Deve-se destacar que essa interface requer a seleção de textos disponíveis em outros sites pelo processo de copiar e colar (copy e paste), e exige que o usuário utilize no mínimo duas instâncias de execução do navegador: uma para o site ou aplicação web que estiver sendo acessado e outra para o Facilita.

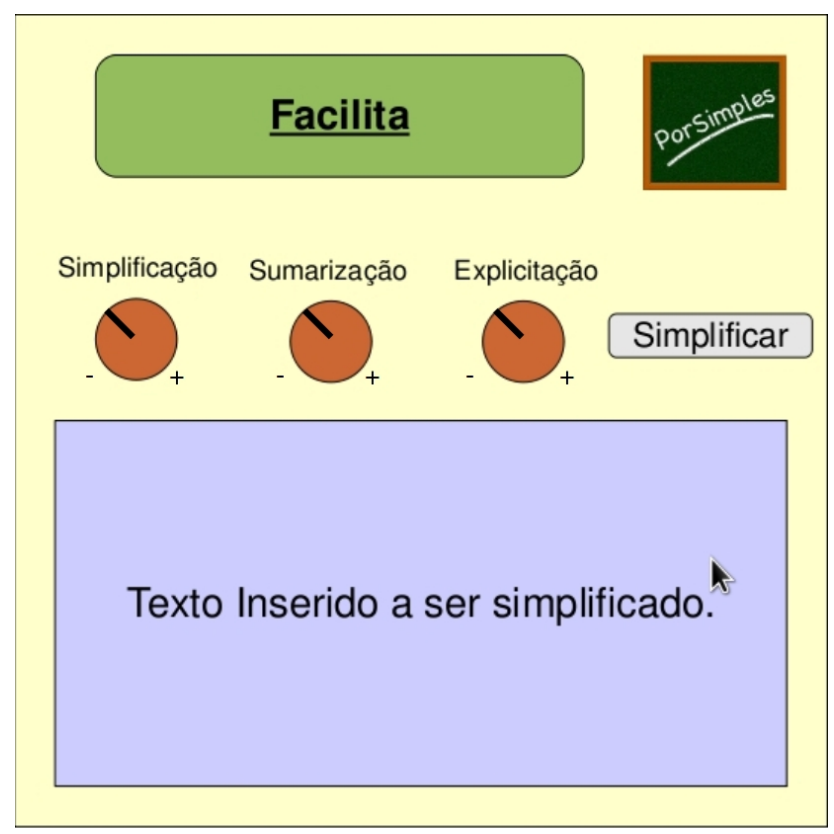

Figura 4.3: Mockup 1: modelo conceitual de um editor de textos.

- Sistema de busca: com um funcionamento semelhante à aplicação web Google Translate ${ }^{2}$. Deve ser passada uma URL (Uniform Resource Locator) indicando o site ou aplicação web que possui o conteúdo textual a ser facilitado para a leitura. Em seguida uma versão do mesmo site indicado pela URL seria apresentada, com todo o seu conteúdo textual sumarizado e simplificado. Esse Mockup (Figura 4.4) possui um determinado limitante de uso

\footnotetext{
${ }^{2}$ http://www.translate.google.com/
} 
de acordo com a sua interface que refere-se ao fato de que analfabetos computacionais, dificilmente, estariam familiarizados com o conceito de endereço de páginas (URL's). O que tornaria difícil sua atribuição no campo de busca dessa interface.

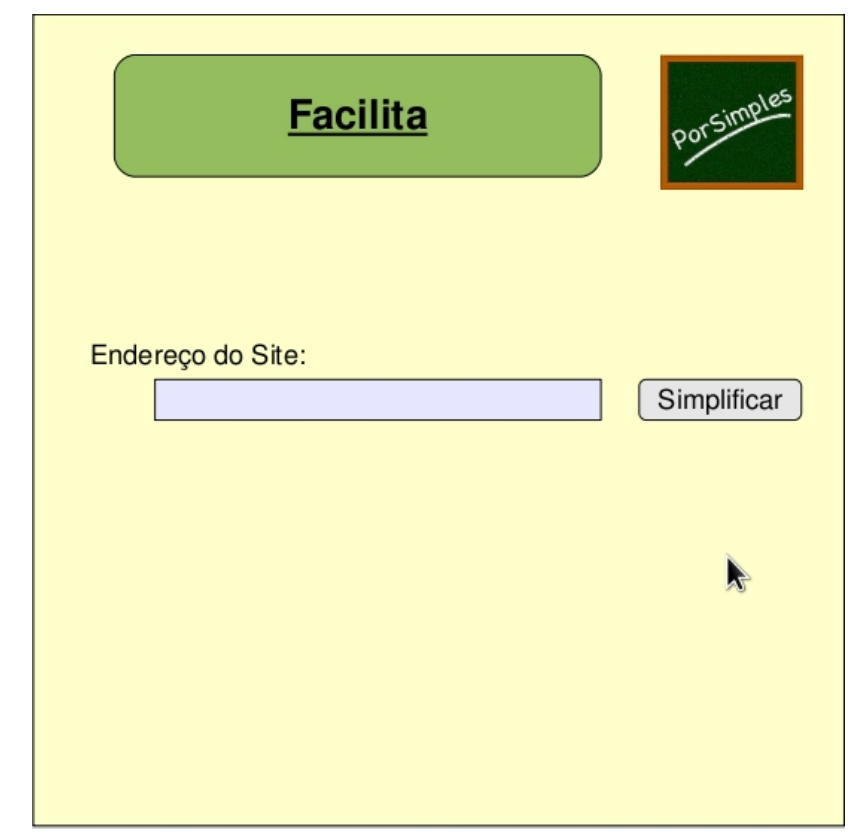

Figura 4.4: Mockup 2: modelo conceitual de um sistema de buscas.

- Inserção do Facilita nos websites: considerando o método utilizado pelo sistema Google Adsense $^{3}$, a aplicação do Facilita poderia ser uma funcionalidade inserida nos próprios sites que desejam tornar seu conteúdo mais acessível aos indivíduos com baixo grau de alfabetização (Figura 4.5). Nesses sites, seria disponibilizado um link para o Facilita, e em seguida seria apresentada uma versão adaptada do conteúdo textual do site. Esse conteúdo poderia ser passado como parâmetro ao Facilita, ou mesmo todo o conteúdo textual do site poderia ser sumarizado e simplificado pelo Facilita, como apresentado no Mockup anterior. No entanto, seria necessária a implementação ou inserção de trechos de código nos sites e aplicações web, por parte dos desenvolvedores web ou web designers autores dos próprios sites, para que seu conteúdo fosse passível de envio e adaptação pelo Facilita. Dessa forma, a aplicação das operações de facilitação seria restrita de uso apenas aos sites que implementassem essa funcionalidade.

- Plugin do navegador: foi também desenvolvido um mockup que realiza a facilitação de conteúdo de um site ou aplicação web por meio de um plugin de um navegador (Figura 4.6). Seria adicionado um botão ou link no navegador que realizaria a disponibilização da versão

\footnotetext{
${ }^{3}$ https://www.google.com/adsense/
} 


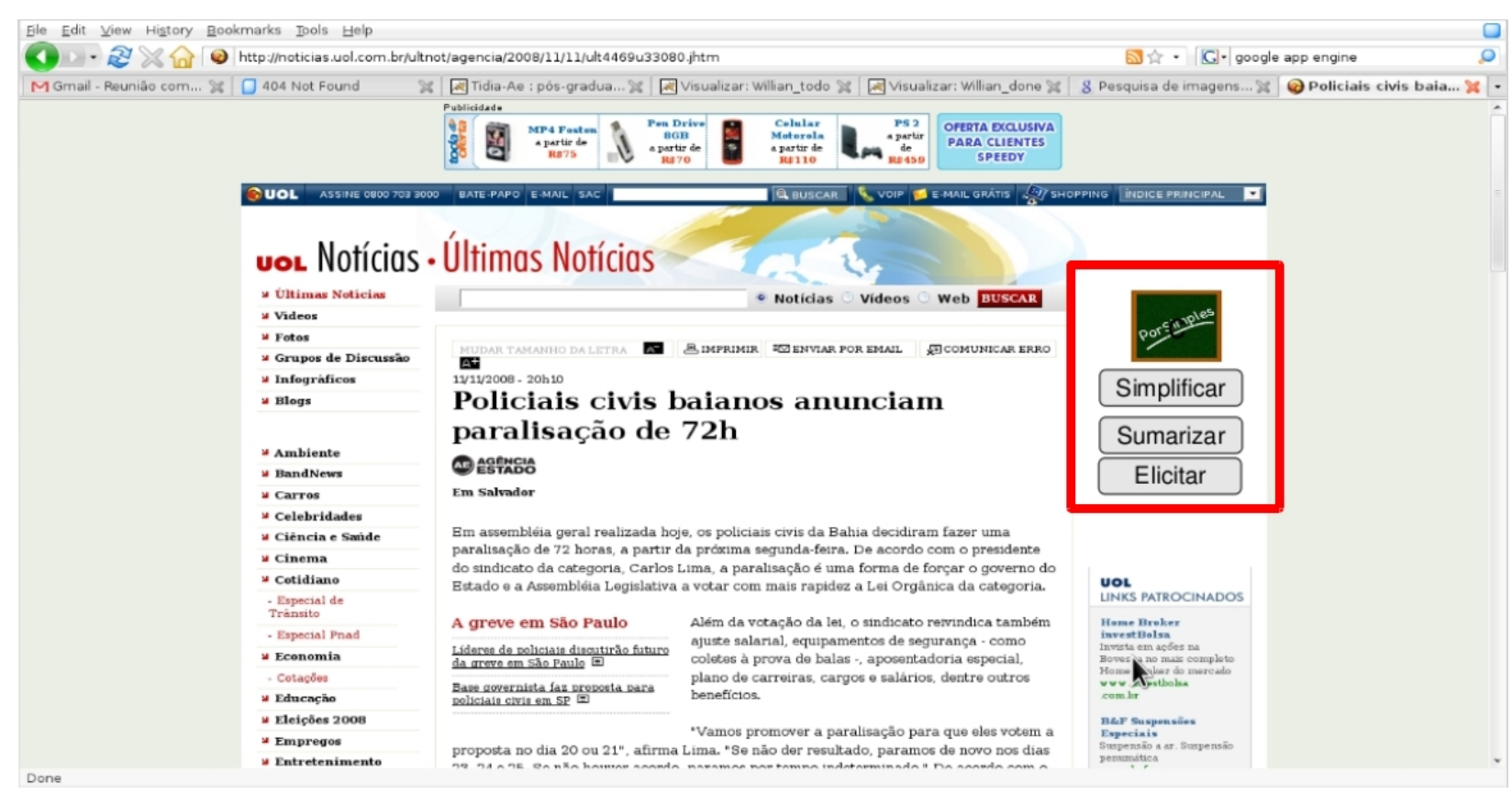

Figura 4.5: Mockup 3: inserção do Facilita nos websites.

Facilitada do conteúdo textual contida no site que estivesse sendo acessado.

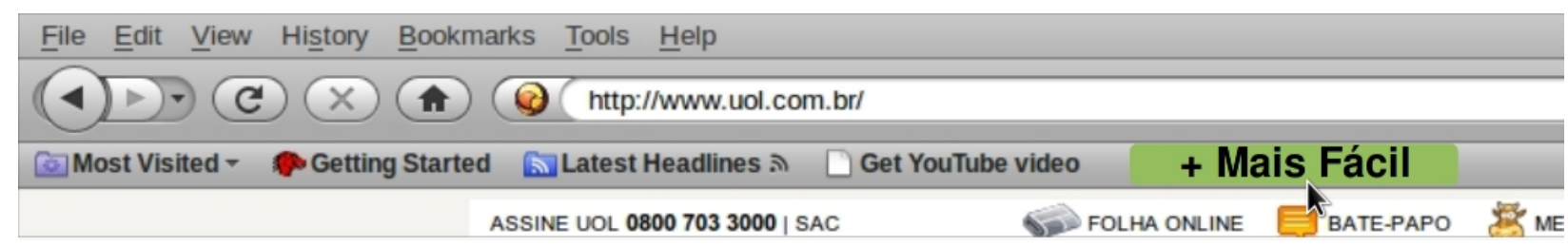

Figura 4.6: Mockup 4: plugin do navegador.

Dentre os Mockups apresentados, o Plugin de Navegador foi identificado como uma das melhores abordagens, visto sua apresentação constante e sempre no mesmo local da interface independentemente do site que esteja sendo apresentado ao usuário, por ser um recurso integrado ao navegador. Essa alternativa de interação, por ser um recurso implementado e disponibilizado diretamente no navegador, pode ser aplicado a qualquer site, diferentemente do Mockup de Inserção do Facilita nos sites.

\subsubsection{Segunda iteração}

Uma vez determinada a forma de ativação do recurso de facilitação, foi dado início ao segundo ciclo de desenvolvimento do Facilita. Diferentemente da primeira iteração, a partir dessa etapa do desenvolvimento, foi utilizada a abordagem de prototipagem evolucionária (Dix et al., 2003), em que o protótipo não mais é descartado, mas evolui a partir de avaliações de usabilidade que indiquem problemas a serem corrigidos no protótipo. 
Os protótipos diferem de acordo com a quantidade de funcionalidade e desempenho que eles disponibilizam em relação ao produto final (Dix et al., 2003). Considerando que os protótipos não mais seriam descartados, a partir dessa iteração, os mesmos foram desenvolvidos como protótipos com implementações reais de suas funcionalidades e foi dedicado um maior gasto de tempo em seu planejamento e codificação.

A decisão por realizar a implementação de protótipos funcionais a partir dessa etapa também foi realizada considerando a necessidade de validação experimental da aplicação sendo desenvolvida. O protótipo de um sistema interativo é utilizado para testar seus requisitos por meio de uma avaliação com usuários reais. Um resultado confiável dos requisitos do sistema final só pode ser estabelecido se as condições de avaliação são similares àquelas esperadas durante a operação real (Dix et al., 2003).

Dessa forma, nessa etapa, foi desenvolvido um protótipo funcional do Facilita que utiliza a Sumarização com $70 \%$ de compressão e a Simplificação forte, ambas detalhadas na Seção 4. A Sumarização com 50\% de compressão e a Simplificação Natural devem ser incluídas em próximos protótipos.

Para que o protótipo realize esse auxílio à leitura, são necessários os seguintes passos, durante uma interação do usuário com a aplicação:

1. O usuário deve acessar um site ou determinada aplicação web.

2. O usuário deve selecionar o conteúdo textual disponível no site que se deseja auxílio na leitura.

3. O usuário deve clicar no link do Facilita disponível na barra de favoritos do navegador (ilustrado na Figura 4.7) e, em seguida, lhe será apresentado o Conteúdo Facilitado (ilustrado na Figura 4.8).

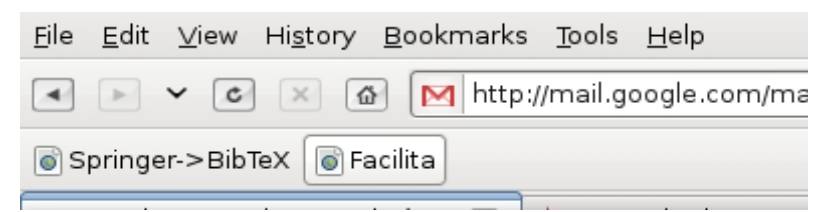

Figura 4.7: Barra de favoritos do navegador com o link do Facilita

Essa abordagem para interação com o usuário é bastante semelhante à utilizada pelo sistema Translate da Google ${ }^{4}$, em que o usuário também deve selecionar textos disponíveis em sites e clicar em um link instalado na barra de favoritos no seu navegador. No entanto, o sistema Translate da Google redireciona o site que estava sendo acessado para a aplicação Translate, enquanto o Facilita

\footnotetext{
${ }^{4}$ http://translate.google.com/translate_tools
} 


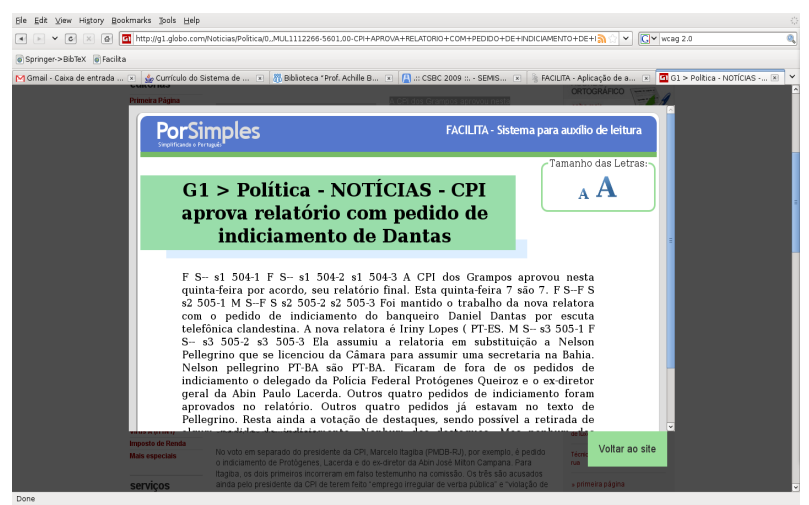

Figura 4.8: Apresentação do conteúdo Facilitado no protótipo inicial.

realiza a disponibilização do conteúdo gerado no próprio site, por meio de um componente de interface рорир.

É importante destacar que a utilização da componente de interface popup foi definida como uma forma de manter informações contextuais relacionadas ao site ou aplicação web sobre o qual foi aplicada a Facilitação do conteúdo. Ao mesmo tempo em que é apresentado o conteúdo Facilitado dentro do elemento popup, pode ser observado, ao fundo, o site ou aplicação web que estava sendo acessado anteriormente. Esse componente popup foi implementado utilizando elementos div do HTML, sem a criação de uma nova janela, visto que o aumento do número de janelas sendo apresentadas pelo sistema operacional poderia atrapalhar o usuário. No canto direito inferior da popup, é disponibilizado um link que fecha a popup, e retorna ao site que estava sendo acessado.

No topo da popup, é disponibilizado o logo do projeto PorSimples e o nome da aplicação Facilita ("FACILITA - Sistema para auxílio a leitura“") como forma de identificação da função da componente de interface.

Um outro recurso utilizado, como forma de manter as informações contextuais, diz respeito à captura do título do site que está sendo acessado no momento de ativação da funcionalidade do Facilita. Esse título é em seguida apresentado dentro da popup como um cabeçalho para o conteúdo Facilitado (elemento HTML header).

Foi observado que as operações de Sumarização com 70\% de compressão e Simplificação Textual Forte precisam de alguns segundos para ser completada, de acordo com o tamanho do texto que for selecionado nos sites. Durante o tempo de processamento necessário à operação de Simplificação Forte, é apresentada uma mensagem de "Aguarde" ao usuário. Também foi adicionado um mecanismo de aumento da fonte do texto sendo utilizado para apresentar o conteúdo Facilitado.

Um fator limitante de acordo com essa forma de ativação diz respeito à seleção do conteúdo textual que se deseja um auxílio à compreensão. Conforme destacado anteriormente, o Facilita deve possuir interações de uso o mais simplificadas possíveis para seus usuários. E, dessa forma, a atividade de seleção textual com o mouse pode não ser adequada aos níveis de habilidade com computadores dos usuários foco da aplicação. No entanto, a extração automática do conteúdo textual de páginas web é uma tarefa complexa, e exigiria um maior tempo e esforço de imple- 
mentação. Com isso, foi determinado que a seleção textual deve ser mantida nos primeiros ciclos de avaliação com os usuários, até que uma alternativa para a extração do conteúdo textual seja determinada e implementada.

O protótipo foi apresentado, novamente, aos membros do projeto para que fosse realizado um levantamento inicial de problemas de usabilidade apresentados pela interface. Nesse levantamento, foram identificados os seguintes problemas:

- As informações presentes no topo da componente popup ocupam uma parcela significativa da popup, e dessa forma diminuem o espaço para disponibilização do conteúdo Facilitado.

- O título das páginas web (conteúdo do elemento title da página), muitas vezes, possuem um número elevado de informações, e essas informações não são, necessariamente, relacionadas ao conteúdo textual selecionado para Facilitação. Considerando isso, a disponibilização desse conteúdo como um elemento heading, dentro da popup pode confundir o usuário da aplicação.

- O tempo de espera necessário para a realização das operações de Sumarização Automática e Simplificação Textual é superior a 10 segundos, dependendo do tamanho do texto selecionado para Facilitação. Dessa forma, para esses casos torna-se necessária a apresentação de informações a respeito do progresso dessas operações de processamento textual ao usuário.

Com isso, foi realizada a adaptação da interface do protótipo considerando esses problemas. A interface resultante desse processo pode ser visualizada na Figura 4.9.

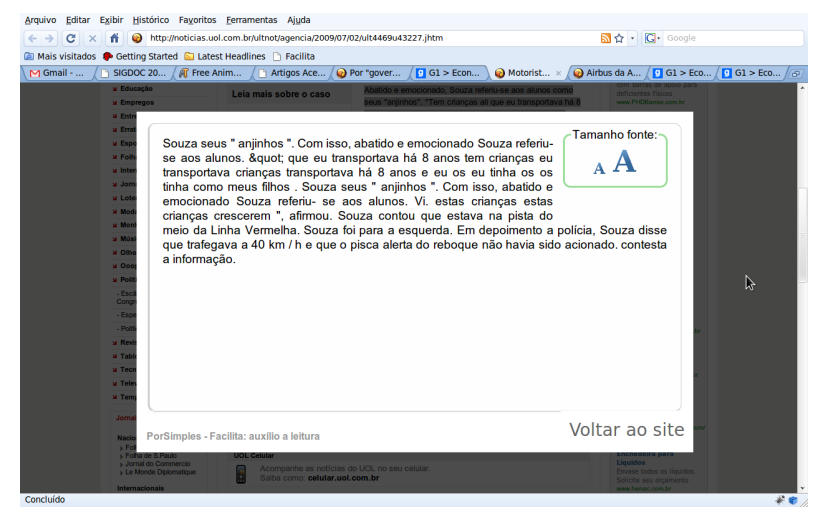

Figura 4.9: Apresentação do conteúdo Facilitado no segundo protótipo.

Nessa interface, o título da popup, antes posicionado na parte superior da componente, foi inserido na parte de inferior e foi diminuído seu contraste em relação a cor do fundo da popup, como uma forma de diminuir a possibilidade de essas informações atrapalharem a leitura do usuário. Também foi removida a disponibilização do título da página em que o Facilita foi ativado, de acordo com o rationale identificado no levantamento inicial de problemas de usabilidade do protótipo. E, por fim, foi adicionada uma barra de progressos que indica o andamento das operações de processamento textual efetuadas pelo Facilita. 
É importante destacar que ainda não foram efetuados testes de usabilidade com usuários para validação do protótipo. No entanto, avaliações de inspeção e testes de usabilidade foram planejadas para as próximas iterações de design do projeto.

\subsection{Considerações finais}

Este capítulo apresentou um conjunto de requisitos sobre as questões de projeto da interação e o desenvolvimento de uma tecnologia assistiva, destinada a usuários com dificuldade de leitura (analfabetos funcionais) de conteúdos textuais em português que são disponibilizados em sites e aplicações web.

Foi descrita a geração automática de conteúdo acessível por meio de operações de adaptação textual (Sumarização Automática e Simplificação Textual), juntamente com abordagens no design de interfaces para usuários com baixos níveis de alfabetização, que, muitas vezes, possuem também pouca experiência e habilidade na utilização de computadores.

Conforme destacado anteriormente, ainda não foram realizadas iterações de design que objetivassem a validação do protótipo com usuários reais da aplicação. Dessa forma, como trabalhos futuros, devem ser conduzidas avaliações de inspeção e testes de usabilidade para validar a interface desenvolvida.

O próximo capítulo descreve os recursos de processamento de língua natural utilizados para o desenvolvimento do Facilita Educacional, juntamente com os requisitos tecnológicos da aplicação desenvolvida. 



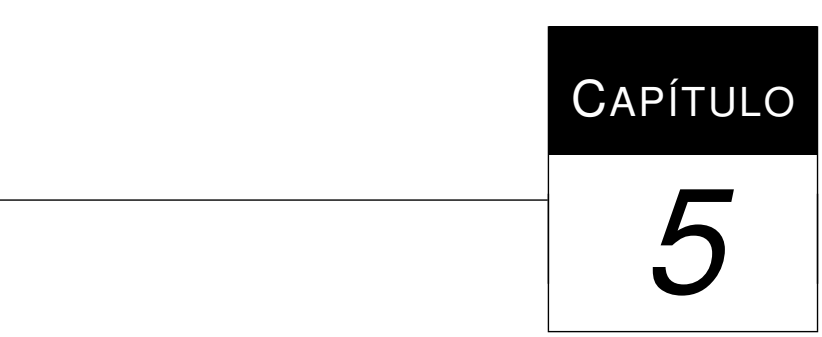

Facilita Educacional

$\mathrm{E}$

ste capítulo apresenta os recursos e o design do Facilita Educacional. O Facilita Educacional é uma aplicação que utiliza as operações de elaboração léxica e reconhecimento das entidades nomeadas para estabelecer mecanismos de auxílio à leitura em páginas web.

O trabalho descrito neste capítulo foi reportado na forma de um artigo científico publicado no W4A 2010 - 7th Cross-Disciplinary Conference on Web Accessibility. O trabalho é intitulado Adapting web content for low-literacy readers by using lexical elaboration and named entities labeling (Watanabe et al., 2010a) e foi apresentado no W4A 2010 - International Cross-Disciplinary Conference on Web Accessibility que foi realizado em Raleigh - Carolina do Norte - Estados Unidos.

\subsection{Considerações iniciais}

O modelo de acessibilidade proposto pela WAI (Web Accessibility Initiative), em seu documento de diretrizes de acessibilidade (WCAG 2.0), estabelece a necessidade de apresentação de mecanismos que auxiliem os usuários a compreender o significado de palavras incomuns ou de contexto específico que possam ser apresentadas nos websites (W3C, 2008c). O Facilita Educacional, nesse contexto, automaticamente adapta o conteúdo dos websites, de forma que sejam disponibilizados mecanismos que forneçam sinônimos ou definições curtas para palavras ou expressões que sejam consideradas incomuns ou difíceis de serem compreendidas pelos usuários. O Facilita Educacional também apresenta informações adicionais ou complementares a respeito das entidades nomeadas disponíveis no conteúdo textual da aplicação web. A Figura 5.1 ilustra a forma como a qual é realizado o auxílio a leitura. O Facilita Educacional (Educational Facilita) 
atua como uma interface entre o usuário (Users na figura) e as aplicações disponíveis na Web (Web pages). O Facilita Educacional recebe como entrada uma página web e disponibiliza ao usuário uma página com o mesmo conteúdo da página passada como entrada, no entanto são adicionados mecanismos de auxílio à leitura.

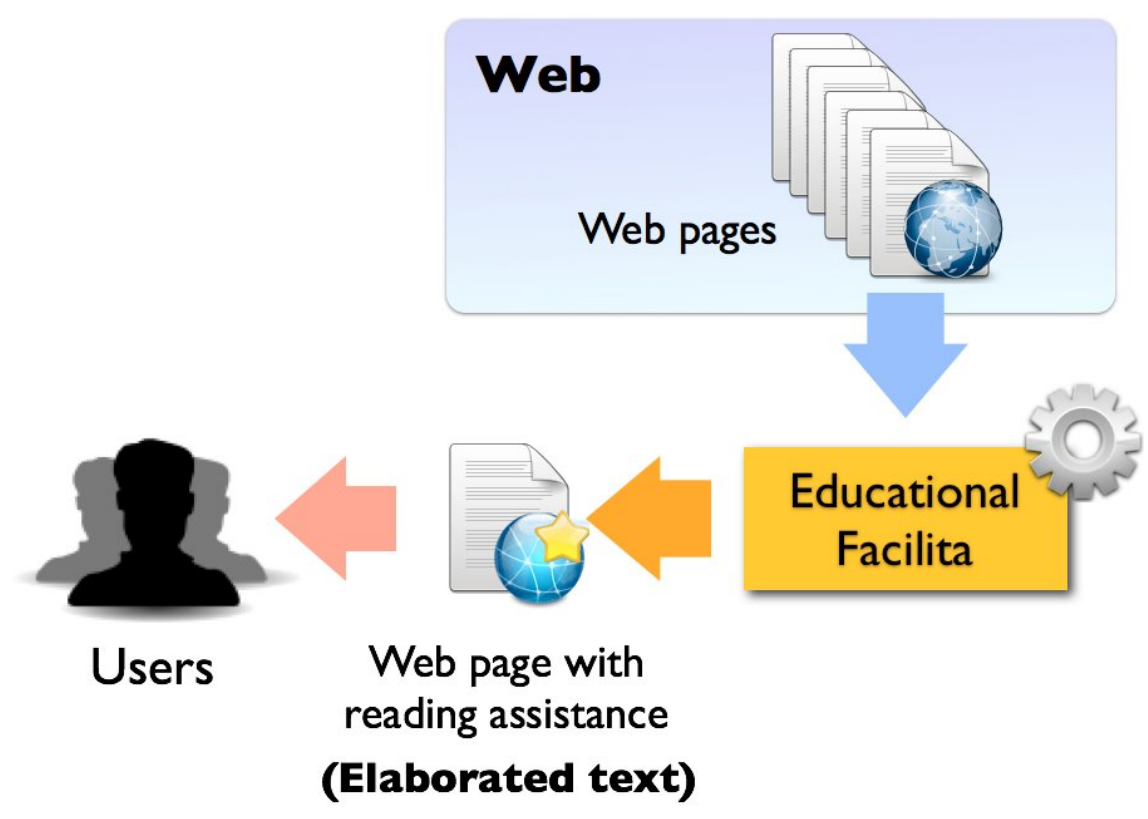

Figura 5.1: Esquema geral de funcionamento do Facilita Educacional (Watanabe et al., 2010a)

É esperado que as informações adicionais apresentadas pelos mecanismos auxiliem os usuários a compreender melhor o conteúdo textual disponível no website e facilitem o aprendizado do significado de palavras/expressões incomuns ou novas.

Para apresentar esse mecanismo de auxílio a leitura, o Facilita Educacional utiliza as seguintes técnicas de processamento de língua natural: Elaboração Léxica (Seção 5.2.1), e Reconhecimento das Entidades Nomeadas e Pós-Classificação (Seção 5.2.2).

Considerando os usuários finais esperados para o Facilita Educacional (indivíduos alfabetizados de níveis rudimentar e básico), também torna-se necessário considerar as limitações de interação apresentadas por usuários com baixo nível de alfabetização. Portanto é importante implementar interações que sejam simples e fáceis de serem realizadas, que sejam adequadas ao seu nível de familiaridade e habilidade com o ambiente computacional.

O Facilita Educacional foi implementado em plataforma web e, para seu funcionamento, são necessários os seguintes recursos: (a) instalação do navegador Firefox $3.5^{1}$, e (b) instalação do ambiente de extensões Mozilla Jetpack ${ }^{2}$.

Nesse contexto, vale destacar que também foram realizados o desenvolvimento e a integração de diferentes tecnologias web utilizadas, com o intuito de manter as interações com a aplicação o

\footnotetext{
${ }^{1}$ http://br.mozdev.org/

${ }^{2}$ https://jetpack.mozillalabs.com/prototype.html
} 
mais simples e naturais possível. Como um resultado, o Facilita Educacional é capaz de automaticamente identificar o conteúdo textual disponível em uma página web, e inserir os mecanismos de auxílio a leitura na própria página que originou a requisição de auxílio, sem alterar o seu design ou funcionalidade.

Nas seções seguintes, são descritos os módulos de processamento de língua natural (Seção 5.2), as características de design desenvolvidas na aplicação (Seção 5.3) e os detalhes de implementação (Seção 5.4), incluindo a arquitetura e os requisitos tecnológicos da aplicação.

\subsection{Módulos de Processamento de Língua Natural}

\subsubsection{Elaboração léxica}

A primeira etapa da elaboração léxica consiste da classificação sintática/morfológica e marcação das palavras que são consideradas complexas ou difíceis. Para classificar as palavras como complexas ou não, são utilizados três dicionários criados para o projeto PorSimples: dicionário com as palavras comuns para jovens; dicionário composto por palavras freqüentes na língua portuguesa; e dicionário com palavras concretas. Se uma palavra não é encontrada em nenhum dos três dicionários mencionados e não é um nome próprio, a aplicação assume que a palavra é uma palavra complexa.

O módulo de elaboração léxica também utiliza o Unitex- $\mathrm{PB}^{3}$ para encontrar o lema das palavras do texto, para poder procurar por essa palavra no dicionário de palavras simples.

Quando utilizando apenas a operação de lematização para encontrar as palavras no dicionário, podem ser estabelecidas ambigüidades entre as palavras. Por exemplo, no Português, a palavra "canto" pode ter seu significado associado ao "canto de um determinado objeto", assim como ao verbo "cantar".

Para lidar com esse tipo de ambigüidade, é utilizado o MXPOST POS tagger (Ratnaparkhi, 1996) treinado com o conjunto de classificações composto pelo NILC ${ }^{4}$, que tem como objetivo automaticamente identificar as classificações sintáticas/morfológicas do texto e resolver as ambigüidades descritas.

Depois da realização do processo de classificação das palavras, as palavras do texto que não são nomes próprios, preposições e numerais, são selecionadas, e a sua classificação é utilizada para procurar por seus lemas nos dicionários de lemas. A classificação não possui um índice de precisão de $100 \%$ e algumas palavras podem não estar no dicionário de lemas. Para esses casos, é utilizado apenas o dicionário de lemas (sem a classificação) quando a combinação de palavra/lema/classificação não está presente no dicionário de lemas. Se, mesmo para esse último caso mencionado, a combinação palavra/lema não seja encontrada no dicionário de lemas, o módulo de elaboração léxica assume a palavra como sendo complexa.

\footnotetext{
${ }^{3}$ http://www.nilc.icmc.usp.br/nilc/projects/unitex-pb/web/dicionarios.html

${ }^{4}$ http://www.nilc.icmc.usp.br/nilc/TagSet/ManualEtiquetagem.htm
} 
O último processo do módulo de elaboração léxica consiste da apresentação de sinônimos mais simples para as palavras classificadas como complexas. Para essas tarefa, são utilizados os thesauruses TeP $2.0^{5}$ e PAPEL ${ }^{6}$ para a língua portuguesa. Conforme a necessidade por apresentação dos sinônimos para as palavras complexas, é realizada uma consulta aos thesauruses por sinônimos que também sejam listados nos dicionários de palavras simples descritos. Caso sejam encontrados sinônimos também classificados como palavras simples (segundo o dicionário de palavras simples), os sinônimos são apresentados em ordem, do sinônimo mais simples para o mais complexo. Para determinar essa ordem, é utilizada a API de buscas do Google, para consultar os sinônimos na Web. Para o projeto, assume-se que as palavras que aparecem mais freqüentemente nas buscas são também as mais simples.

O processo geral de identificação e busca por sinônimos é esquematizado na Figura 5.2.

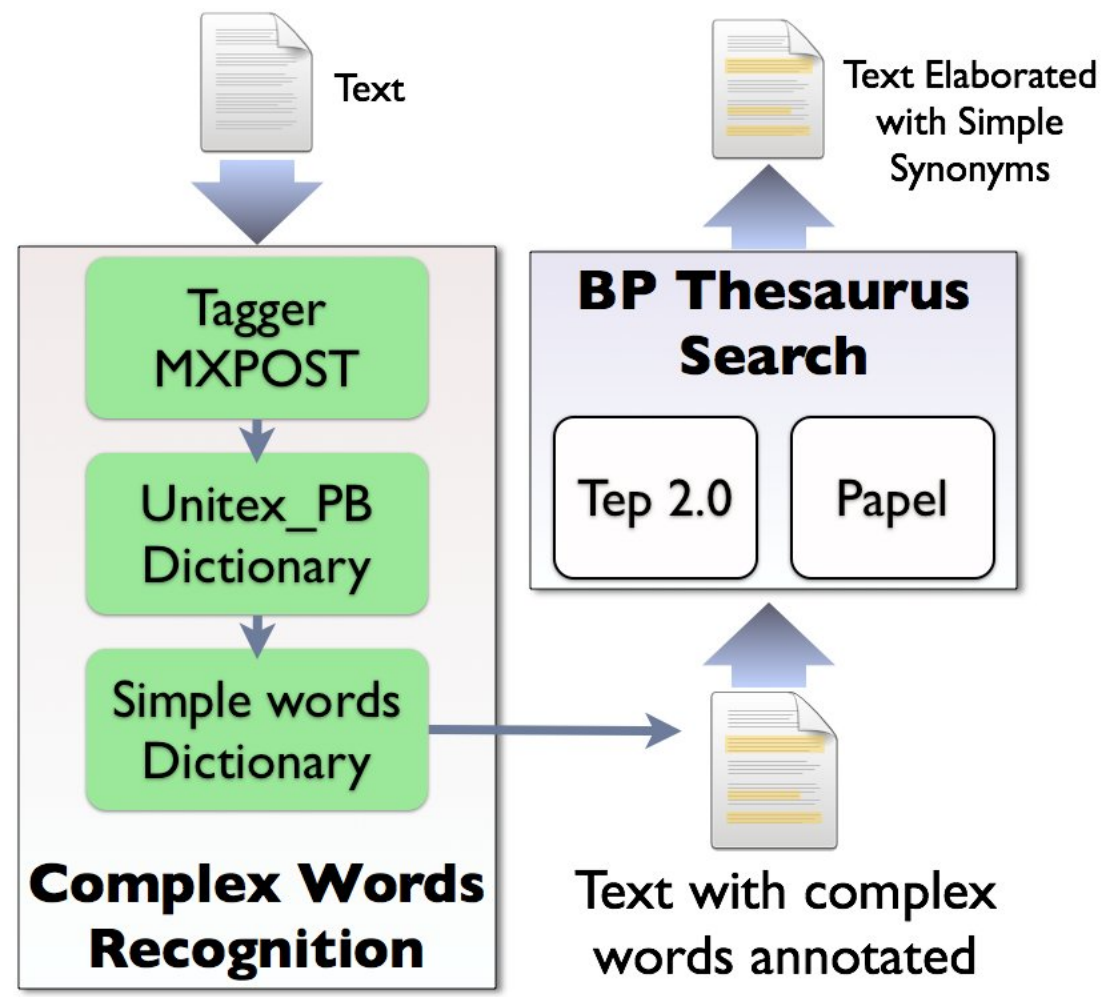

Figura 5.2: Processamento da elaboração léxica (Watanabe et al., 2010a)

\subsubsection{Reconhecimento das entidades nomeadas e pós-classificação}

Considerando estudos educacionais que sugeriram que a adaptação textual poderia ser utilizada para facilitar as atividades de compreensibilidade de leitura e aquisição de vocabulário, no Facilita Educacional, foi adicionado conhecimento disponível em enciclopédias como informações adicionais para determinados textos que possam estar presentes nos textos. Particularmente na aplicação

\footnotetext{
${ }^{5}$ http://www.nilc.icmc.usp.br/tep2/

${ }^{6} \mathrm{http}: / /$ www.linguateca.pt/PAPEL/
} 
desenvolvida, foram utilizadas informações disponíveis na Wikipedia ${ }^{7}$. A Figura 5.3 apresenta a arquitetura geral desse auxílio.

Para o Facilita Educacional, os termos escolhidos para apresentar essas informações adicionais foram as entidades nomeadas. As entidades nomeadas se referem a nomes próprios e sua definição está associada a nomes de pessoas, locais, organizações e outras entidades. A atividade estendida do reconhecimento das entidades nomeadas também inclui frases numéricas, como datas, tempo, quantidades monetárias, e percentuais.

Como entidades nomeadas podem ser destacados nomes de pessoas, localidade e organizações: "João de Almeida", "Rio de Janeiro" e "Petrobrás", por exemplo. A atividade de reconhecimento das entidades nomeadas corresponde à identificação automática desses termos nas frases. A sentença descrita abaixo apresenta um exemplo de uma sentença com as entidades nomeadas identificadas:

$<\mathrm{NE}$ class="PersonName" $>$ Alberto Santos Dumont $</ \mathrm{NE}>$ foi um inventor brasileiro.

Em avaliações de sistemas de reconhecimento de entidades nomeadas para o Português, conduzidos pela Linguateca ${ }^{8}$, um dos sistemas que obteve os melhores resultados foi o Rembrandt (Cardoso, 2008), alcançando um índice de acertos de aproximadamente 57\%. O Rembrandt classifica as entidades nomeadas em 9 classes gerais, que são, em seguida, sub-categorizadas em outras 47. O Rembrandt utiliza a base de dados da Wikipedia para melhorar a categorização e identificação das entidades nomeadas. Dessa forma, além de classificar as entidades nomeadas, o sistema também recupera as definições básicas desses elementos da Wikipedia. O sistema é livre e de código aberto.

Para esse projeto, foi necessária a adaptação do Rembrandt para os nossos usuários finais. A primeira adaptação realizada no sistema foi a redefinição das classes, para remover as subcategorias complexas e alterar os nomes de classes que possam ser difíceis de ser compreendidos por classes mais comuns. Essas alterações tornam as classificações das entidades nomeadas mais facilmente compreendidas por usuários com baixo nível de alfabetização. Por exemplo, a subcategoria "efeméride" foi renomeada como "evento histórico". Essas decisões foram realizadas com base em consultas realizadas a vários recursos, como o TeP 2.0, Wikipedia e outros dicionários.

Determinadas entidades nomeadas apresentam uma definição na Wikipedia. Para essas entidades, o Facilita Educacional disponibiliza uma pequena definição extraída da Wikipedia. Nesse contexto, durante o projeto, foi verificado se a primeira sentença disponível na página da Wikipedia realmente descrevia a definição da entidade nomeada identificada. Foi realizado um teste estatístico com um grupo de 10 páginas aleatórias selecionadas da DBPedia ${ }^{9}$, que é uma amostra

\footnotetext{
${ }^{7}$ http://pt.wikipedia.org/wiki/Pagina_principal

${ }^{8} \mathrm{http}: / /$ www.linguateca.pt/harem/

${ }^{9}$ http://dbpedia.org/
} 
dos artigos presentes na Wikipedia com 250.000 artigos. Em 9 desses 10 grupos foram extraídas definições para as entidades nomeadas, o que significa um resultado de $95 \%$ de acerto para a hipótese considerada.

\subsection{Características de Design}

Um dos maiores desafios no desenvolvimento de interfaces para usuários com baixo nível de alfabetização está relacionado com a falta de experiência no uso de computadores desses usuários. Assim, todas as decisões de design realizadas no projeto foram realizadas com foco em interações simples, para exigir mínimo esforço dos usuários.

No projeto de design do Facilita Educacional, foram realizadas duas decisões de projeto relacionadas à limitação no uso de computadores apresentada pelos usuários alvo da aplicação:

- Identificação automática do conteúdo textual de uma página web sendo visualizada no navegador.

- Integração dos mecanismos de assistência à leitura com os mecanismos disponibilizados na própria página web em que o recurso foi ativado.

Para implementar essas funcionalidades, o Facilita Educacional utiliza-se dos seguintes módulos de processamento textual:

Módulo readability - as técnicas que realizam o processamento textual requerem o estabelecimento de relacionamentos concretos entre as palavras que pertencem a uma mesma frase. Assim, para que esses métodos de processamento textual possam ser aplicados, torna-se necessário que sejam identificadas as frases presentes no website. Para efetuar essa tarefa, no Facilita Educacional, foi utilizada a ferramenta Readability ${ }^{10}$. Essa ferramenta remove elementos que possam atrapalhar a leitura do conteúdo textual de uma página web, gerando um novo layout de apresentação contendo apenas o texto principal do website. O módulo Readability, nesse contexto, consiste de uma adaptação da ferramenta Readability, para que fosse apenas identificada a parte da página que correspondesse ao texto principal de uma aplicação web, para o qual então fossem aplicadas as operações de processamento textual de elaboração léxica e reconhecimento das entidades nomeadas.

Elaboração léxica - o módulo de elaboração léxica, inicialmente, identifica as palavras complexas contidas no texto de uma página. Para cada uma das palavras identificadas como complexas no texto, o módulo de elaboração léxica apresenta sinônimos ao usuário. Os sinônimos apresentados ao usuário são mais simples e, dessa forma, mais facilmente compreendidos pelos usuários. É importante destacar que os sinônimos não são carregados, juntamente,

\footnotetext{
${ }^{10} \mathrm{http} / / /$ lab.arc90.com/experiments/readability
} 
com a atividade de identificação das palavras complexas no texto. A busca por sinônimos nos thesauruses é realizada apenas dada a requisição dos usuários pela apresentação desse auxílio. Antes disso, as palavras complexas são apenas apresentadas e marcadas para visualização do usuário.

Reconhecimento das entidades nomeadas - esse módulo é responsável por identificar e apresentar informações adicionais e complementares a respeito das entidades nomeadas do texto. Para realizar essa tarefa, é utilizada a aplicação Rembrandt, que identifica as entidades e também indica o link referente a essa entidade na Wikipedia. O método de identificação das entidades nomeadas, utilizado no projeto, também classifica as entidades. Essa classificação pode ser utilizada para estender a funcionalidade do Facilita Educacional para procurar por referências das entidades em outros recursos disponíveis na Web. Por exemplo, se o Facilita Educacional identifica a entidade nomeada "Nova York" e a classifica como sendo da classe "Localização", o sistema poderia procurar por uma referência a respeito da entidade em uma aplicação web de localização geográfica, como o Google Maps ${ }^{11}$. Ao resultado dessa busca, poderia ser também adicionada a apresentação da localização da entidade nomeada "Nova York" em um mapa da própria aplicação web do Google Maps. Essa possibilidade de extensão das funcionalidades do Facilita Educacional é ilustrada na Figura 5.3. É importante destacar que, embora o Facilita Educacional possa ser integrado com outros recursos web para auxiliar a leitura dos usuários, até o momento, foi implementada somente a integração da aplicação com a Wikipedia para apresentar uma definição curta e uma imagem para as entidades nomeadas.

Os três módulos são integrados conforme ilustrado na Figura 5.4. Inicialmente, é executado o módulo de readability para identificar o texto principal da página web que ativou o recurso do Facilita Educacional. Em seguida, são executados, paralelamente, os módulos de elaboração léxica e reconhecimento das entidades nomeadas, tendo como entrada o texto principal identificado pelo módulo readability. Os resultados das operações de elaboração léxica e reconhecimento das entidades nomeadas são integrados em um único código HTML. Por fim, esse código HTML é inserido na página web que ativou a assistência de leitura do Facilita Educacional.

É importante destacar que o Facilita Educacional foi implementado, inicialmente, apenas para o Português Brasileiro, uma vez que as aplicações e módulos utilizados para integrar a solução foram implementados para essa língua. No entanto, portar essa solução para outras línguas requer apenas a substituição dos módulos de processamento de língua natural (Seções 5.2.1 e 5.2.2) por outros módulos com a mesma funcionalidade para outras línguas, preservando a mesma arquitetura da solução.

É possível que as páginas que tenham ativado o recurso de auxílio à leitura já implementem algum mecanismo de acessibilidade que tenha uma funcionalidade semelhante à disponibilizada

\footnotetext{
${ }^{11}$ http://maps.google.com
} 


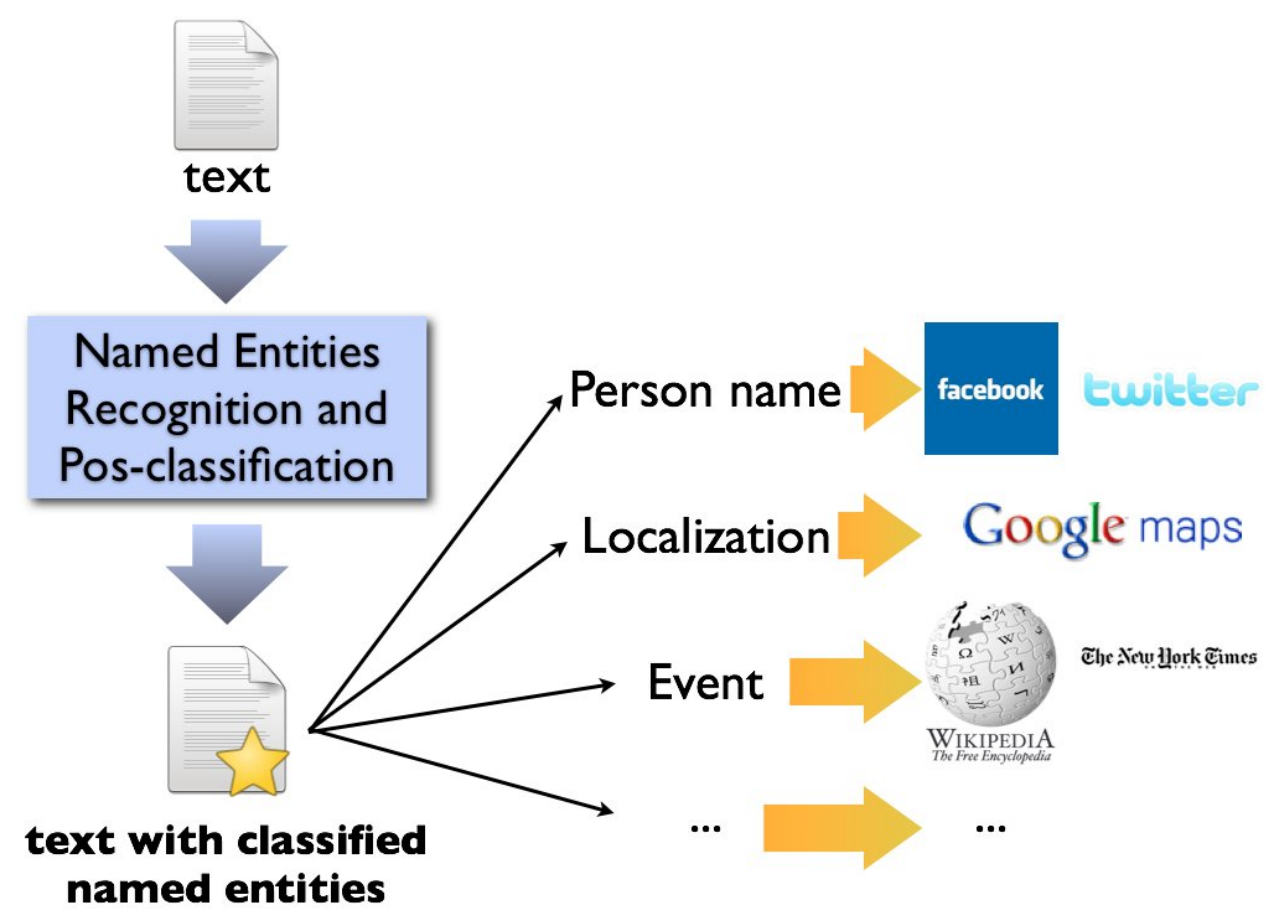

Figura 5.3: Processamento do reconhecimento das entidades nomeadas (Watanabe et al., 2010a)

pelo Facilita Educacional. Existe também a possibilidade que as páginas utilizem outras características de design para resolver outros requisitos de acessibilidade. Para interferir o mínimo possível com os recursos de acessibilidade já disponíveis na página, o Facilita Educacional realiza a integração dos mecanismos resultados do processamento textual com as tecnologias da página web que ativou o recurso de auxílio à leitura, seguindo uma abordagem que altera minimamente as funcionalidades e layout da página.

Essa abordagem de alterar minimamente as funcionalidades e layout da página web que ativou o recurso de auxílio à leitura é realizada por meio da adaptação apenas das partes da página web que foram apontadas pelas técnicas de processamento textual. Ou seja, apenas determinadas partes da página são modificadas, sem alterar a estrutura geral da página, atuando somente no nível dos nós folha (nós textuais) da árvore DOM (Document Object Model).

É importante destacar, portanto, que a abordagem não altera ou substitui mecanismos já inseridos na página. Caso o Facilita Educacional identifique algum tipo de mecanismo ou funcionalidade já implementada para um elemento (como um link ou uma âncora), o Facilita Educacional não modifica esse elemento, mesmo que o elemento seja também uma entidade nomeada ou um termo classificado como complexo pelo processo de elaboração léxica. No projeto, esse comportamento foi implementado, uma vez que os mecanismos de acessibilidade gerados pelo autor do conteúdo ou da página web, freqüentemente, são mais precisos e específicos que os mecanismos gerados automaticamente. 


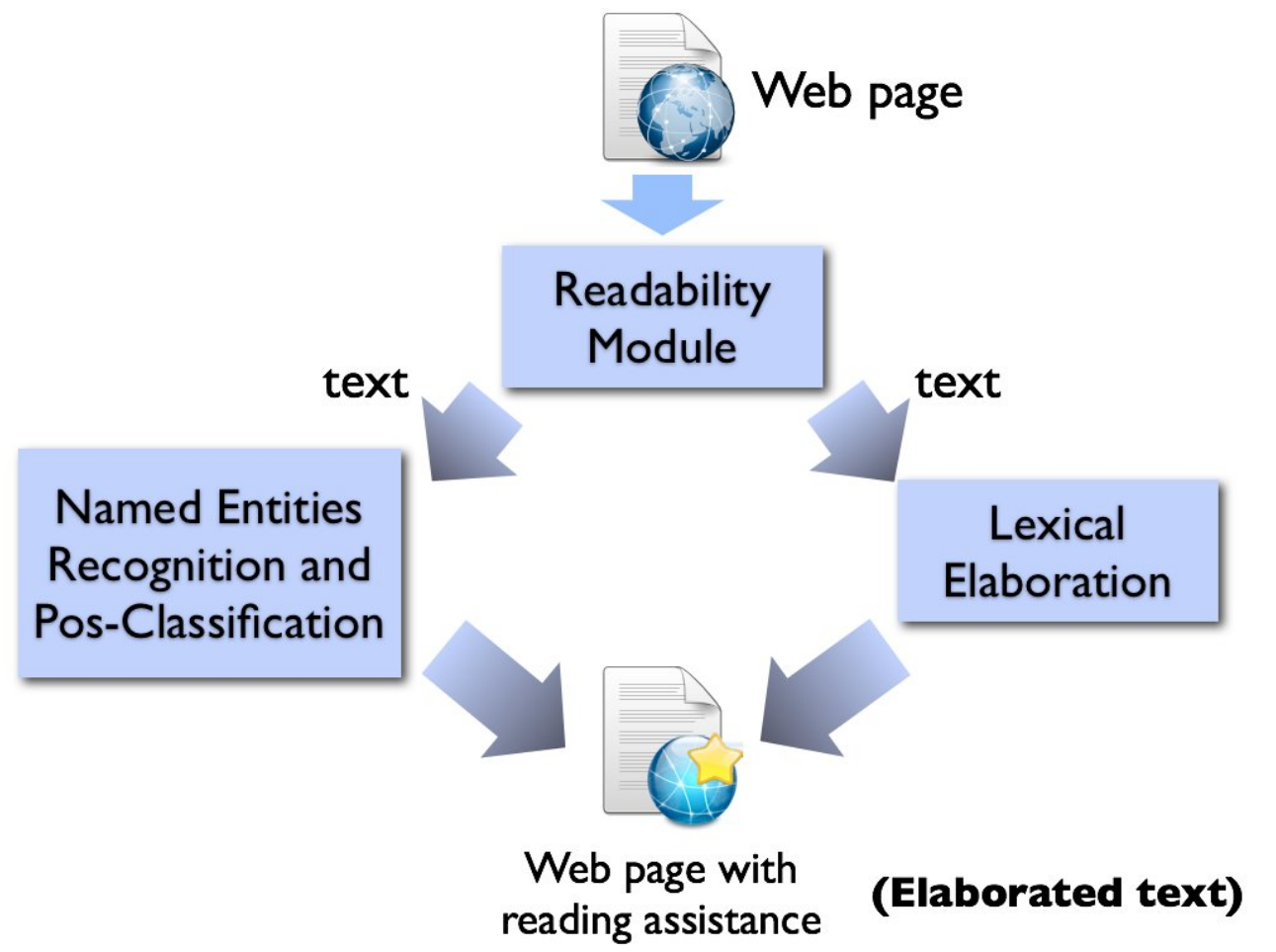

Figura 5.4: Integração entre os módulos do Facilita Educacional (Watanabe et al., 2010a)

\subsection{Implementação Web}

O desenvolvimento das características de design do Facilita Educacional tem como requisitos determinados recursos que não estão disponíveis nas tecnologias web comuns. Alguns exemplos dessas limitações dos recursos das tecnologias web incluem:

- Política de mesma origem: a política de mesma origem (same-policy origin) é uma restrição de segurança imposta a scripts executados no lado cliente da aplicação web (como o Javascript). Essa política restringe o uso de requisições remotas HTTP (HyperText Transport Protocol) que sejam direcionadas a domínios diferentes do domínio que originou a interação da aplicação web. Isso significa que, utilizando Javascript, o Facilita Educacional não poderia, diretamente, realizar requisições por dados da Wikipedia, em páginas que não pertençam ao mesmo domínio da Wikipedia.

- Proxy HTTP: para adaptar a estrutura e conteúdo de aplicações Web existentes, do ponto de vista de desenvolvimento na plataforma web, uma abordagem a ser considerada é a implementação de um proxy HTTP. O proxy funcionaria como um middleware entre o servidor da aplicação web que se deseja alterar e o navegador. No entanto, para ativar o auxílio a leitura do Facilita Educacional, seria necessário redirecionar a interação com a página web para o proxy, mudando todo o contexto da aplicação web que ativou o Facilita Educacional. Essa abordagem é implementada pela aplicação Google Translate ${ }^{12}$, e pode interferir

\footnotetext{
${ }^{12} \mathrm{http}: / /$ translate.google.com.br
} 
no funcionamento de scripts do lado cliente da aplicação web que foi alterada, devido a incompatibilidades de contexto de execução na linguagem Javascript.

Dessa forma, o Facilita Educacional foi implementado na camada de desenvolvimento do navegador. Foi utilizada a plataforma Mozilla Jetpack ${ }^{13}$ para possibilitar a implementação do Facilita Educacional como uma extensão ao navegador Firefox ${ }^{14}$. Como resultado do uso da plataforma Mozilla Jetpack para o desenvolvimento, também foi possível utilizar outros recursos disponíveis apenas para implementações na camada do navegador. Como exemplos de recursos disponíveis apenas na camada tecnológica do navegador, podem ser citados:

- Não restrição a requisições remotas HTTP;

- Melhor controle sobre os dados persistentes do navegador, permitindo a implementação de estratégias de cache de informações;

- Gerenciamento de componentes de interface do próprio navegador (abas, janelas de notificações, menus).

O uso de rotinas disponíveis na camada de desenvolvimento do navegador também viabiliza com mais facilitadade a integração dos diferentes módulos de processamento textual que são necessários para o Facilita Educacional. Cada um dos módulos (descritos nas Seções 5.2.1 e 5.2.2) foi implementado em um ambiente distinto, de forma que eles não possam ser implementados diretamente em linguagem Javascript ou na plataforma Jetpack. Por exemplo, o módulo de elaboração léxica foi implementado em $\mathrm{PhP}$, enquanto a técnica de identificação das entidades nomeadas do texto são executadas sobre a plataforma Groovy ${ }^{15}$ na linguagem Java. Esses tipos de requisitos motivaram a utilização de web services para integrar os módulos de processamento textual no Facilita Educacional.

Do ponto de vista tecnológico, a arquitetura utilizada para integrar os diferentes módulos e funcionalidades do Facilita Educacional é ilustrada na Figura 5.5. Na Figura 5.5, também são apresentadas as formas com as quais seriam integradas futuras funcionalidades que utilizassem outros recursos web como Facebook ou Google Maps, por exemplo.

\subsection{Protótipo do Facilita Educacional}

O Facilita Educacional foi implementado na plataforma Jetpack, como uma extensão para o navegador Firefox.

O auxílio à leitura é disponibilizado para o usuário pelas seguintes interações:

1. Ativar o link do Facilita Educacional, disponível na barra de status do navegador Firefox. Link ilustrado na Figura 5.6.

\footnotetext{
${ }^{13}$ https://jetpack.mozillalabs.com/

${ }^{14} \mathrm{http} / / /$ br.mozdev.org/

${ }^{15}$ http://groovy.codehaus.org/
} 


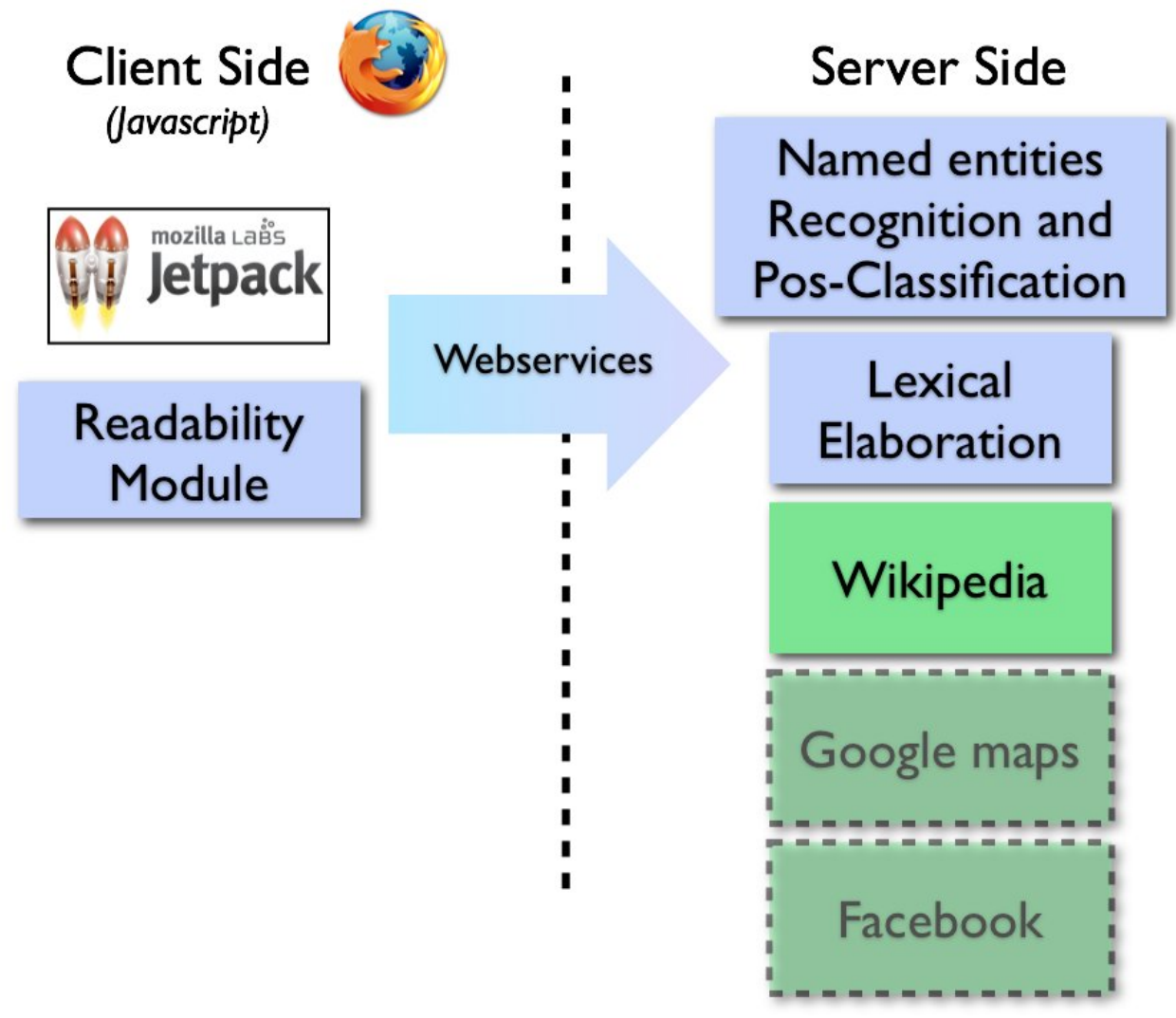

Figura 5.5: Arquitetura de integração dos módulos e funcionalidades do Facilita (Watanabe et al., 2010a)

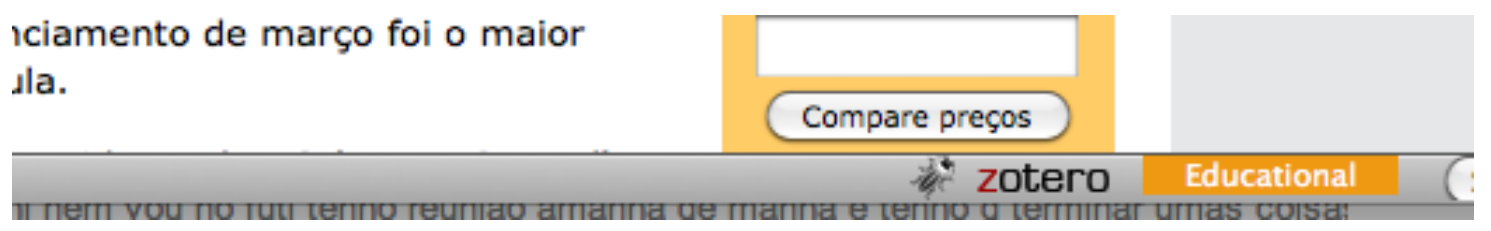

Figura 5.6: Screenshot do link do Facilita Educacional.

2. Navegar pelas entidades textuais destacadas na aplicação. As entidades textuais destacadas representam palavras complexas ou entidades nomeadas identificadas no texto. As entidades destacadas são ilustradas na Figura 5.7.

3. Clicar nas entidades destacadas para apresentar os sinônimos das palavras complexas (Figura 5.8) e informações adicionais a respeito da entidade nomeada (Figura 5.9).

Depois de ativar o Facilita Educacional, o navegador apresenta uma mensagem de carregamento das operações de processamento textual. É importante destacar que as operações de processamento textual utilizadas no Facilita Educacional requerem uma determinada quantidade de tempo para serem finalizadas, especialmente aquelas que são executadas no lado servidor da aplicação. Enquanto a mensagem de carregamento é apresentada, o usuário pode alternar entre <abas $>$ ou janelas no navegador, e continuar interagindo com outras aplicações web. 


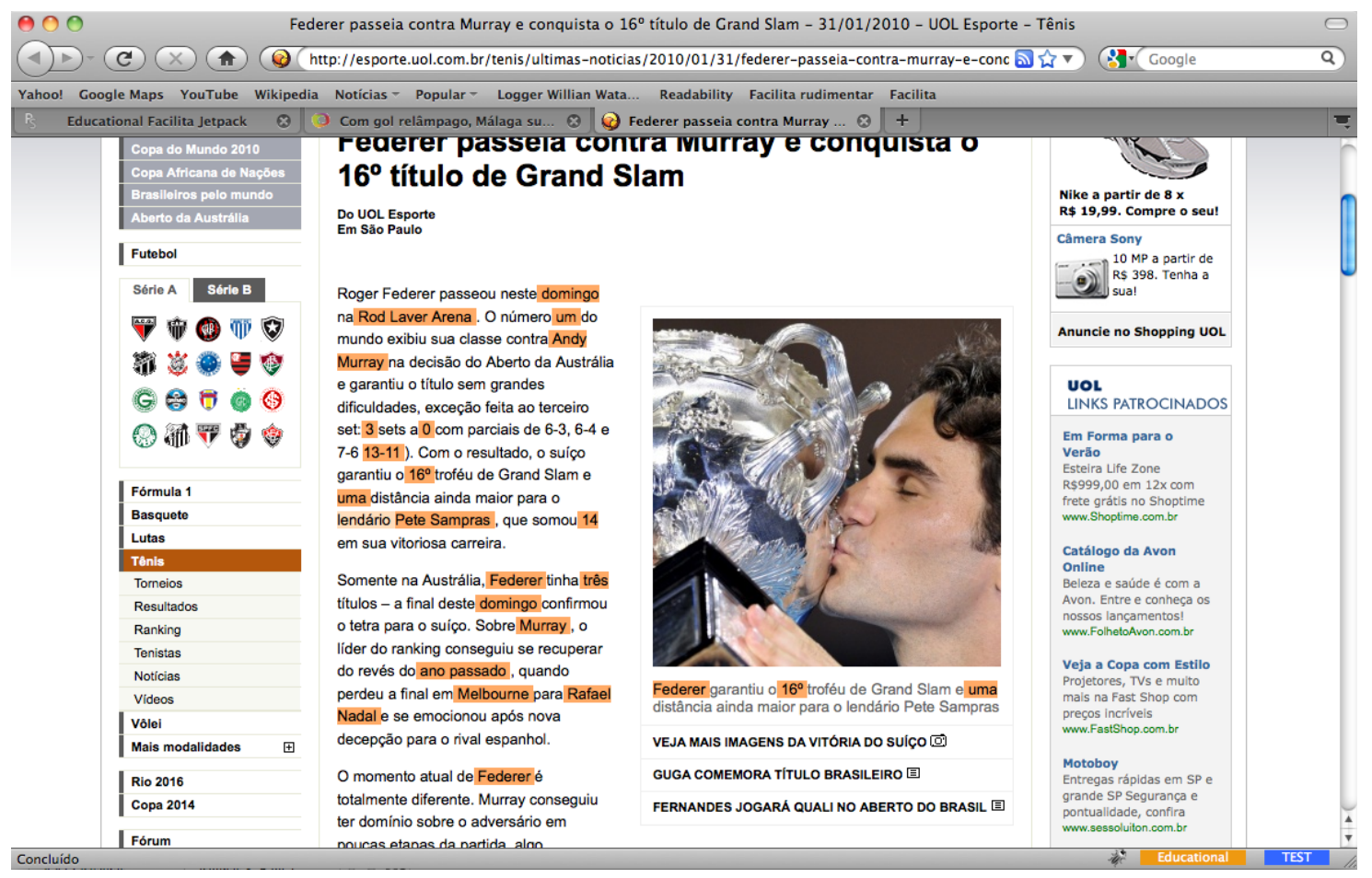

Figura 5.7: Screenshot apresentando as entidades destacadas no Facilita Educacional.

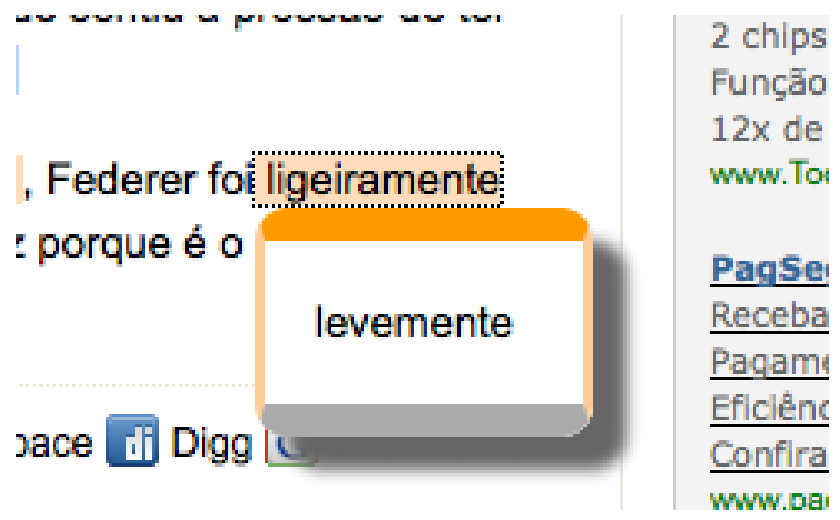

Figura 5.8: Screenshot da apresentação dos sinônimos para as palavras complexas destacadas no texto.

Ao final do processamento das operações textuais, é apresentada uma notificação no canto direito superior da tela e a $<$ aba $>$ do navegador que ativou o Facilita Educacional muda de cor. Ambas alterações nos componentes de interface descritas são apenas disponíveis com o desenvolvimento no nível de navegadores (browser).

Por fim, é apresentada a mesma página web que ativou a assistência de leitura, mas contendo então as palavras complexas e entidades nomeadas destacadas com uma cor diferente. 


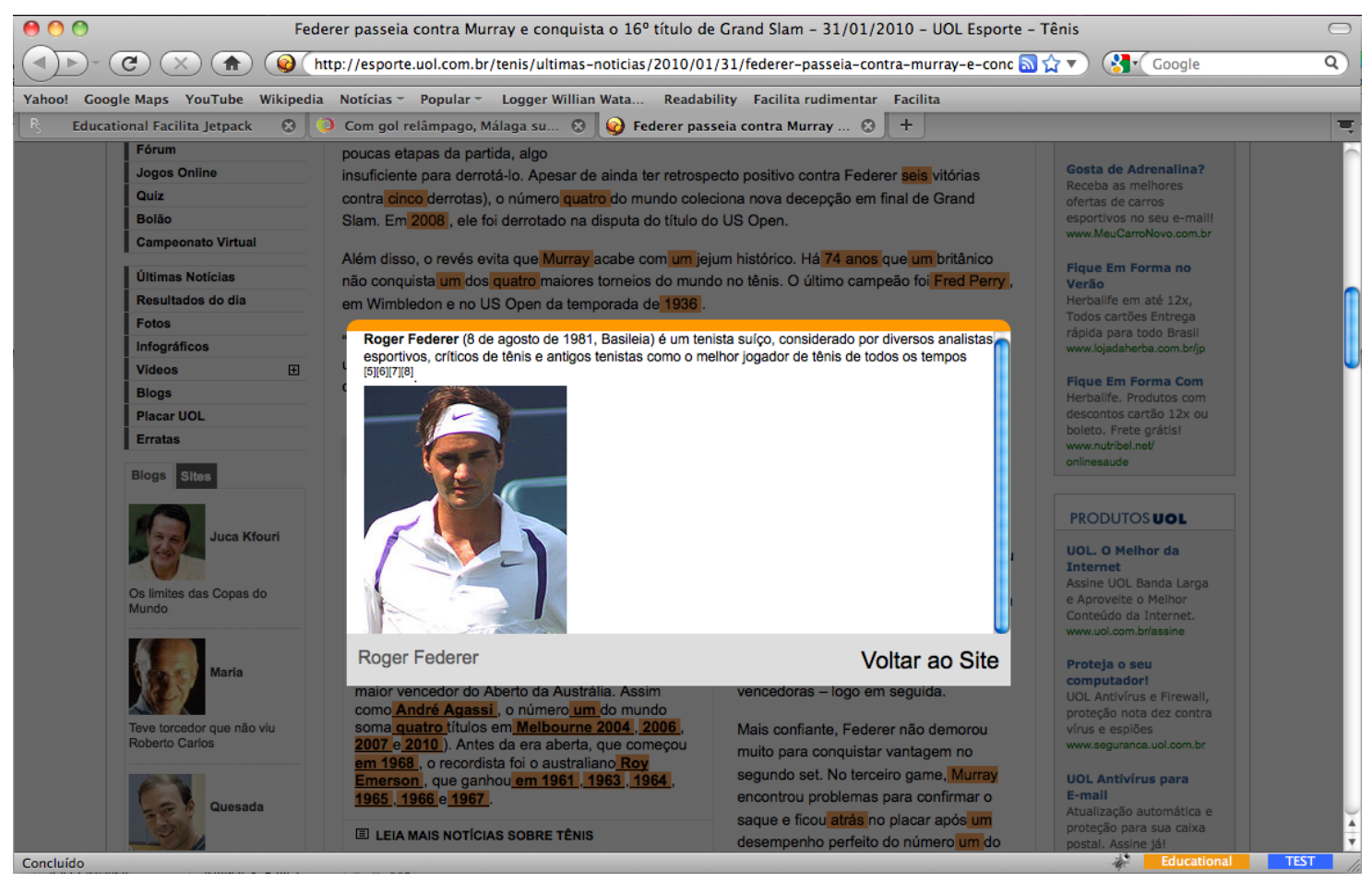

Figura 5.9: Screenshot da apresentação das informações adicionais a respeito da entidade nomeada destacada no texto.

\subsection{Considerações finais}

O Facilita Educacional adapta automaticamente os conteúdos de páginas web quaisquer para entrar em conformidade com o critério de sucesso 3.1.3 da WCAG 2.0. Adicionalmente, a aplicação pode também ser utilizada para propósitos educacionais, auxiliando o usuário a compreender o significado de palavras complexas ou incomuns, e aprender o significado de determinadas entidades nomeadas apresentadas nos textos de websites.

O Facilita Educacional ainda não foi avaliado formalmente. Deverão ser efetuadas avaliações e testes de usabilidade sobre a aplicação desenvolvida com crianças e adultos em processo de alfabetização. Também serão realizados estudos para analisar a inteligibilidade e compreensão dos textos pelos usuários.

Uma das questões que precisam ser resolvidas no projeto está relacionada aos usuários foco do projeto. Usuários com baixo nível de alfabetização requerem soluções inovadoras e design intuitivo para possibilitar a interação. A avaliação de usabilidade prevista no projeto deve estabelecer critérios para testar e verificar a efetividade do design desenvolvido para a aplicação.

O Facilita Educacional foi desenvolvido no contexto do projeto PorSimples e, dessa forma, pode se utilizar de outros módulos também desenvolvidos no projeto, como por exemplo: a sumarização ou a simplificação sintática descritas nas seções anteriores.

Como trabalhos futuros, devem ser desenvolvidas estratégias para melhorar o desempenho dos módulos de processamento textual. Os módulos e técnicas requerem um longo intervalo de tempo 
para completar suas tarefas. Esse intervalo de tempo pode vir a afetar a interação do usuário com a aplicação.

Também devem ser explorados os aspectos semânticos do módulo de reconhecimento de entidades nomeadas utilizado no Facilita Educacional. A identificação da classe da entidade nomeada reconhecida pode ser utilizada para apresentar diferentes informações relevantes ao usuário. Essas informações podem ser obtidas a partir de outros recursos disponíveis na web. Como por exemplo: caso seja identificada a entidade nomeada "São Paulo" da classe localização, pode ser apresentado um mapa gerado na API do Google Maps como forma de auxílio à compreensão do usuário sobre a entidade nomeada.

O próximo capítulo apresenta trabalhos futuros e considerações finais a respeito das propostas desenvolvidas nas duas aplicações: Facilita e Facilita Educacional. 


\section{CAPÍTULO}

\section{6}

\section{Conclusões e Trabalhos Futuros}

A Web foi desenvolvida com o intuito de armazenar dados e informações de maneira que ficasse disponível para todas as plataformas e sistemas. Para permitir que esse conteúdo armazenado pudesse ser acessado por qualquer software ou hardware sendo utilizados pelos usuários, foram criados o HTML - HyperText Markup Language e o HTTP - HyperText Transport Protocol como uma forma de transmitir arquivos de texto, representando informações, através de diferentes plataformas e sistemas operacionais conectados à rede.

Atualmente, o desenvolvimento da Web apresenta diferentes desafios que estendem a idéia inicial de independência de plataforma e interoperabilidade atingidos com HTML e HTTP. Esses desafios muitas vezes correspondem a barreiras de acessibilidade aos usuários e consideram as habilidades, cultura, idioma, linguagem, necessidades especiais, entre outras características relacionadas ao usuário como um ser humano, em contraste com os requisitos de software e hardware anteriormente retratados. A característica humana do desafio pode ser vista como a última barreira dos requisitos iniciais da Web de independência de plataforma e interoperabilidade, e tem como objetivo a inclusão social das pessoas na Web independentemente das diferenças que possam ser apresentadas.

A presente pesquisa de mestrado teve como principal objetivo investigar mecanismos para auxiliar a utilização de técnicas de processamento de língua natural para melhorar a acessibilidade de conteúdos web para usuários com baixo nível de alfabetização.

No Capítulo 2, foi apresentado o modelo da WAI - Web Accessibility Initiative para acessibilidade na Web. Esse modelo é constituído de três conjuntos de diretrizes destinadas a diferentes componentes da Web: WCAG - Web Content Accessibility Guidelines, para os desenvolvedores de aplicações web; ATAG - Authoring Tools Accessibility Guidelines, para desenvolvedores de ferra- 
mentas de autoria de conteúdo web; e UAAG - User Agents Accessibility Guidelines. O modelo estabelece uma forma de garantia de acessibilidade com base no nível de conformidade apresentado pelos três componentes (conteúdo, ferramentas de autoria e agentes de usuário) descritos com seus respectivos conjuntos de diretrizes de acessibilidade.

No Capítulo 3, foi descrito o procedimento de revisão sistemática realizado durante este projeto de mestrado. A revisão foi realizada no intuito de identificar requisitos de desenvolvimento de aplicações para o público alvo do projeto (usuários com baixo nível de alfabetização). Como resultados da revisão, foram identificados princípios de design que guiam o desenvolvimento de interfaces para usuários com baixo nível de alfabetização.

Durante o projeto foi proposta a utilização das técnicas de processamento de língua natural na camada de desenvolvimento de navegadores, para disponibilizar os incrementos de acessibilidade a uma ampla variedade de websites já disponíveis na Web, sem a necessidade de alterações ou melhorias em seus códigos. As técnicas de processamento textual também foram utilizadas como uma forma de adaptar automaticamente os websites aos critérios de acessibilidade apresentados no modelo de acessibilidade da WAI (Web Accessibility Initiative). Como resultados deste trabalho, foram desenvolvidas duas aplicações: o Facilita ${ }^{1}$ (Capítulo 4), que explora o uso de técnicas de simplificação sintática e sumarização automática; e o Facilita Educacional ${ }^{2}$ (Capítulo 5), que utiliza técnicas de elaboração léxica e reconhecimento das entidades nomeadas.

Durante o desenvolvimento do mestrado, os resultados foram reportados nos seguintes trabalhos:

1. Artigo publicado no SEMISH 2009 - 36th Seminar on Software and Hardware: Revisão Sistemática sobre princípios de design de aplicações web acessíveis para analfabetos funcionais. O aluno também apresentou este trabalho no Congresso da Sociedade Brasileira de Computação 2009, que foi realizado em Bento Gonçalves - RS - Brasil (Watanabe e Fortes, 2009).

2. Artigo publicado no Webmedia 2009: Facilita: auxílio à leitura de textos disponíveis na Web (Watanabe et al., 2009b).

3. Artigo publicado no SIGDOC 2009: Facilita: reading assistance for low-literacy readers (Watanabe et al., 2009a). O aluno apresentou este trabalho no SIGDOC 2009 - 27th International Conference on Design of Communication, que foi realizado em Bloomington Indiana - Estados Unidos.

4. Artigo submetido para o CLEI 2010 - Conferência Latino-americana de Informática: “Ajax Design Patters for Usability in Web applications: a Case Study" (Watanabe et al., 2010c).

\footnotetext{
${ }^{1}$ http://vinho.intermidia.icmc.usp.br:3001

${ }^{2} \mathrm{http}: / /$ vinho.intermidia.icmc.usp.br/watinha/Educational-Facilita
} 
5. Artigo publicado no W4A 2010: Adapting web content for low-literacy readers by using lexical elaboration and named entities labeling (Watanabe et al., 2010a). O aluno apresentou este trabalho no W4A 2010 - International Cross-Disciplinary Conference on Web Accessibility, que foi realizado em Raleigh - Carolina do Norte - Estados Unidos.

6. Artigo submetido ao Webmedia 2010: Improving WCAG Conformance: Browser Strategies (Watanabe et al., 2010b).

\subsection{Contribuições}

Este trabalho de mestrado apresentou as seguintes contribuições para o tópico de acessibilidade na web:

- Identificação de requisitos de acessibilidade para usuário com baixo nível de alfabetização: durante o programa de mestrado, o aluno realizou uma ampla revisão bibliográfica para identificar requisitos e princípios de design de desenvolvimento de interfaces para usuários com baixo nível de alfabetização. Detalhes a respeito dessa contribuição foram descritos nos Capítulos 2 e 3.

- Modelo de acessibilidade para automatizar a conformidade com a WCAG: foi definido um modelo de acessibilidade por meio da adaptação automática de conteúdos disponíveis em aplicações web para garantir a acessibilidade web por usuários com baixo nível de alfabetização. Conforme destacado nos Capítulos 4 e 5, o modelo de acessibilidade da WAI não garante a acessibilidade para todos os contextos de utilização da web. Dessa forma, torna-se necessário o desenvolvimento de mecanismos de acessibilidade que assegurem a disponibilização de informações textuais de conteúdos na web, de forma acessível para os usuários, independentemente do contexto em que as aplicações web estejam sendo utilizadas. No trabalho de mestrado, foram desenvolvidas duas aplicações web considerando esses requisitos de acessibilidade: o Facilita (descrito em detalhes no Capítulo 4) e o Facilita Educacional (descrito no Capítulo 5).

- Desenvolvimento de soluções de acessibilidade na camada de agentes de usuário (navegador web): conforme reportado no trabalho (Watanabe et al., 2010b), mecanismos de adaptação automática de conteúdo podem ser implementados nas camadas de conteúdo web ou de agentes de usuário (navegadores). O desenvolvimento desses mecanismos na camada de agentes de usuário apresenta uma maior disponibilidade do recurso de adaptação automática, de forma que a aplicação do recurso pode ser efetuada em qualquer aplicação na Web, sem a necessidade de alterações ou melhorias no seu código. A estratégia de desenvolvimento desses mecanismos na camada de agente de usuário também garante um maior grau de compatibilidade com tecnologias de manipulação dinâmica de conteúdos de páginas web, como o AJAX, viabilizando o uso dos recursos para um maior número de aplicações web. 


\subsection{Limitações das Aplicações Desenvolvidas}

No desenvolvimento do Facilita e Facilita Educacional, foram identificadas as seguintes limitações considerando as tecnologias utilizadas:

- Tempo de processamento textual: tanto o Facilita quanto o Facilita Educacional utilizam recursos de processamento textual para automaticamente adaptar textos disponíveis em aplicações web. Em ambas as aplicações é realizado o parseamento sintático dos elementos contidos no textos das aplicações web. Essa etapa do processamento consome um tempo demasiado longo, de forma que torna-se inviável a sua aplicação em ambientes reais para experimentos. Essa demora de processamento exigiu a simulação do processamento durante os testes efetuados com as aplicações.

- Ambigüidades no resultado do processamento textual: considerando especificamente o Facilita Educacional, determinadas entidades nomeadas e palavras complexas podem apresentar um significado ambíguo, de forma que as funcionalidades de processamento textual podem oferecer informações que não auxiliem efetivamente a compreensão do usuário, podendo até atrapalha-la. Um exemplo pode ser observado na entidade nomeada "Roland Garros" que pode estar se referindo a uma pessoa francesa pioneira da aviação ou ao torneio do esporte tênis também conhecido aberto da França. O Facilita Educacional identifica essa entidade nomeada seguindo a primeira opção apresentada, e dessa forma caso o texto fizesse referência ao torneio de tênis, o usuário poderia ser confundido pelas informações adicionais oferecidas pela aplicação.

- Utilização de recursos Javascript: o Facilita e o Facilita Educacional foram desenvolvidos na camada de agentes de usuário utilizando a linguagem Javascript. No entanto, aplicações web que utilizam Javascript apresentam barreiras de acessibilidade para usuários que utilizem agentes do usuário incompatíveis com os recursos e funcionalidades sendo desenvolvidos. Com isso, o Facilita e o Facilita Educacional devem ser inacessíveis para determinados usuários. No entanto, vale destacar que os recursos Javascript foram utilizados com o objetivo de fornecer uma interação simplificada para os usuários foco do trabalho (usuários com baixo nível de alfabetização), considerando o fato de que esses usuários também são muitas vezes classificados como analfabetos computacionais.

\subsection{Trabalhos Futuros}

Como trabalhos futuros identificados a partir do projeto desenvolvido, podem ser destacados:

- Avaliação e testes de usabilidade: avaliação da real efetividade das aplicações desenvolvidas como resultado do projeto. O design de interface do Facilita e do Facilita Educacional 
foi realizado considerando requisitos extraídos do processo de revisão sistemática (Watanabe e Fortes, 2009). Seria de grande valia para o projeto o efetivo teste das características de design utilizadas nas aplicações, para analisar como usuários com baixo nível de alfabetização interagem com a Web. As avaliações podem ser conduzidas de forma quantitativa (de acordo com métricas e avaliações de inteligibilidade e compreensão de informações textuais) e qualitativa, considerando o uso de protocolos como o think aloud (Brajnik, 2008; Romen e Svanaes, 2008).

- Avaliação de inteligibilidade em larga escala de portais web: durante o desenvolvimento do Facilita Educacional, foi utilizada a ferramenta Readability. Essa ferramenta automaticamente identifica a parte da página que contém a informação textual principal da página. Essa ferramenta poderia automatizar o processo de extração de textos de páginas e portais web. Dessa forma, poderiam ser realizados estudos em larga escala, quantitativos com métricas de inteligibilidade. A WCAG estabelece critérios e métricas que deveriam ser utilizadas para definir a simplicidade do conteúdo textual disponibilizado em uma página web. Poderia ser realizada uma avaliação de como determinados portais web disponibilizam seu conteúdo textual de acordo com essas métricas e obter um resultado estatisticamente relevante, considerando o alto número de textos a ser extraído por essa abordagem. Adicionalmente, poderiam ser testadas as diferenças entre resultados de diferentes métricas de inteligilidade.

- Integração de novos recursos informacionais ao Facilita Educacional: o Facilita Educacional realiza a classificação semântica de determinados elementos de um texto. Conforme descrito em (Watanabe et al., 2010a), essa classificação semântica pode ser utilizada como um indicador de buscas especializadas para determinados termos. Por exemplo: a classificação de localização para um determinado elemento pode determinar que seja realizada uma busca sobre o elemento em uma API de mapas como o Google Maps, para facilitar a compreensão do texto pelo usuário. Um estudo específico poderia ser realizado com a ferramenta para determinar quais recursos seriam passíveis de integração e como esses recursos poderiam beneficiar o usuário.

- Automatização de conformidade com a WCAG: o contexto geral deste trabalho foi a automatização de conformidade com a WCAG por meio de técnicas de processamento de língua natural. De forma semelhante, outras abordagens poderiam ser aplicadas para estabelecer a conformidade com outros critérios de acessibilidade diferentes dos abordados neste projeto (3.1.3 e 3.1.5 da WCAG 2.0). Por exemplo: utilização de técnicas de processamento de imagem para estabelecer níveis de contraste automáticos para as páginas de forma que elas sejam melhor visualizadas por usuário com baixa acuidade visual. Dado o contexto atual estabelecido pelo HTML5 na Web, novos recursos de processamento de imagens estão agora disponíveis até mesmo para desenvolvimento cliente em uma aplicação web ou mesmo no navegador. Essas tecnologias poderiam atuar como facilitadoras no processo de desenvol- 
vimento dessas soluções e generalizar as mesmas para que sejam disponíveis a qualquer website, sem a necessidade de melhoria ou mudança na arquitetura original da Web.

- Web 2.0, colaboração e estratégias de navegador: as ferramentas utilizadas para o desenvolvimento do Facilita e Facilita Educacional incluem recursos de customização das funcionalidades do navegador. Essa customização poderia ser utilizada de forma a melhorar ou mediar a interação entre o usuário e a Web. A possibilidade de customizar o navegador permitiria a realização de experimentos para testar novas possibilidades de interação do navegador com o usuário de forma a maximizar a acessibilidade.

Quando considerando o contexto da possibilidade de mediação entre as informações, poderiam ser estabelecidas estratégias de colaboração para a acessibilidade no contexto da Web 2.0. Aplicações Web 2.0 permitiriam a criação de comunidades virtuais que contribuem com a acessibilidade por meio do fornecimento de dados referentes a alternativas textuais para imagens, por exemplo, e o respectivo armazenamento dessas informações em um repositório centralizado de dados. A customização de navegador poderia realizar automaticamente o mapeamento de uma determinada imagem com sua respectiva alternativa textual localizada no repositório de dados, sem a necessidade de nenhuma alteração por parte dos reais autores do website que disponibilizaram a imagem sem a alternativa textual.

- Engenharia de Usabilidade e Acessibilidade: o contexto geral deste trabalho teve como base o fato de que o simples estabelecimento de diretrizes de acessibilidade não garante a acessibilidade na Web. Um dos motivos é a falta de métodos ou processos sistemáticos para a engenharia de aplicações web acessíveis. Atualmente, o desenvolvimento de aplicações acessíveis é realizado seguindo o mesmo modelo de engenharia de usabilidade. As diretrizes muitas vezes são utilizadas apenas para testar as aplicações depois que as mesmas já foram implementadas. Dessa forma, o desenvolvimento é realizado seguindo um ciclo de design iterativo, com múltiplas iterações de implementação, avaliação, melhorias e correções da interface. No entanto, esse modelo de desenvolvimento, em geral, resulta em códigos complexos e desorganizados, de difícil manutenção (Mahemoff e Johnston, 1999). Nesse contexto, a elaboração de um processo de desenvolvimento de software que considere a implementação de aplicações web acessíveis durante todas as etapas contribuiria significantemente para o tema de acessibilidade na web. 


\section{Referências Bibliográficas}

Agarwal, S.; Chakraborty, D.; Challa, S.; Kambhatla, N.; Kumar, A.; MukherJEA, S.; NAnavati, A. A.; Rajput, N. Pyr.mea.it: permeating it towards the base of the pyramid. New York, NY, USA: ACM, 2008, p. 108-109.

Akan, K.; Farrell, S.; Zerull, L.; Mahone, I.; Guerlain, S. escreening: Developing an electronic screening tool for rural primary care. Systems and Information Engineering Design Symposium, 2006 IEEE, p. 212-215, 2006.

Allen, J. Designing desirability in an augmentative and alternative communication device. Univers. Access Inf. Soc., v. 4, n. 2, p. 135-145, 2005.

Aluisio, S. M.; Specia, L.; Pardo, T. A.; Maziero, E. G.; Fortes, R. P. Towards brazilian portuguese automatic text simplification systems. In: DocEng '08: Proceeding of the eighth ACM symposium on Document engineering, New York, NY, USA: ACM, 2008, p. 240-248.

BECKER, S. A. A study of web usability for older adults seeking online health resources. ACM Trans. Comput.-Hum. Interact., v. 11, n. 4, p. 387-406, 2004.

Beyer, H.; Holtzblatt, K. Contextual design. interactions, v. 6, n. 1, p. 32-42, 1999.

BICK, E. The parsing system "Palavras": Automatic grammatical analysis of portuguese in a constraint grammar framework. PhD Thesis - Aarthus University, 2000.

Blake, E. H. Extended abstract a field computer for animal trackers. CHI '02: CHI 'O2 extended abstracts on Human factors in computing systems, p. 532-533, 2002.

BouCHEIX, J.-M. Multimedia simulation and comprehension aid for complex technical documents: A course for crane drivers. ICALT '04: Proceedings of the IEEE International Conference on Advanced Learning Technologies, p. 898-899, 2004. 
BRAJNIK, G. Beyond conformance: The role of accessibility evaluation methods. In: Web Information Systems Engineering - WISE 2008 Workshops, Springer Berlin / Heidelberg, 2008, p. 63-80 (Lecture Notes in Computer Science, v.5176).

Disponível em: http://www.springerlink.com/content/ p317030k62j65029/

CARdoso, N. Rembrandt - reconhecimento de entidades mencionadas baseado em relações e análise detalhada do texto. In: Encontro do Segundo HAREM, PROPOR 2008, Aveiro, Portugal, 2008.

Centeno, V. L.; Kloos, C. D.; Gaedke, M.; Nussbaumer, M. Wcag formalization with w3c standards. In: $W W W$ '05: Special interest tracks and posters of the 14th international conference on World Wide Web, New York, NY, USA: ACM, 2005, p. 1146-1147.

Cervantes, R.; Sambasivan, N. Voicelist: user-driven telephone-based audio content. MobileHCI '08: Proceedings of the 10th international conference on Human computer interaction with mobile devices and services, p. 499-500, 2008.

Cook, A. M.; Hussey, S. M. Assistive technologies: Principles and practice, v. 2a ed. Mosby - Year Book, 523 p., 2001.

Dahlback, N.; Jonsson, A.; Ahrenberg, L. Wizard of oz studies: why and how. In: IUI '93: Proceedings of the 1st international conference on Intelligent user interfaces, New York, NY, USA: ACM, 1993, p. 193-200.

Dix, A.; Finlay, J. E.; Abowd, G. D.; BeAle, R. Human-computer interaction (3rd edition). Upper Saddle River, NJ, USA: Prentice-Hall, Inc., 2003.

Freire, A. P.; Fortes, R. P. M.; Turine, M. A. S.; Paiva, D. M. B. An evaluation of web accessibility metrics based on their attributes. In: SIGDOC '08: Proceedings of the 26th annual ACM international conference on Design of communication, New York, NY, USA: ACM, 2008a, p. 73-80.

Freire, A. P.; Goularte, R.; Fortes, R. P. M. Techniques for developing more accessible web applications: a survey towards a process classification. In: SIGDOC '07: Proceedings of the 25th annual ACM international conference on Design of communication, New York, NY, USA: ACM, 2007, p. 162-169.

Freire, A. P.; Russo, C. M.; Fortes, R. P. M. A survey on the accessibility awareness of people involved in web development projects in brazil. In: W4A '08: Proceedings of the 2008 international cross-disciplinary conference on Web accessibility (W4A), New York, NY, USA: ACM, 2008b, p. 87-96. 
Fulcher, J.; Gluck, R.; Worthy, M.; Draisma, K.; Vialle, W. A neural network, speech-based approach to literacy. ISICT '03: Proceedings of the 1st international symposium on Information and communication technologies, p. 40-45, 2003.

Ghosh, K.; PARIKh, T. S.; ChaVAn, A. L. Design considerations for a financial management system for rural, semi-literate users. CHI '03: CHI '03 extended abstracts on Human factors in computing systems, p. 824-825, 2003.

GIBSON, B. Enabling an accessible web 2.0. In: W4A '07: Proceedings of the 2007 international cross-disciplinary conference on Web accessibility (W4A), New York, NY, USA: ACM, 2007, p. $1-6$.

Hahn, E. A.; Cella, D.; Dobrez, D.; Shiomoto, G.; Marcus, E.; Taylor, S. G.; Vohra, M.; Chang, C.-H.; Wright, B. D.; Linacre, J. M.; Weiss, B. D.; ValenZuela, V.; Chiang, H.-L.; Webster, K. The talking touchscreen: A new approach to outcomes assessment in low literacy. Psycho-Oncology, v. Volume 13, Issue 2, p. 86-95, 2004.

Hemmings, T.; Crabtree, A. Ethnography for design? International Workshop on "Interpretive” Approaches to Information Systems and Computing Research, 2002.

IBGE Mais um registro da maior operação censitária do país. 2000a.

Disponível em: http://www.ibge.gov.br/censo/revista9.pdf

IBGE Tendências demográficas no período de 1950/2000. 2000 b.

Disponível em: http://www.ibge.gov.br/home/estatistica/populacao/ censo2000/tendencias_demograficas/comentarios.pdf

IBGE Síntese dos indicadores sociais - uma análise das condições de vida da população brasileira. 2008.

Disponível em: http://www.ibge.gov.br/home/estatistica/populacao/ condicaodevida/indicadoresminimos/sinteseindicsociais2008/ indic_sociais2008.pdf

IBGE Síntese dos indicadores sociais - uma análise das condições de vida da população brasileira. 2009.

Disponível em: http://www.ibge.gov.br/home/estatistica/populacao/ condicaodevida/indicadoresminimos/sinteseindicsociais2009/ indic_sociais2009.pdf

Jibaja-Weiss, M. L.; Volk, R. J.; Friedman, L. C.; Granchi, T. S.; NefF, N. E.; Spann, S. J.; Robinson, E. K.; AOKI, N.; BECK, J. R. Preliminary testing of a just-in-time, userdefined values clarification exercise to aid lower literate women in making informed breast cancer treatment decisions. Health Expectations, v. Volume 9, Issue 3, p. 218-231, 2006. 
Jones, M.; Harwood, W.; Buchanan, G.; Lalmas, M. Storybank: an indian village community digital library. JCDL '07: Proceedings of the 7th ACM/IEEE-CS joint conference on Digital libraries, p. 257-258, 2007.

Joshi, A.; Welankar, N.; BL, N.; Kanitkar, K.; Sheikh, R. Rangoli: a visual phonebook for low-literate users. MobileHCI '08: Proceedings of the 10th international conference on Human computer interaction with mobile devices and services, p. 217-223, 2008.

Kelly, B.; Sloan, D.; Brown, S.; Seale, J.; Petrie, H.; Lauke, P.; Ball, S. Accessibility 2.0: people, policies and processes. In: W4A '07: Proceedings of the 2007 international cross-disciplinary conference on Web accessibility (W4A), New York, NY, USA: ACM, 2007, p. $138-147$.

Kelly, B.; Sloan, D.; Phipps, L.; Petrie, H.; Hamilton, F. Forcing standardization or accommodating diversity?: a framework for applying the wcag in the real world. In: $W 4 A$ '05: Proceedings of the 2005 International Cross-Disciplinary Workshop on Web Accessibility (W4A), New York, NY, USA: ACM, 2005, p. 46-54.

Kitchenham, B. Procedures for performing systematic reviews. Relatório Técnico, Keele University and NICTA, 2004.

Kumar, A.; Rajput, N.; Chakraborty, D.; Agarwal, S. K.; Nanavati, A. A. Voiserv: Creation and delivery of converged services through voice for emerging economies. World of Wireless, Mobile and Multimedia Networks, 2007. WoWMoM 2007. IEEE International Symposium on $a$, p. 1-8, 2007a.

Kumar, A.; Rajput, N.; Chakraborty, D.; Agarwal, S. K.; Nanavati, A. A. Wwtw: the world wide telecom web. NSDR '07: Proceedings of the 2007 workshop on Networked systems for developing regions, p. 1-6, 2007b.

Lima CAldas, E. Da experiência do microcrédito à microfinança. Revista Diálogo Econômico Local, , n. 1, 2003.

Lucca, G. A. D.; Fasolino, A. R.; Tramontana, P. Web site accessibility: Identifying and fixing accessibility problems in client page code. In: WSE '05: Proceedings of the Seventh IEEE International Symposium on Web Site Evolution, Washington, DC, USA: IEEE Computer Society, 2005, p. 71-78.

Mahemoff, M.; Johnston, L. Reusing knowledge about users. In: 4th Australian Conference on Requirements Engineering, 1999, p. 59-69.

MAPleson, D. L. Post-grammatical processing for discourse segmentation. PhD Thesis University of East Anglia, Norwich, 2006. 
Margarido, P.; Pardo, T.; Antonio, G.; Fuentes, V.; Aluísio, S.; Fortes, R. Automatic summarization for text simplification: Evaluating text understanding by poor readers. In: Anais do VI Workshop em Tecnologia da Informação e da Linguagem Humana, In: VI Workshop em Tecnologia da Informação e da Linguagem Humana, 2008, Vila Velha., 2008a, p. 310-315.

Margarido, P. R. A.; Pardo, T. A. S.; Aluísio, S. M. Sumarização automática para simplificação de textos: Experimentos e lições aprendidas. In: Anais do Workshop de Usabilidade, Acessibilidade e Inteligibilidade aplicadas em interfaces para analfabetos, idosos e pessoas com deficiência, 2008, In: Workshop de Usabilidade, Acessibilidade e Inteligibilidade aplicadas em interfaces para analfabetos, idosos e pessoas com deficiência, 2008, Porto Alegre, 2008b, p. 1-6.

Martins, I. H.; Carvalho, L. A. V.; Ferreira, L.; Socorro Martins Calháu, M.; BENÍCIO, M. L. T. Man-computer interaction aspects in systems for the young people and nonalphabetized adults. CLIHC '03: Proceedings of the Latin American conference on Humancomputer interaction, p. 235-238, 2003.

Max, A. Writing for language-impaired readers. In: Computational Linguistics and Intelligent Text Processing, Springer Berlin / Heidelberg, 2006, p. 567-570 (Lecture Notes in Computer Science, v.3878).

Disponível em: http://www.springerlink.com/content/ $73214815467 j 1502 /$

Medhi, I.; PrasAd, A.; TOYAmA, K. Optimal audio-visual representations for illiterate users of computers. WWW '07: Proceedings of the 16th international conference on World Wide Web, p. 873-882, 2007a.

Medhi, I.; SAgar, A.; Toyama, K. Text-free user interfaces for illiterate and semiliterate users. Inf. Technol. Int. Dev., v. 4, n. 1, p. 37-50, 2007 b.

Montenegro, I. P.; Educativa, A. Inaf - 2007. 2007.

Disponível em: http://epoca.globo.com/edic/499/_INAF_2007_dez07_ .$p d f$

Montenegro, I. P.; Educativa, A. Inaf brasil - indicador de alfabetismo funcional. 2009.

Disponível em: http://www.ibope.com.br/ipm/relatorios/relatorio_ inaf_2009.pdf

Munson, E. V.; GraçA Pimentel, M. Specialized documents. In: Web Accessibility, Springer London, 2008, p. 274-285 (Human-Computer Interaction Series, v.4).

Disponível em: http://www.springerlink.com/content/ x226q248w51j6qg0/ 
Nielsen, J. Ten usability heuristics. 1994.

Disponível em: http://www.useit.com/papers/heuristic/heuristic_ list.html

Nielsen, J.; Molich, R. Heuristic evaluation of user interfaces. In: CHI '90: Proceedings of the SIGCHI conference on Human factors in computing systems, New York, NY, USA: ACM, 1990, p. 249-256.

Parikh, T.; Ghosh, K.; Chavan, A. Design studies for a financial management system for micro-credit groups in rural india. CUU '03: Proceedings of the 2003 conference on Universal usability, p. 15-22, 2003.

Petrie, H.; KHEIR, O. The relationship between accessibility and usability of websites. In: CHI '07: Proceedings of the SIGCHI conference on Human factors in computing systems, New York, NY, USA: ACM, 2007, p. 397-406.

Petta, T. D.; Woloshyn, V. E. Voice recognition for on-line literacy: Continuous voice recognition technology in adult literacy training. Education and Information Technologies, v. 6 , n. 4, p. 225-240, 2001.

Plauche, M.; Nallasamy, U.; Pal, J.; Wooters, C.; Ramachandran, D. Speech recognition for illiterate access to information and technology. Information and Communication Technologies and Development, 2006. ICTD '06. International Conference on, p. 83-92, 2006.

Plauché, M.; Prabaker, M. Tamil market: a spoken dialog system for rural india. CHI '06: CHI 'O6 extended abstracts on Human factors in computing systems, p. 1619-1624, 2006.

Prasad, A.; Medhi, I.; Toyama, K.; BALAKrishnan, R. Exploring the feasibility of video mail for illiterate users. AVI '08: Proceedings of the working conference on Advanced visual interfaces, p. 103-110, 2008.

RATNAPARKHI, A. A maximum entropy model for part-of-speech tagging. In: BRILl, E.; Church, K., eds. Proceedings of the Empirical Methods in Natural Language Processing, 1996, p. 133-142.

Disponível em: http://acl.ldc.upenn.edu/W/W96/W96-0213.pdf

REID, L. G.; SNOW-WEAVER, A. Wcag 2.0: a web accessibility standard for the evolving web. In: W4A '08: Proceedings of the 2008 international cross-disciplinary conference on Web accessibility (W4A), New York, NY, USA: ACM, 2008, p. 109-115.

Romen, D.; SvanAes, D. Evaluating web site accessibility: validating the wai guidelines through usability testing with disabled users. In: NordiCHI '08: Proceedings of the 5th Nordic conference on Human-computer interaction, New York, NY, USA: ACM, 2008, p. 535-538. 
Sevilla, J.; Herrera, G.; Martinez, B.; Alcantud, F. Web accessibility for individuals with cognitive deficits: A comparative study between an existing commercial web and its cognitively accessible equivalent. ACM Trans. Comput.-Hum. Interact., v. 14, n. 3, p. 12, 2007.

ShakeEl, H.; BeSt, M. Community knowledge sharing: an internet application to support communications across literacy levels. Technology and Society, 2002. (ISTAS'02). 2002 International Symposium on, p. 37-44, 2002.

Siddharthan, A. Syntactic simplification and text cohesion. PhD Thesis - University of Cambridge, 2003.

Siddharthan, A. Syntactic simplification and text cohesion. Research on Language and Computation, v. 4, n. 1, p. 77-109, 2006.

Disponível em: http://dx.doi.org/10.1007/s11168-006-9011-1

SouZA, C. F. R.; Nunes, M. G. V. Avaliação de algoritmos de sumarização extrativa de textos em português. Technical Report at ICMC-USP, NILC-TR-01-09, 2001.

Spool, J. M.; Scanlon, T.; Schroeder, W.; Snyder, C.; DeAngelo, T. Web site usability: A designer's guide, user interface engineering. North Andover MA, 1997.

Summers, K.; Langford, J.; Wu, J.; Abela, C.; SouZA, R. Designing web-based forms for users with lower literacy skills. Proceedings of the American Society for Information Science and Technology, v. Volume 43, Issue 1, p. 174, 2006.

TAOUfiK, I.; Kabaili, H.; KetTANi, D. Designing an e-government portal accessible to illiterate citizens. ICEGOV '07: Proceedings of the 1st international conference on Theory and practice of electronic governance, p. 327-336, 2007.

Thatcher, J.; WAdDEll, C. Constructing accessible websites. APress L. P., 2003.

W3C Web content accessibility guidelines 1.0. W3C Recommendation, 1999.

Disponível em: http: / / www.w3.org/TR/WCAG10/

W3C Authoring tool accessibility guidelines 1.0. W3C Recommendation, 2000a.

Disponível em: http://www.w3.org/TR/ATAG10/

W3C Techniques for web content accessibility guidelines 1.0. W3C Note, 2000b.

Disponível em: http: //www.w3.org/TR/WCAG10/

W3C User agent accessibility guidelines 1.0. W3C Recommendation, 2002.

Disponível em: http: //www.w3.org/TR/WCAG10/

W3C A guide to understanding and implementing web content accessibility guidelines 2.0. W3C Working Group Note, 2008a. 
Disponível em: http://www.w3.org/TR/UNDERSTANDING-WCAG20/Overview . html

W3C Techniques and failures for web content accessibility guidelines 2.0. W3C Working Group Note, $2008 \mathrm{~b}$.

Disponível em: http: / / www .w3 .org/TR/WCAG20-TECHS /

W3C Web content accessibility guidelines (wcag) 2.0. W3C Recommendation, 2008c.

Disponível em: http: //www.w3.org/TR/WCAG20/

Walsh, P.; Meade, J. Speech enabled e-learning for adult literacy tutoring. Advanced Learning Technologies, 2003. Proceedings. The 3rd IEEE International Conference on, p. 17-21, 2003.

WATANABE, W. M.; ForTeS, R. P. M. Revisão sistemática sobre princípios de design de aplicações web acessíveis para analfabetos funcionais. In: SEMISH - XXXVI Seminário Integrado de Software e Hardware, 2009, CSBC - XXIX Congresso da Sociedade Brasileira da Computação, 2009, p. 403-417.

Watanabe, W. M.; Jr., A. C.; AmÂncio, M. A.; Oliveira, M.; Fortes, R. P. M.; Pardo, T. A. S.; Aluísio, S. M. Adapting web content for low-literacy readers by using lexical elaboration and named entities labeling. In: Proceedings of W4A 2010 - 7th International Cross-Disciplinary Conference on Web Accessibility, Raleigh, NC, USA: ACM, 2010a, p. 1-9.

Watanabe, W. M.; Jr., A. C.; Dias, A. L.; Pardo, T. A. S.; Fortes, R. P. M.; Aluísio, S. M. Improving wcag conformance: Browser strategies. In: Webmedia 2010, Belo Horizonte, MG, Brazil: ACM, 2010b, p. 1-8.

Watanabe, W. M.; Jr., A. C.; Uzeda, V. R.; Fortes, R. P. M.; Pardo, T. A. S.; AluíSIO, S. M. Facilita: Reading assistance for low-literacy readers. In: ACM SIGDOC 2009, Bloomington, IN, USA: ACM, 2009a, p. 29-36.

Watanabe, W. M.; Mattos Fortes, R. P.; Sandra Maria Aluísio, T. A. S. P. Facilita: Auxílio a leitura de textos disponíveis na web. In: Webmedia 2009, Fortaleza, CE, Brazil, 2009b, p. 1-4.

Watanabe, W. M.; Neto, A. T.; Silva Filho, A. G.; Neto, D. F.; Santos, E. P. B.; ForTES, R. P. M. Ajax design patterns for usability in web applications: a case study. In: CLEI 2010 - XXXVI Conferência Latino-americana de Informática, Asunção - Paraguai, 2010c, p. 1-14.

Young, D. N. Linguistic simplification of sl reading material. The Modern Language Journal, v. 83 , n. 3, p. 350-366, 1999. 